\title{
Efeito nas Mudanças Temporárias dos Limiares Auditivos Durante o Uso de Próteses Auditivas de Alta Potência
}

Tese de doutorado apresentada ao Departamento de Fisiopatologia da Faculdade de Medicina da Universidade de São Paulo para a obtenção do título de Doutor em Ciências.

Área de concentração: Fisiopatologia Experimental. Orientador: Prof. Dr. Oswaldo Laércio Mendonça Cruz. 
“Pessoas que, por ainda possuírem a dureza das pedras, não percebem a força da brandura.

Pessoas que não se cansam de cruzar pontes para descobrirem-se num outro espaço.

Pessoas que chegam a um ponto e, com a leveza das pétalas, permanecem em movimento.

Raimundo Gadelha A todas elas, este trabalho é dedicado." 
Dedicatória Especial

"Aos meus queridos pais, Celso e Meiga, por me transmitirem os verdadeiros valores. Estou certa de que de onde estiverem estarão sempre iluminando o meu caminho.

A você, Auli, meu querido companheiro, por estar sempre ao meu lado e me fazer acreditar mesmo nos momentos em que tudo parecia impossível.

As minhas amadas filhas, Thais e Paulinha, sem as quais nada faz sentido". 
Agradecimento Especial

“A este orientador tão especial, Prof. Dr. Oswaldo Laércio

Mendonça Cruz, por acreditar e tornar viável as propostas contidas neste trabalho". 


\section{Agradecimentos}

Às assistentes sociais e auxiliares administrativas, Marcia Diogo, Magally e Thirza e ao otorrinolaringologista Dr Fábio Freire, profissionais colaboradores do Programa de doação de Órteses e Próteses Auditivas do Ambulatório de Especialidades do Hospital Regional da Zona Sul, pela boa vontade e solicitude sem as quais seria impraticável a execução deste trabalho.

Ao Prof. Dr. Sylvio Reynaldo Bistafa do Departamento de Engenharia Mecânica da Escola Politécnica da Universidade de São Paulo pelas orientações fundamentais e pela generosidade em ceder os equipamentos de acústica utilizadas nesta pesquisa.

A minha secretária Fabiana Borges por seu carinho, interesse, responsabilidade e principalmente pela paciência nas inúmeras correções.

Ao departamento técnico da Danavox pelas medições eletroacústicas das próteses auditivas utilizadas nesta pesquisa.

Ao Sr Marcos Maeda, pela importante contribuição prestada na análise estatística da pesquisa.

Aos pacientes e seus familiares e todos os demais pela valiosa e imprescindível contribuição a este trabalho.

A todos, 


\section{SUMÁRIO}

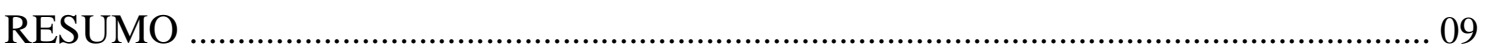

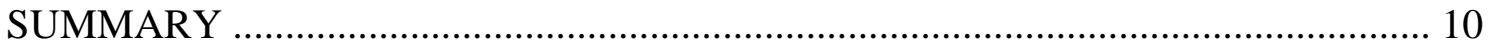

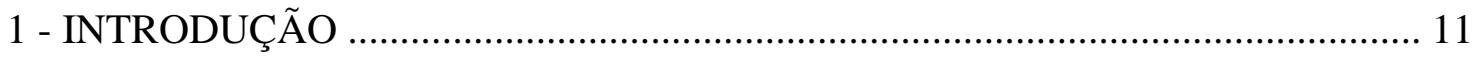

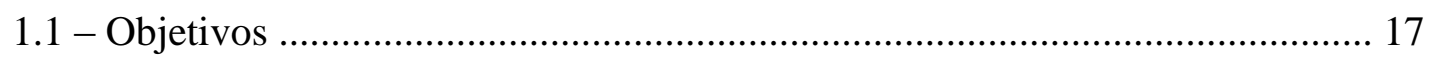

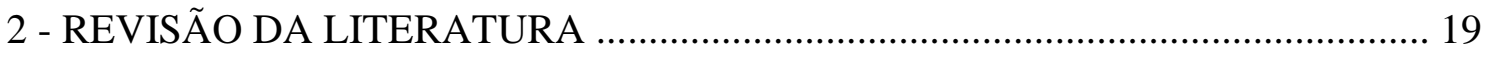

2.1 - Etiopatôgenia e fisiopatôgenia da perda auditiva induzida

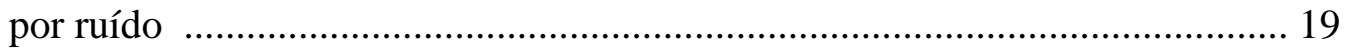

2.2 - Sistemas de proteção à níveis elevados de pressão sonora .............................. 26

2.3 - Resistência adquirida às perdas auditivas induzidas por ruído ........................ 34

3 - CASUÍSTICA E MÉTODOS ........................................................................ 42

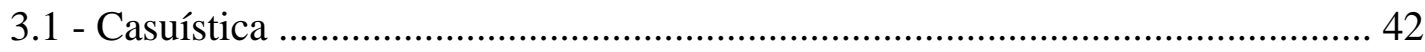

3.1.1 - Critérios gerais de inclusão no estudo ............................................... 45

3.1.2 - Critérios específicos de inclusão nos grupos de estudo ....................... 45

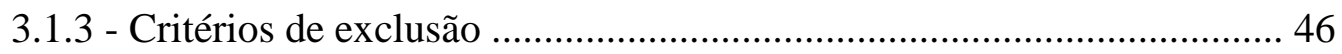

3.1.4 - Distribuição percentual das características gerais da amostra

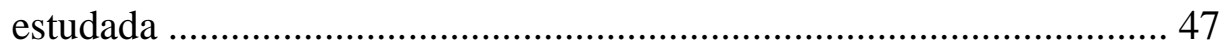

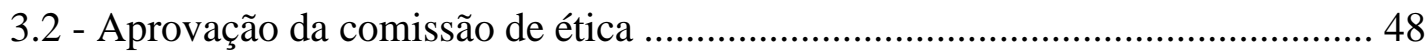

3.3 - Termo de consentimento livre e esclarecido ................................................ 48

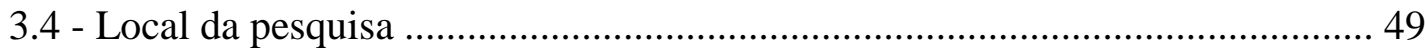

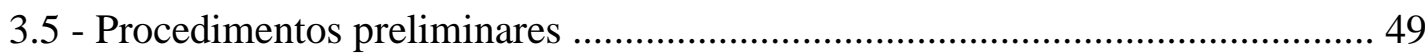

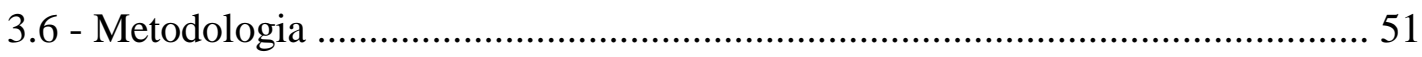

3.6.1 - Representação esquemática integrada da metodologia ...................... 52

3.6.2 - Descrição da metodologia ................................................................... 53

3.6.3 - Redução da amplificação "usual" para o treinamento das orelhas do Grupo Experimental ................................................................. 55

3.6.4 - Orientação para o uso externo das próteses auditivas .......................... 57 
3.7 - Padronização de testes e equipamentos 57

3.7.1 - Equipamentos 57

3.7.2 - Medidas das mudanças temporárias dos limiares

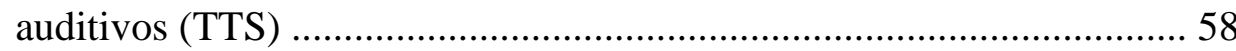

3.7.3 - Medidas "In Situ” das próteses auditivas .......................................... 59

3.7.4 - Medidas dos parâmetros acústicos do Estímulo - Teste (RAE) .......... 60

3.7.4.1 - Análise do espectro acústico de freqüências ................................... 60

3.7.4.2 - Registro dos níveis de pressão sonora e do tempo de exposição ..... 62

3.8 - Esquema geral da metodologia para a análise estatística ............................... 62

3.8.1 - Descrição da metodologia estatística .............................................. 64

3.8.2 - Cálculo do valor médio em dB dos limiares auditivos e das mudanças dos limiares auditivos (TTS) por freqüência... ............................... 65

3.8.3 - Critérios da avaliação estatística ...................................................... 65

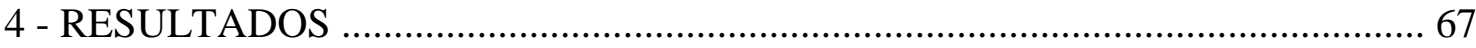

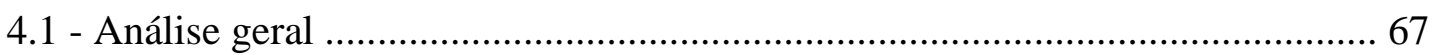

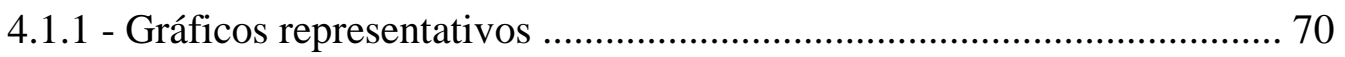

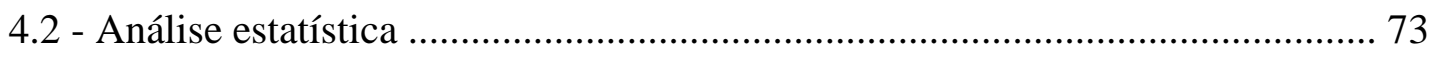

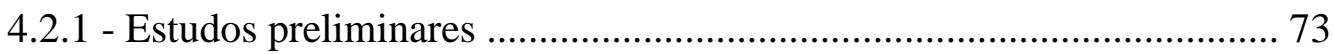

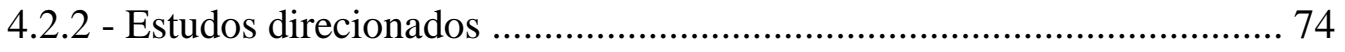

4.2.3 - Análise estatística da média dos limiares auditivos nas orelhas incluídas no GE e GC na etapa pré-experimental ............................ 74

4.2.4 - Análise estatística do TTS nas orelhas desprovidas de próteses auditivas incluídas no GE e no GC na etapa pré-experimental ........... 77

4.2.5 - Análise estatística do TTS com as orelhas desprovidas e providas das próteses auditivas no GE e no GC na etapa pré-experimental ............. 78

4.2.6 - Análise estatística do TTS com as próteses auditivas reguladas na maior amplificação (usual) e na menor amplificação (treinamento) para as orelhas do GE

4.2.7 - Análise estatística do comportamento do TTS nas três etapas do estudo para o GE

4.2.8 - Análise estatística do comportamento do TTS nas três etapas do estudo para o GC

4.2.9 - Análise estatística do TTS na etapa pré-experimental para o GE e GC 
4.2.10 - Análise estatística do TTS na etapa pós-experimental para o GE e GC 94

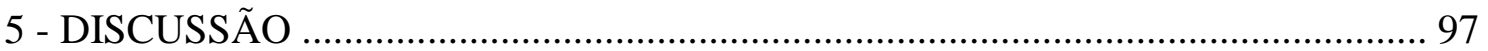

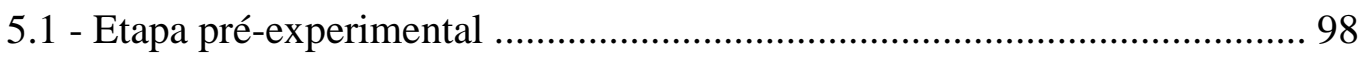

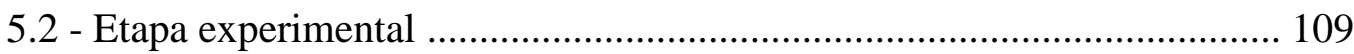

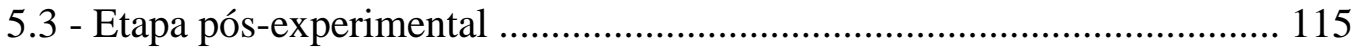

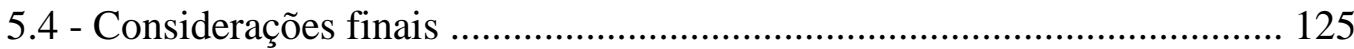

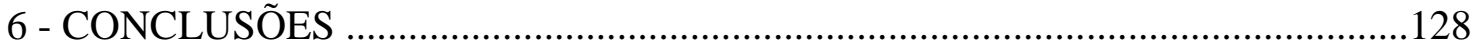

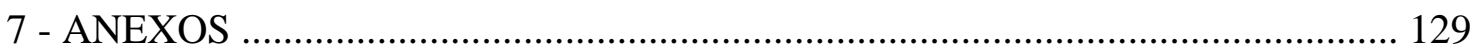

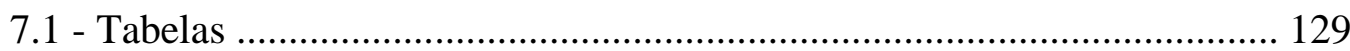

7.2 - Instruções e modelo da ficha de controle do uso regular das próteses auditivas ........................................................................... 138

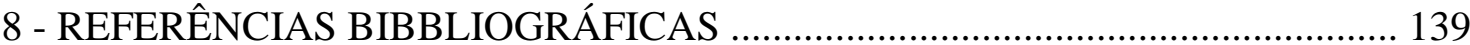




\section{RESUMO}

\section{DE VITTO, U.M.L Efeito nas mudanças temporárias dos limiares auditivos durante o uso de próteses auditivas de alta potência. São Paulo, 2004. 145 p. Tese (Doutorado) Faculdade de Medicina, Universidade de São Paulo.}

Alterações temporárias ou permanentes na audição podem ser encontradas nas orelhas submetidas a níveis elevados de pressão sonora. As mudanças temporárias induzidas nas orelhas protetizadas, quando estimuladas por suas próteses auditivas ajustadas na amplificação prescrita, foram avaliadas em um grupo de 25 pacientes após um período controlado (2 a $21 \frac{1}{2} \mathrm{~h}$ ) de exposição ao ruído presente em um ambiente acústico comum. $\mathrm{O}$ estudo foi dividido em três etapas. Uma medida inicial foi realizada na primeira etapa para mensurar a magnitude das mudanças temporárias dos limiares auditivos, induzidas nas 42 orelhas ( 25 pacientes) durante um período contínuo de exposição ao ruído, com suas próteses auditivas ajustadas na amplificação prescrita. Na segunda etapa, essas 42 orelhas foram divididas em dois grupos distintos: as 22 orelhas protetizadas (13 pacientes) que apresentaram maior mudança temporária inicial nos limiares auditivos foram incluídas no Grupo Experimental e as 20 orelhas protetizadas (12 pacientes) que apresentaram menor mudança temporária inicial nos limiares auditivos foram incluídas no Grupo Convencional. Nesta etapa, as próteses auditivas, adaptadas nas 22 orelhas incluídas no Grupo Experimental, tiveram a sua amplificação reduzida por um período de 60 a 90 dias proposto para o "treinamento" das orelhas no uso cotidiano de suas próteses auditivas. Após este período de treino, a amplificação das próteses auditivas retornou ao nível prescrito. No Grupo Convencional, a amplificação prescrita das próteses auditivas adaptadas não foi alterada. Durante esta etapa, quatro medidas das mudanças temporárias induzidas nos limiares auditivos foram realizadas para os dois grupos nas mesmas condições de exposição ao ruído adotadas para a determinação da medida inicial. Uma última medida das mudanças temporárias induzidas nos limiares auditivos foi realizada na terceira etapa, também em idênticas condições. Esta última medida ocorreu em média 30/35 dias depois do término do treinamento, quando os pacientes do Grupo Experimental já faziam o uso cotidiano de suas próteses auditivas reajustadas na amplificação prescrita. A análise estatística de variância (ANOVA) comparou o comportamento das mudanças temporárias induzidas nos limiares auditivos nas três etapas do estudo. Para as orelhas incluídas no Grupo Experimental, foram verificadas alterações estatisticamente significantes $(\mathrm{f}<0,05)$ durante as etapas do estudo. As mudanças temporárias induzidas nos limiares auditivos das orelhas incluídas no Grupo Experimental aumentaram nos primeiros quinze a trinta e cinco dias após o inicio do treinamento. Com a continuidade do treinamento essas alterações foram gradualmente se reduzindo. As mudanças temporárias induzidas no final do treinamento (etapa pós-experimental) foram as menores observadas durante o estudo. A redução teve inicio nas freqüências abaixo de $1000 \mathrm{~Hz}$ e se extendeu na faixa de freqüência mais afetada nas orelhas protetizadas durante a exposição inicial ao ruído ambiente (250 a $2000 \mathrm{~Hz}$ ). Para as orelhas incluídas no Grupo Convencional não foram constatadas alterações estatisticamente significantes $(f>0,05)$ nas mudanças temporárias induzidas nos limiares auditivos quando avaliadas nas mesmas condições de exposição ao ruído ambiente. Entretanto, para as frequiências mais graves $(250 \mathrm{~Hz})$, foi verificada uma tendência a redução nestas alterações no decorrer do estudo. 


\section{SUMMARY}

\section{DE VITTO, U.M.L Effect in the temporary threshold shift during the use of the high power hearing aid. São Paulo, 2004. 145 p. These - Faculdade de Medicina, Universidade de São Paulo.}

It is well known that the temporary threshold shift in hearing sensitivity is the most obvious hearing effect of the high level acoustic stimulation. Temporary threshold shifts induced in the aided ears were measured in 25 patients after the use of the hearing aids fitted in the prescribed gain during a controlled exposition time ( 2 a $2 \frac{1 / 2}{h}$ ) to an environmental noise. The study was performed in three phases. In the first phase a first measure of the temporary threshold shift was obtained for 42 aided ears ( 25 patients) in order to measure the initial amount of temporary threshold shift induced by the hearing aids fitted in the prescribed acoustic gain. In the second phase the ears were included into two study groups: The Experimental Group (EG) formed by 22 ears (13 patients) with greater temporary threshold shift in the initial measure and the Conventional Group(CG), formed by 20 ears with the shorter temporary threshold shift in the initial measure. The hearing aids amplification in the 22 aided ears of the Experimental Group was reduced during the daily use for a "training" period of about 60 to 90 days, and after that was turned to the prescribed gain. The prescribed gain was not modified to the 20 ears of the Conventional Group. Four measure of temporary threshold shift were performed in the second phase when the patients included in the two groups were exposed to an environmental noise in the same conditions used to obtain the initial measure. The last measure (post-experimental phase) of the temporary threshold shift was performed in the same conditions , 30 days in average after the patients of Experimental Group had returned to use their hearing aids in the prescribed gain. In the Experimental Group, the analysis of the variance (ANOVA) showed significant differences $(\mathrm{f}<0,05)$ in the amount of induced temporary threshold shifts measured during the three phases of the study. Fifteen or thirteen five days after the training had begun the amount of temporary threshold shift increase, but with the continuous training it was gradually to reduced .In the end of the study, the last measure (post-experimental phase) was performed and the amount of temporary thresholds shift was very shorter. This reduction of temporary threshold shift was initially verified in the frequencies below $1000 \mathrm{~Hz}$ and at the end of the study all of the frequencies initially affected during the exposition time to the environmental noise $(250$ to $2000 \mathrm{~Hz})$ were significantly reduced. In the ears included in the Conventional Group it was not verified temporary threshold shift statistically significant $(f>0,05)$ in any moment, but in the low frequencies $(250 \mathrm{~Hz})$ it was noticed a gradually reduction of the amount of temporary threshold shift during the period of this study. 


\section{1- INTRODUÇÃO}

É consensual que a exposição a níveis elevados de pressão sonora possa provocar danos irreversíveis ao sistema auditivo, e que recursos que promovam a redução destes devam ser implementados.

Alguns estudos atribuem a grande diversidade das perdas auditivas permanentes, encontradas nos indivíduos submetidos a condições idênticas de exposição ao ruído, a um fator biológico inerente que tornaria alguns indivíduos mais predispostos do que outros ao efeito deletério provocado pela estimulação acústica (DE VITTO, 2000).

As pesquisas não afirmam que orelhas com perdas auditivas pré-existentes sejam menos susceptíveis ao efeito do ruído. Assim, nos parece evidente que as orelhas lesadas também devam ser preservadas. Todavia, como proceder se, paradoxalmente, necessitamos utilizar sistemas de amplificação de alta potência para compensar as perdas da audição decorrentes, muitas vezes, do excesso desta?

As regras de prescrição da frequiência de resposta têm sido utilizadas na adaptação das próteses auditivas e se popularizaram na prática clínica nesta última década, principalmente após o advento dos circuitos digitais de amplificação. No entanto, não há unanimidade entre os profissionais com relação à escolha de uma regra, porque, na realidade, elas propõem diferentes ganhos acústicos para um mesmo grau de perda auditiva. Além do mais, nem todas consideram os níveis de desconforto, e sabemos que, para haver uma correção adequada da perda auditiva, é essencial que a amplificação acústica fornecida esteja contida na faixa dinâmica da audição, tornando os sons audíveis e ao mesmo tempo confortáveis. 
Estes critérios têm por objetivo não apenas otimizar a adaptação ao estímulo acústico introduzido, como promover uma adequada proteção das orelhas contra a superamplificação provocada pela alta potência destes dispositivos eletrônicos. Mas será que isto ocorre sempre?

MACRAE (1994), utilizando a fórmula desenvolvida pela NAL (National Acoustic Laboratories) como referência para o cálculo do ganho de inserção das próteses auditivas em função dos limiares tonais, e o valor do TTS (temporary threshold shift) como índice de dano a perdas permanentes de audição, concluiu que, nas perdas auditivas superiores a $100 \mathrm{~dB}$, todos os TTS induzidos pela amplificação acústica das próteses auditivas são de risco, e que, se o ganho de inserção for superior a $15 \mathrm{~dB}$ do valor recomendado pela NAL, a quantidade de TTS produzido pela amplificação gerada pode ser um fator de risco de dano permanente para as perdas auditivas superiores a 80 dB.

Deste modo, os pacientes portadores de perdas severas e profundas da audição e que usam amplificadores de alta potência adaptados dentro dos critérios recomendados por algumas regras de prescrição, não têm garantido a efetiva proteção contra a superamplificação.

Os efeitos agudos ou crônicos mais comuns provocados por uma estimulação sonora de alta intensidade são as alterações transitórias ou permanentes nos limiares auditivos (QUARANTA et al, 1998), e o uso de amplificadores de alta potência expõem as orelhas a esta condição. De acordo com MACRAE (1995), a amplificação gerada por próteses auditivas pode provocar alterações temporárias ou permanentes nos limiares auditivos, e estas parecem estar associadas a superamplificação gerada por estes amplificadores, pois tendem a aumentar com o aumento da amplificação destes. 
Para se proteger dos efeitos transitórios e permanentes provocados pela estimulação sonora elevada, as orelhas parecem dispor de mecanismos protetores.

Nas orelhas normais, são conhecidos dois sistemas que atuam de modo eficiente e diferenciado na proteção da orelha interna durante as exposições traumáticas. A ação reflexa dos músculos da orelha média, particularmente a do estapédio, aumenta a rigidez do sistema tímpano-ossicular, atenuando o efeito traumático da passagem do estímulo sonoro elevado, principalmente na região das baixas frequiências, inferiores a $2000 \mathrm{~Hz}$ (MOLLER, 1965). A ativação do sistema eferente, em especial a ação do reflexo acústico eferente medial, age na motilidade das células ciliadas externas, reduzindo as vibrações da membrana basilar durante a estimulação sonora de alta intensidade, diminuindo o ganho do amplificador coclear. Este mecanismo permite um contínuo ajuste da faixa dinâmica da audição, promovendo uma proteção adequada nas freqüências mais agudas, por volta de $10 \mathrm{kHz}$ (OLIVEIRA, 2001).

Além destes dois mecanismos de defesa, que parecem agir rapidamente durante as exposições traumáticas, vários trabalhos utilizando modelos animais, cobaias (CANLON, 1988), gerbils (RYAN et al., 1994), chinchilas (HENDERSON et al, 1994), ratos (YOSHIDA e LIBERMAN, 2000), gatos (RAJAN, 2001), e também orelhas humanas (MIYAKITA et al., 1992), demonstraram que é possível aumentar a proteção da orelha interna submetida a níveis elevados de pressão sonora.

Desde os trabalhos clássicos de MILLER (1963), que encontrou redução do efeito traumático nas orelhas de gatos quando expostas repetidamente a um estímulo sonoro de alta intensidade, é que se vem estudando os efeitos protetores desenvolvidos pelas orelhas submetidas a níveis elevados de pressão sonora. 
O importante é que a ativação do efeito protetor das orelhas submetidas a condições traumáticas só parece ser ativado ou induzido quando sob condições favoráveis de estimulação sonora.

CANLON et al. (1999), analisaram um número expressivo de pesquisas recentes que demonstraram a possibilidade de redução na susceptibilidade da orelha interna à ação de um ruído traumático quando esta foi previamente exposta a condições específicas de estimulação acústica. Neste artigo, foram definidos os dois paradigmas que as pesquisas empregaram para a ativação destes sistemas de proteção da orelha interna. O primeiro paradigma utiliza um ruído contínuo de baixa intensidade, precedendo a estimulação traumática. $\mathrm{O}$ efeito protetor gerado nesta condição de estimulação, denominado de "condicionamento por som", já foi demonstrado ocorrer em um número considerável de mamíferos de pequeno porte (CANLON, 1988; RYAN et al., 1994; DAGLI e CANLON, 1995; BOETCHER e SCHIMIEDT, 1995; WHITE et al., 1998; RAJAN, 2001).

Segundo CANLON et al. (1999), para que haja um efeito protetor eficiente, é necessário que o estímulo que precede as exposições traumáticas não provoque alterações significantes, temporárias ou permanentes, nos limiares auditivos ou danos às células ciliadas. Em algumas pesquisas, utilizou-se um estímulo relativamente baixo no condicionamento das orelhas (CANLON, 1988). Em outras, se interpôs um período de repouso após a exposição condicionante para que os limiares retornassem aos níveis do pré-condicionamento antes que se procedesse a exposição traumática (RYAN et al., 1994).

O segundo paradigma utiliza um protocolo de exposições interrompidas e repetidas a níveis de pressão sonora que produzem inicialmente mudanças temporárias 
nos limiares auditivos. Entretanto na medida em que se aumenta o número de exposições, essas alterações vão gradativamente se reduzindo. Esta redução gradual na susceptibilidade das orelhas tem sido denominada de "toughening" ou resistência à perda auditiva induzida por ruído, nome ainda sem correspondência em português (OLIVEIRA, 2001).

Vários trabalhos têm confirmado o efeito do "toughening" nas orelhas de animais quando submetidas a repetidas exposições interrompidas (MILLER , 1963; CLARK et al., 1987; CAMPO et al., 1991; HENDERSON et al., 1994 ; WHITE et al., 1998; AHROON e HAMERNIK, 1999).

Poucas pesquisas estudaram este efeito em orelhas humanas. O estudo realizado por MIYAKITA et al., 1992, que conseguiu provocar o "toughening" em orelhas normais de doze adolescentes quando expostas durante seis horas por dia por nove dias consecutivos a uma seleção musical emitida a baixa intensidade (70dBA), é o mais citado nos trabalhos a respeito do tema.

No entanto, a maioria das pesquisas que utilizou estes dois protocolos de investigação para promover a estimulação dos sistemas de proteção nas orelhas internas, usou animais com o sistema auditivo comprovadamente íntegro.

Nas pesquisas que utilizaram um protocolo de exposições interrompidas para desenvolver a proteção contra ruídos de impacto de alta intensidade, os resultados não foram favoráveis. As orelhas de um grupo de chinchilas com perdas pré-existentes não desenvolveram a resistência ou o "toughening" quando estimuladas com um ruído de impacto de banda estreita centrado a $1000 \mathrm{~Hz}$ e emitido a 115 dBNPS, 6 horas por dia durante 10 dias (AHROON e HAMERNIK, 2000). 
Entretanto, este fenômeno tem sido tão pouco explorado em orelhas doentes que seria prematuro desconsiderar a sua possibilidade.

Esta hipótese poderia ser verdadeira se admitíssemos que a susceptibilidade das orelhas com perdas neurossensoriais pré-existentes não seja diferente das orelhas normais, e se as orelhas normais tem sistemas de proteção eficientes agindo durante as exposições traumáticas, poderiam as orelhas lesadas também tê-los?

O Comitê da Audição, Bioacústica, Biomecânica e a Comissão das Ciências Sociais, do Comportamento e da Educação, Washington DC 20418, elaborou um extenso manuscrito publicado em 1991. Considerando neste documento o aumento das perdas de audição devido a dois fatores integrados, a idade e exposição ao ruído elevado, foi enfatizada a necessidade de se promover melhorias na performance dos sistemas convencionais de amplificação acústica para a percepção da fala.

Em um dos tópicos abordados, o da proteção contra a amplificação excessiva, fizeram a seguinte análise: “É inevitável que as próteses auditivas indicadas para pacientes com perdas severas da audição gerem altos níveis sonoros e que estes possam comprometer a audição remanescente. A prática clínica admite que, embora o ganho acústico necessário para otimizar o reconhecimento da fala possa danificar as estruturas sensoriais e neurais remanescentes, este risco é preferível ao isolamento social resultante do não uso da amplificação. É também admitido que os elementos sensoriais e neurais remanescentes destas orelhas sejam resistentes a estimulação sonora elevada. No entanto, mais pesquisas são necessárias para avaliar este assunto"(WORKING GROUP, 1991).

Partindo então da hipótese de que as orelhas com perdas auditivas neurossensoriais pré-existentes poderiam ser capazes de desenvolver "toughening" ou 
resistência à estimulação sonora elevada para atenuar os efeitos da superamplificação, foi desenhado este estudo prospectivo, que nos permitiu acompanhar um grupo de pacientes com perdas auditivas neurossensoriais bilaterais recém adaptados com suas próteses auditivas, durante um período pré-determinado, para observar a manifestação do fenômeno pesquisado.

Este estudo é relevante por dois motivos principais:

1. Pela possibilidade de uma confirmação clínica da existência de mecanismos naturais capazes de proteger as sensíveis células sensoriais, remanescentes nas orelhas internas lesadas, contra os efeitos nocivos da estimulação sonora elevada.

2. Por sugerir metodologias que possam auxiliar na estimulação dos mecanismos induzidos de autodefesa, durante a fase inicial de adaptação das orelhas às próteses auditivas de alta potência.

Isto poderá reduzir a margem de risco decorrente do uso desses dispositivos eletrônicos, em especial para os pacientes portadores de perdas auditivas severas e profundas, onde se espera uma maior probabilidade de ocorrência de superamplificação.

\section{1 - Objetivos}

O objetivo geral deste estudo prospectivo é o de investigar os mecanismos de proteção a níveis elevados de pressão sonora, desenvolvidos nas orelhas com perdas auditivas neurossensoriais, avaliando o comportamento das alterações ou das mudanças temporárias nos limiares auditivos, Temporary Threshold Shift (TTS), induzidas nas orelhas recém protetizadas quando estimuladas sistematicamente pela alta amplificação eletrônica gerada por suas próteses auditivas. 
São objetivos específicos deste trabalho:

1- Verificar se a amplificação das próteses auditivas pode induzir "TTS" em situações acústicas convencionais de uso.

2- Avaliar se a redução da amplificação das próteses auditivas por um período determinado pode favorecer o treinamento ou o desenvolvimento da resistência, reduzindo a susceptibilidade das orelhas expostas a níveis elevados de pressão sonora. 


\section{2 - REVISÃO DA LITERATURA}

A revisão da literatura será abordada por assunto pertinente ao tema principal.

\section{1 - Etiopatogenia e Fisiopatogenia da Perda Auditiva Induzida por Ruído} (PAIR)

Pequenas ou grandes variações no nível da pressão sonora podem sensibilizar as orelhas normais, se estiverem contidas na faixa das freqüências audíveis pelo ouvido humano, aproximadamente entre 20 a $20.000 \mathrm{~Hz}$. O menor nível de pressão sonora capaz de provocar a sensação de audibilidade nas orelhas normais é da ordem de 0,0002 dinas por centímetro quadrado para um tom de $1000 \mathrm{~Hz}$, enquanto que o limite doloroso é de aproximadamente 140 dBNPS (decibel nível de pressão sonora) ou 2000 dinas por centímetro quadrado (DAVIS e SILVERMANN, 1971).

Há uma concordância generalizada de que a exposição a níveis elevados de pressão sonora produz deficiência auditiva, embora haja uma considerável divergência nas opiniões com relação ao limite que separa as exposições traumáticas das não traumáticas. Este limite é denominado de nível crítico do ruído ou nível seguro de intensidade (SATALLOF e MICHAEL, 1973).

A estimulação prolongada pode, sob determinadas condições, ter um efeito adverso, tornando os receptores sensoriais periféricos, e até os centrais, menos responsivos, presumivelmente devido à depleção dos metabólitos ou de outros materiais fisiologicamente necessários para manter a resposta do sistema auditivo à estimulação sonora, ou, em outras palavras, o sistema se torna fatigado. Se a exposição é suficiente para causar fadiga, o limiar da pós-exposição é elevado, mas gradualmente retorna ao nível da pré-exposição após um tempo de recuperação, que depende dos parâmetros da exposição e do estímulo-teste. Esta perda reversível na sensibilidade auditiva é chamada 
de mudança temporária do limiar ou temporary threshold shift (TTS), e é freqüentemente usada como índice da fadiga auditiva.

A fadiga auditiva é um reflexo da intolerância do sistema auditivo a excessiva exposição sonora. Para os autores, "excessiva" exposição significa exposições curtas a níveis elevados de pressão sonora ou exposições a níveis menos intensos, mas por períodos prolongados de tempo. (DURANT e LOVRINIC, 1984).

Os efeitos psicofísicos que resultam do aumento da intensidade da estimulação sonora incluem adaptação, mudanças temporárias nos limiares auditivos e perdas permanentes na audição. Os fatores envolvidos nas perdas permanentes produzidas logo após uma estimulação sonora de alta intensidade são principalmente mecânicos, enquanto que as lesões permanentes decorrentes da exposição a ruídos de intensidade moderada são conseqüências da descompensação metabólica com subsequente degeneração dos elementos sensoriais (SPOENDLIN, 1985).

CLARK, em 1991, elaborou uma revisão dos resultados das pesquisas recentes das mudanças temporárias e permanentes nos limiares auditivos em animais. Desta revisão foram extraídas algumas conclusões: (1) abaixo do "nível crítico" de aproximadamente $115 \mathrm{~dB}$, as alterações permanentes nos limiares auditivos e a perda de células ciliadas são geralmente relacionadas a energia total contida durante uma exposição contínua; (2) as perdas permanentes da audição dependem da intensidade, da freqüência e da duração da exposição; (3) períodos de repouso inseridos durante a exposição são protetores e resultam em menor perda auditiva e dano coclear do que a energia total contida na exposição contínua; (4) as alterações nos limiares auditivos aumentam durante os primeiros dias de exposição e, sob determinadas condições de repouso, podem recuperar mais do que $30 \mathrm{~dB}$ com a continuidade da exposição. 
As células ciliadas externas e internas, localizadas no Orgão de Corti, são as responsáveis pela transdução inicial do estímulo mecânico, gerando o aparecimento de potenciais elétricos receptores, os quais, por sua vez, ativam os neurônios do oitavo nervo. As três fileiras de células ciliadas externas e a fileira única de células ciliadas internas estão dispostas paralelamente ao longo da membrana basilar, desde a sua base até o seu ápice. Após uma exposição sonora traumática, o metabolismo destas células é alterado, a arquitetura celular é danificada e sua função normal alterada. O processo da perda auditiva induzida por ruído envolve não somente a perda de células sensoriais, mas também as células de suporte, as fibras do nervo acústico e o suprimento vascular podem ser comprometidos. A perda progressiva de células sensoriais pode se prolongar mesmo após o trauma como conseqüência da mistura dos fluídos cocleares extravasados por orifícios formados entre as junções das células da lâmina reticular com a degeneração das células sensoriais. Esta perda pode ser correlacionada com o aumento dos limiares auditivos medido várias horas após uma severa exposição sonora. O limite superior da faixa dinâmica da audição, ou seja, aquela na qual o ouvido é capaz de codificar com fidelidade os estímulos sonoros, corresponde a 120 dBNPS, porém, exposições repetidas a níveis de pressão sonoras superiores a 85 dBNPS, já comprometem o órgão auditivo periférico ou a cóclea que progressivamente se deteriora (HENDERSON e HARMERNICK, 1995).

A lesão coclear ocorre principalmente e primeiramente na região basal, mesmo em exposições a ruídos com predomínio de baixas freqüências. O dano máximo ocorre a mais ou menos 8 a $10 \mathrm{~mm}$ da janela oval. As perdas auditivas permanentes induzidas por ruído são do tipo neurossensorial, geralmente bilateral e simétrica. O reflexo estapediano apresenta-se alterado ou ausente nas baixas freqüências. A lesão inicia-se 
na freqüência de 4 ou $6 \mathrm{kHz}$ e se expande para as frequiências de 3;2;0,5 e 0,25 kHz. Na evolução clínica há queixas de zumbido fugaz ou persistente, dificuldades na identificação têmporo-espacial dos sons e na percepção e discriminação de estímulos sonoros quando na presença de ruído de fundo, distorção na percepção da intensidade sonora, hipoacusia de leve a severa e presença de recrutamento (SANTOS e MORATA, 1996).

As alterações na sensibilidade auditiva são os efeitos agudos ou crônicos mais comuns provocados pela estimulação sonora de alta intensidade. O método típico para se avaliar estes efeitos é medir os limiares auditivos antes e um tempo específico após cessar a exposição ao ruído. Caso o limiar alterado retorne ao nível da pré-exposição, a alteração do limiar é chamada de transitória. Entretanto, se, por outro lado, esta alteração persiste 20 à 30 dias depois de cessada a exposição, a alteração do limiar ou a perda auditiva é considerada permanente. O TTS é utilizado nas pesquisas laboratoriais e nos estudos clínicos para se avaliar o efeito deletério provocado por uma estimulação sonora de alta intensidade.

Tipicamente o TTS decresce durante o primeiro minuto pós-exposição e então aumenta até o seu máximo durante os 2 ou 3 minutos subseqüentes, quando volta a decrescer. Para evitar flutuações, o TTS é usualmente medido aproximadamente 2 minutos depois de cessada a exposição e é chamado de $\mathrm{TTS}_{2}$. Uma vez alcançado o seu valor máximo, o decréscimo do $\mathrm{TTS}_{2}$ é aproximadamente linear no logaritmo do tempo e os limiares alterados retornam usualmente ao nível da pré-exposição em menos de um dia. Para exposições sonoras mais prolongadas (alguns dias) e para alterações nos limiares auditivos pós-exposição superiores a $40 \mathrm{~dB}$, esta recuperação é geralmente lenta, particularmente durante as primeiras 12 horas. Exposições sonoras a ruídos 
intermitentes produzem menos $\mathrm{TTS}_{2}$ do que exposições de igual energia a ruídos contínuos. $\mathrm{O} \mathrm{TTS}_{2}$ não é considerado um bom teste para predizer a susceptibilidade individual ao desenvolvimento de perdas permanentes da audição. Qualquer perda na sensibilidade auditiva presente quatro semanas após a exposição deve ser considerada permanente (QUARANTA et al., 1998).

Uma típica perda auditiva causada por ruído é acompanhada por um número considerável de mudanças no código dos neurônios que chegam ao sistema nervoso central (SNC) pelas vias auditivas. Há evidências de que o sistema auditivo central tem um certo grau de plasticidade e que profundas alterações no processamento do SNC estão associadas com os danos periféricos causados pelo ruído (HENDERSON e SALVI, 1998).

Os níveis de pressão sonora devem ultrapassar uma determinada intensidade para que possa ocorrer TTS, mesmo para exposições mais prolongadas. Nos períodos de exposição sonora de 8 a 16 horas, se a pressão sonora for constante e não exceder a 75 dBA (nível da pressão sonora medido em decibel na escala A), não haverá TTS. De acordo com a American Academy of Otolaryngology - Head and Neck Surgery, 1988, os seguintes fatores contribuem para o risco potencial de dano auditivo: o nível sonoro total medido em dB; a distribuição espectral (distribuição da energia por freqüência); a duração e a distribuição do ruído (exposição sonora durante um dia típico); e a exposição cumulativa em dias, semanas ou anos. A dimensão da perda auditiva e a frequiência na qual ela ocorre estão relacionadas à energia contida na faixa de freqüência da oitava do ruído abaixo da freqüência afetada. O conceito de nocividade igual envolve uma relação entre o tempo de exposição e a intensidade do ruído. Aqueles que propõem que a nocividade do ruído seja equacionada com a energia sonora contida nele, 
estabelecem relações entre tempo e igual energia. Para estes, a energia aumenta $3 \mathrm{~dB}$ quando a duração da exposição sonora é dobrada. Portanto, quando o período de exposição é dobrado, a energia precisa ser reduzida pela metade para que possamos manter o risco da lesão auditiva sob controle. Pela simplicidade física, este conceito de igual energia é adotado por muitos profissionais que atuam na área da preservação auditiva (MELNICK, 1999).

Para se quantificar a energia do ruído em decibel são utilizados equipamentos capazes de medir as variações nos níveis de pressão sonora. Na prática, os mais utilizados são os medidores de nível de pressão sonora e os dosímetros de ruído. A escolha do tipo de equipamento de medição depende do dado que se quer obter ou do tipo de ruído a ser avaliado. Como nem todas as freqüências componentes do ruído contribuem igualmente para o dano coclear, para medir o nível da pressão sonora nas pesquisas audiológicas utiliza-se o filtro acústico conhecido como tipo A, cujas características específicas de resposta de frequiência são derivadas das curvas de igual sensação de Fletcher-Munson (EARSHEN, 1999).

Segundo NORDMANN et al. (2000), há diferentes hipóteses concernentes aos mecanismos envolvidos nos efeitos provocados pela exposição ao ruído, que incluem danos mecânicos, processos isquêmicos, danos por excitotoxidade, por exaustão metabólica ou por alterações no equilíbrio iônico dos fluídos da orelha interna. Estes estudos geralmente têm como foco a pesquisa de alterações patológicas em somente um ou dois tipos de células incluindo: (1) as células sensoriais do Orgão de Corti; (2) células sensoriais dos esteriocilios; (3) as fibras do nervo na cóclea, particularmente na área situada abaixo das CCI, incluindo os feixes internos espiral e os aferentes radiais; e (4) a estria vascular e a vascularização da cóclea. Segundo esses autores, em muitos 
destes estudos é difícil distinguir as alterações reversíveis das irreversíveis ou mesmo os efeitos agudos dos crônicos, pois a função e o efeito de longo termo, provocado por diferentes exposições, nem sempre foram determinados nas cócleas morfologicamente examinadas.

No estudo realizado por NORDMANN et al. (2000), examinando as alterações estruturais associadas às mudanças temporárias e permanentes nos limiares auditivos em cócleas sadias de 11 chinchilas expostas 24 horas por dia a um ruído de oitava de banda com a freqüência central em $4000 \mathrm{~Hz}$ emitido a um nível de pressão sonora de 86 dBNPS, e que foram avaliadas em diferentes momentos pós-exposição, concluíram que os mecanismos que resultam em alterações transitórias nos limiares auditivos parecem ser distintos dos mecanismos que agem nas alterações permanentes. Todas as 11 cócleas examinadas desenvolveram alterações transitórias de magnitude similar, enquanto que somente quatro das onze cócleas desenvolveram perdas permanentes. Duas destas cócleas com perdas permanentes não mostraram nenhuma alteração patológica em seus esteriocilios quando examinadas por microscopia eletrônica. Uma outra apresentou um desarranjo dos esteriocilios na região das CCI, mas que não correspondia à região das freqüências afetadas. Somente uma delas apresentou alterações morfológicas (dano moderado nos esteriocilios) correspondente a região afetada pela perda permanente.

Os dados deste estudo sugerem que a susceptibilidade ao ruído depende mais de processos ligados a recuperação ou reparos dentro da cóclea do que da magnitude inicial das alterações dos limiares auditivos. Segundo conclusão deste estudo, embora perdas transitórias e permanentes possam ocorrer em um mesmo indivíduo, os processos envolvidos na produção de uma perda transitória induzida por um estímulo moderado não resultam, necessariamente, em alterações permanentes. 


\section{2 - Sistemas de Proteção das Orelhas Expostas à Níveis Elevados de Pressão Sonora}

Nas orelhas normais são conhecidos dois sistemas naturais de proteção contra a estimulação sonora de alta intensidade, resultado de dois reflexos acústicos: primeiro a ação reflexa dos músculos da orelha média, particularmente a do estapédio, que, sob o efeito das contrações simultâneas, restringe a movimentação da cadeia ossicular e pelo aumento da rigidez do sistema reduz a ação traumática do estímulo sonoro elevado sobre a orelha interna; e segundo a ativação reflexa dos eferentes mediais que, agindo na motilidade das células ciliadas externas, reduz as vibrações da membrana basilar durante a estimulação sonora elevada, diminuindo o ganho do amplificador coclear durante as exposições traumáticas.

REGER (1960), estudando a ação dos músculos da orelha média, comprovou que nas orelhas humanas a ativação do estapédio determina uma atenuação de 20 a $30 \mathrm{~dB}$ para as freqüências abaixo de $2000 \mathrm{~Hz}$ com o máximo efeito protetor entre 0,125 e 0,25 $\mathrm{kHz}$.

MOLLER (1965) demonstrou que esta atenuação é quase que exclusivamente devida à contração do músculo do estapédio.

WARD (1965) comparou os TTS medidos em um grupo de 49 normo-ouvintes após exposições ipsilaterais a um estímulo de $750 \mathrm{~Hz}$, emitido a 125 dBNPS por 5 minutos, antes e após a introdução de um ruído contralateral de banda estreita de freqüência emitido na mesma intensidade que o estímulo teste. Ele observou que as exposições binaurais produzem menor TTS do que as exposições monoaurais, e que estas diferenças são mais significativas nas baixas freqüências. Atribuiu estes resultados, principalmente, à atuação dos músculos da orelha média. Segundo o autor, a "loudness", ou a sensação de intensidade produzida por um estímulo binaural, é duas 
vezes maior comparativamente a apresentação monoaural do estímulo sonoro, o que provoca uma maior contração reflexa, reduzindo a energia acústica das freqüências inferiores a $2000 \mathrm{~Hz}$.

O efeito da contração do estapédio na redução do TTS foi estudado por ZAKRISSON et al (1980) comparando as orelhas com reflexo normal com as orelhas com o reflexo acústico inativo de pacientes portadores de paralisia unilateral de Bell. Foi observado que, nas orelhas com o reflexo inoperante expostas a um ruído de 102 dBA durante 15 minutos, os limiares auditivos aumentaram consideravelmente com relação as orelhas com os músculos da orelha média intactos. O TTS ocorreu principalmente entre 3-5 Khz nas orelhas com os reflexos acústicos normais e entre 1,5 - 3kHz nas orelhas com o músculo do estapédio paralisado.

Em um estudo similar, BORG et al. (1983) expôs coelhos com o reflexo acústico desativado a um Leq entre 115-130 dB durante 15 minutos, demonstrando que as orelhas afetadas apresentaram perdas permanentes na audição 30 a $40 \mathrm{~dB}$ maiores do que as orelhas íntegras.

HENDERSON et al. (1994), referindo-se aos trabalhos de Zakrisson e Borg, observou que, embora o reflexo acústico produza atenuação para estímulos abaixo de $2000 \mathrm{~Hz}$, seu efeito protetor pode ser observado em baixas e altas freqüências.

Segundo RYAN et al. (1994), o reflexo acústico se fatiga rapidamente durante a estimulação sonora com tons puros de alta freqüência e opera com uma latência muito grande para fornecer proteção a sons de impacto. Esta propriedade não contribuiu em especial para a proteção da orelha interna exposta a sons agudos.

O reflexo acústico tem sido sugerido como um dos principais mecanismos envolvidos no desenvolvimento da resistência da orelha às perdas induzidas por ruído 
quando submetidas a repetidas exposições (HENDERSON et al., 1994). No entanto, parece que ele não é o principal moderador do fenômeno (HENDERSON et al., 1994; RYAN et al., 1994; DAGLI e CANLON, 1995).

HENDERSON et al. (1994), avaliou a participação da contração dos músculos da orelha média no desenvolvimento do aumento da resistência em chinchilas. As orelhas de um grupo de animais com os músculos seccionados foram comparados às orelhas de um outro grupo de animais com os músculos intactos quando expostos a um ruído de oitava de banda com a freqüência central a $500 \mathrm{~Hz}$ emitido a $95 \mathrm{~dB}$ durante 10 dias consecutivos, 6 horas por dia. Os resultados mostraram que os animais com os músculos afetados apresentaram maior alteração inicial nos limiares auditivos pós-exposição ao ruído do que os animais com os músculos íntegros, e que esta alteração se reduziu durante os 10 dias de exposição em ambos os grupos. Esses dois grupos experimentais foram submetidos a cinco dias de recuperação e depois novamente expostos ao mesmo ruído emitido a $106 \mathrm{~dB}$ por 48 horas. As alterações permanentes nos limiares auditivos dos dois grupos experimentais foram comparadas às alterações permanentes dos limiares auditivos de um grupo controle exposto somente à estimulação sonora mais alta. Ambos os grupos "condicionados" apresentaram perdas permanentes significativamente menores quando comparadas às do grupo controle, exposto somente a estimulação sonora elevada.

RYAN et al. (1994) também pesquisou a efetividade da participação da contração reflexa dos músculos da orelha média no aumento da resistência das orelhas em um grupo de gerbils mongolianos. Os animais tiveram os tendões do estapédio e do tensor timpânico de uma das orelhas cortados. Um grupo destes animais foi posteriormente condicionado com um ruído de duas oitavas de banda $(1414-5656 \mathrm{~Hz})$ emitido a 81 
dBNPS durante três semanas. Após o condicionamento, esses animais foram expostos, em dois momentos distintos (imediatamente após o condicionamento e uma semana após um período de recuperação), ao mesmo estímulo sonoro emitido a uma intensidade mais elevada (110 dBNPS) durante uma hora. Os limiares auditivos eletrofisiológicos registrados na ABR (Auditory Brainstem Evoked Response), após estas duas exposições traumáticas, foram comparados aos de um grupo controle (animais não condicionados), que foram expostos somente ao estímulo traumático (110dBNPS por 1 hora). As orelhas não operadas e condicionadas quando testadas imediatamente após (sem o período de recuperação) não mostraram alteração no efeito provocado pelo estímulo traumático, mas as orelhas testadas após um período de recuperação de uma semana mostraram redução nas alterações transitórias e permanentes de seus limiares auditivos. Nos animais não condicionados, as orelhas com os músculos seccionados e não seccionados não apresentaram alterações nos efeitos transitórios e permanentes provocados pela estimulação traumática.

DAGLI e CANLON (1995) também realizaram um estudo semelhante com o objetivo de pesquisar a participação dos músculos da orelha média no condicionamento das orelhas em um grupo de cobaias. Eles empregaram um estímulo sonoro de 103 dBNPS, emitido a $2767 \mathrm{~Hz}$ durante 5 minutos para induzir alterações transitórias nos limiares auditivos em dois grupos de cobaias previamente condicionadas durante 24 dias por um estímulo sonoro de $81 \mathrm{dBNPS}$, emitido a $1000 \mathrm{~Hz}$. Um grupo destes animais foi condicionado com os músculos da orelha média intactos e o outro grupo com os músculos paralisados. A magnitude, a duração e o tempo de recuperação da amplitude dos produtos de distorção das emissões otoacústicas foram determinadas em 1.75, 2.2, 
2.8 e $3.5 \mathrm{kHz}$ durante os 90 minutos após a exposição e nenhuma diferença foi encontrada nestes parâmetros avaliados entre os dois grupos condicionados.

A participação do sistema eferente na proteção da orelha interna durante as estimulações traumáticas é um outro fenômeno bastante estudado. Segundo ZHENG et al., 1997b, essa proteção é extensiva às baixas e altas frequiências.

ZHENG et al. (1997b), expôs um grupo de chinchilas a um ruído de banda larga emitido a 105 dBNPS durante seis horas. A função das CCE foi avaliada através dos produtos de distorção das otoemissões acústicas (PDOEAs) nas frequiências de 1.2 a 9.6 $\mathrm{kHz}$ e o microfonismo coclear (MC) nas freqüências de 1 a $8 \mathrm{kHz}$. Um dos grupos de chinchilas teve o feixe olivococlear seccionado antes da exposição, enquanto que o outro grupo foi exposto às mesmas condições de estimulação com o sistema eferente intacto. Após a exposição traumática, o grupo com as orelhas de-eferenciadas (feixe olivococlear inoperante) apresentou uma significante redução nas PDOEAs e na amplitude do MC. As diferenças entre as orelhas íntegras e as orelhas lesionadas foram evidentes ao longo de toda a faixa de freqüência testada.

Segundo ZHENG et al, (1997a), o sistema eferente medial é importante na proteção das perdas temporárias dos limiares auditivos que decorrem de exposições a um estímulo único ou a um a série de estímulos moderados (“toughening”). Entretanto, a participação do feixe olivococlear na redução da susceptibilidade às perdas permanentes da audição permanece ainda em questão. ZHENG et al. (1997 a), expôs um grupo de chinchilas com os feixes olivococlear ipsi e contralateral inativos a um ruído de banda de oitava com a frequiência central em $4000 \mathrm{~Hz}$, emitido a 85 dBNPS durante 10 dias, e, posteriormente, os expôs a este mesmo estímulo emitido em intensidade mais elevada (95dBNPS) por 48 horas. A completa de-eferenciação das orelhas mostrou 
aumento substancial das alterações transitórias, aumento das alterações permanentes e lesão significativa de CCE. Segundo o autor, este resultado sugere que o sistema eferente pode influenciar a habilidade da orelha em desenvolver resistência às exposições traumáticas.

Se a inativação do sistema eferente medial contribui para o aumento das alterações transitórias e permanentes após a exposição a um ruído elevado (ZHENG ,et al. 1997 a), a sua participação no desenvolvimento da resistência das orelhas expostas a condições traumáticas não ficou comprovada (YAMASOBA e DOLAN,1998).

YAMASOBA e DOLAN (1998) compararam as perdas auditivas induzidas após exposição a um estimulo traumático de 110 dB NPS, durante 5 horas, em um grupo de cobaias previamente condicionado com um estímulo de banda larga de $85 \mathrm{~dB}, 5$ horas por dia durante 10 dias, com um outro grupo não condicionado e exposto ao mesmo estímulo traumático. A orelha esquerda de todos os animais dos dois grupos foi submetida à perfusão intracoclear com estriquinina, para inibir a atuação do sistema eferente medial, antes de ser exposta ao condicionamento. Os animais condicionados apresentaram significativa redução nos limiares auditivos depois de submetidos ao ruído traumatizante, quando comparado aos do grupo não condicionado, enquanto que os animais de ambos os grupos condicionados ou não condicionados tratados com estriquinina apresentaram limiares auditivos maiores comparativamente a um outro grupo de animais condicionados e não condicionados, mas que não foram tratados com estriquinina. Os autores sugeriram então que, embora o sistema eferente medial atue na atenuação das perdas auditivas induzidas por ruído, ele não contribui para o desenvolvimento da resistência nas orelhas expostas ao condicionamento. 
A resistência adquirida pelas orelhas expostas ao condicionamento parece ser primariamente mediada por mudanças restritas à cóclea e não por alterações sistêmicas, já que orelhas que foram expostas ao condicionamento com o meato acústico externo ocluso e submetidas posteriormente a uma estimulação traumática após a remoção da oclusão, apresentaram alterações dos limiares auditivos significativamente maiores do que as orelhas contra-laterais expostas às mesmas condições, mas sem a oclusão do meato acústico (YAMASOBA et al., 1999).

Segundo YAMASOBA et al. (1998 e 1999), vários mecanismos têm sido atribuídos ao fenômeno da resistência adquirida pelas orelhas. Estas incluem mudanças fundamentais no Orgão de Corti, alterações na distribuição da F-actina nas células ciliadas e de suporte e mudanças nas regiões pré-sinapticas das CCE opostas às terminações nervosas aferentes.

Outra possibilidade aventada (YAMASOBA e DOLAN, 1999) se refere ao aumento da atividade enzimática oxidante provocado pela exposição condicionante. Com a liberação do glutadione redutase, presume-se que haveria um aumento da proteção das células ciliadas contra o efeito decorrente da liberação de substâncias oxigênio-reativa provocado pela super-estimulação acústica e que poderiam levar a célula a apoptose.

O condicionamento sonoro poderia ainda provocar a disruptura nos filamentos de actina nas células ciliadas, alterando a distribuição secundária da actina (F-actina), podendo atenuar o dano por ruído provocado nas células ciliadas. $\mathrm{O}$ decréscimo da actina nos esteriocílios faria decrescer o mecanismo de rigidez do Órgão de Corti, reduzindo a possibilidade de fratura ou ruptura nas junções das células provocadas por um estímulo acústico elevado. Sabe-se que também que o aumento intracelular do Ca 
$2+$ contribui para a morte de uma variedade de células. Assim, o efeito dos sistemas tampões de cálcio estariam também envolvidos na proteção das orelhas expostas ao ruído. Portanto, as mudanças na distribuição da actina nas células ciliadas e nas células de suporte, assim como os sistemas tampões de cálcio, se envolvidos no condicionamento, seriam regulados pelo som condicionante (YAMASOBA, 1999).

Uma outra possível explicação para o fenômeno do aumento da resistência das orelhas (YAMASOBA et al., 1998 e 1999) seria a indução de proteínas de choque térmico (HSPs) como o HSP 72, HSP 27 e o HSP 70, que, sob determinadas condições de estresse, exerceriam seu papel protetor na redução e na recuperação do trauma induzido por ruído. Embora os mecanismos exercidos pelas HSPs na proteção contra o trauma acústico sejam desconhecidos, acredita-se que eles atuem na proteção das células ciliadas pela modulação dos sistemas endogenos anti-oxidantes. Parece que as HSPs estariam envolvidas na tolerância adquirida ao estresse, pois, quando ocorre a primeira exposição ao estresse, decrescem os efeitos patológicos da segunda e isso poderia ser chamado de resistência ou treino quando falamos de exposição ao ruído (OLIVEIRA, 2001).

Segundo NIU e CANLON (2002), muitas hipóteses tem sido aventadas para explicar os efeitos do som condicionante na proteção da orelha exposta a níveis elevados de pressão sonora, porém a maioria destes estudos não é conclusiva. Há evidências que a melhora nos sistemas de proteção endógenos na cóclea pode prover proteção contra o trauma induzido por ruído. Estes sistemas endógenos incluem antioxidantes, radicais livres, sistemas tampão de cálcio, proteínas de choque (HSPs), receptores do glutamato e fatores neurotróficos. 
A atuação das enzimas antioxidantes poderia ser um dos fatores responsáveis pela proteção localizada das estruturas cocleares pelo som condicionante, incluindo as CCE e as terminações eferentes (NIU e CANLON, 2002).

\section{3 - Resistência Adquirida às Perdas Auditivas Induzidas por Ruído}

Na última década, a hipótese de que a história de exposição prévia ao ruído pode ser um fator determinante na susceptibilidade das orelhas às perdas auditivas induzidas por ruído, tem gerado um número considerável de pesquisas.

Partindo desta hipótese, a magnitude das alterações transitórias e permanentes da audição provocadas por uma exposição traumática pode ser reduzida se as orelhas forem previamente "condicionadas" por um estímulo sonoro.

Evidências deste fenômeno surgiram com os trabalhos clássicos de MILLER et al. (1963). Esses autores observaram um decréscimo significativo nas alterações temporárias dos limiares auditivos observadas em um grupo de gatos treinados quando expostos a repetidas exposições a um estímulo de banda larga, emitido a 115 dBNPS por 7 minutos e meio, a cada 24 horas. Eles verificaram que as alterações transitórias nos limiares auditivos de aproximadamente $45 \mathrm{~dB}$, registradas em $4000 \mathrm{~Hz}$ após a primeira exposição de uma série de dezesseis, decresceram para $10-15 \mathrm{~dB}$ entre a $5^{\mathrm{a}} \mathrm{e}$ a $16^{\mathrm{a}}$ exposição. Algumas hipóteses foram aventadas pelos autores para justificar estes resultados inesperados, como a dos gatos terem aprendido a distinguir o estímulo-teste do tinnitus provocado pela exposição sonora, ou mesmo a da melhora na performance decorrente do número de repetições do experimento, uma vez que os limiares tonais foram obtidos por métodos comportamentais . 
Como os resultados do experimento não podiam ser explicados pelo conceito de igual energia que atribui a magnitude da perda auditiva à intensidade do estímulo e ao tempo de exposição, este aumento da resistência nas orelhas observada nos trabalhos de Miller et al. (1963), foi negligenciado até 1987, quando Clark publicou a sua pesquisa.

CLARK et al. (1987) expôs dois grupos de chinchilas a um ruído de banda de oitava com a frequiência central em $0,5 \mathrm{kHz}$ emitido a 95 dBNPS. Utilizou dois protocolos de exposição: 6 horas por dia durante 36 dias e 15 minutos por dia durante 144 dias. Os limiares auditivos foram obtidos por técnicas comportamentais nas freqüências de 0,125 à 16,0 kHz, e avaliados antes, durante e por um período de um a dois meses após a exposição. O dano coclear foi determinado pela contagem do número de células sensoriais perdidas. Ambas as exposições produziram um aumento inicial nos limiares auditivos de 35-45 dB. Entretanto, após poucos dias de exposições, as alterações começaram a reduzir, tendo os limiares auditivos retornado a 10-15 dB do nível anterior à exposição mesmo com a continuidade desta. Os dados comportamentais e anatômicos indicaram que as exposições intermitentes produziam menos perdas temporárias e permanentes e menor dano coclear do que exposições contínuas de igual energia.

Para CLARK, esta recuperação nos limiares auditivos comportamentais estava em consonância com os resultados de SINEX et al. (1987), que utilizou as medidas do potencial total de ação da fibra auditiva e dos limiares dos neurônios do nervo auditivo para avaliar as alterações auditivas em chinchilas expostas às mesmas condições de estimulação descritas anteriormente. SINEX demonstrou que os limiares auditivos e o componente do potencial de ação da fibra auditiva também se recuperavam durante as exposições intermitentes. Segundo CLARK et al. (1987), estes resultados eram 
evidências de que a recuperação observada nos trabalhos de MILLER et al. (1963) foi real e que o "locus" do fenômeno de recuperação seria periférico, provavelmente à nível das células ciliadas.

O histórico da exposição prévia parece ser também um fator determinante na redução das perdas permanentes. CANLON et al. (1988), expôs cobaias durante 24 dias a um estímulo acústico moderado (81 dBSPL a $1000 \mathrm{~Hz}$ ), antes de expô-las a um estímulo elevado (105 dBSPL a $1000 \mathrm{~Hz}$ por 72 horas), capaz de provocar perdas permanentes na audição. Os animais, expostos previamente ao estimulo moderado, tiveram em média uma redução de $20 \mathrm{~dB}$ nas alterações de seus limiares comparativamente ao grupo de animais controle, expostos somente à exposição traumática. Os animais do grupo experimental tiveram uma completa recuperação de seus limiares auditivos dois meses após a exposição, enquanto nenhuma das orelhas dos animais do grupo controle retornou aos limiares auditivos da pré-exposição durante o período de estudo. Segundo os autores, a pré-exposição a um estímulo de menor intensidade reduziu o efeito danoso da segunda exposição. Assim, as condições traumáticas da exposição utilizadas nesta investigação provocaram somente alterações temporárias na audição, ao contrário de perdas permanentes, como seria o esperado. Os autores concluíram que os mecanismos bioquímicos e as estruturas anatômicas responsáveis pelo fenômeno do aumento da resistência das orelhas seria ainda desconhecido. Como hipóteses prováveis, citaram a atuação dos músculos da orelha média, o aumento da atividade metabólica da orelha interna durante a exposição de longo termo a um estímulo de baixa intensidade, a plasticidade de estruturas funcionais das células ciliadas externas como esteriocílios e lâmina cuticular, ou mesmos as mudanças nas regiões das sinapses aferentes ou eferentes após a indução do trauma. 
Todos estes fatores poderiam estar envolvidos no aumento da resistência da orelha a super-estimulação, com conseqüente redução nas alterações temporárias e permanentes da audição.

SUBRAMANIAM e HENDERSON (1991), expuseram chinchilas a um ruído de oitava de banda com a freqüência central a $500 \mathrm{~Hz}$, emitido a diferentes níveis de pressão sonora: 85, 95 ou 100 dBNPS, seis horas por dia durante 10 dias. Os limiares auditivos eletrofisiológicos (ABR) foram avaliados antes e após cada exposição. Verificaram-se reduções nas alterações transitórias dos limiares auditivos para todos os níveis de pressão sonora com o aumento do número de exposições. De acordo com estes resultados, os autores levantaram a possibilidade de um possível "toughening", responsável pelo mecanismo da resistência das orelhas.

O "toughening” foi atribuído por CLARK em 1991 a um ajuste nas curvas de sintonia das células remanescentes para maximizar a sensitividade da cóclea.

MIYAKITA et al. (1992), pesquisou este efeito em orelhas humanas, tendo conseguido verificar a capacidade destas em desenvolver resistência ou "toughening" à estimulação sonora elevada quando previamente treinada com um estimulo de banda larga de freqüência (seleção musical) e de baixa intensidade (70dBA), durante exposições interrompidas (6 horas por dia por 9 dias consecutivos). Demonstrou nesta experiência que as alterações transitórias dos limiares auditivos, induzidas por um estímulo de banda estreita e intensidade elevada (1/3 de oitava centrado a $2 \mathrm{kHZ}$ e emitido a 105 dBNPS por 2 minutos), observadas nas orelhas experimentais de 8 jovens normo-ouvintes, apresentaram sensível redução na faixa de frequiências de 3-3,5 kHz no $5^{\circ}$ dia de treinamento, e que se estendeu para a faixa de $2-5 \mathrm{kHz}$ com a continuidade do treinamento. 
FOWLER (1995) utilizando o rato como modelo experimental usou em sua pesquisa um protocolo de exposições interrompidas (96 dBNPS, 6 horas por dia durante 10 dias), e um protocolo de exposição contínua com um estímulo de menor intensidade (80 dBNPS durante 24 dias), antes da exposição traumática. $\mathrm{Na}$ avaliação eletrofisiológica (ABR) foi observado que as alterações permanentes aumentaram após a exposição ao estímulo traumático, ou seja, nenhum efeito protetor foi observado com a exposição prévia das orelhas a um estimulo de menor intensidade precedendo a exposição traumática.

SKELLET et al. (1998) e WHITE et al. (1998) compararam a efetividade da exposição contínua com a da exposição interrompida na proteção das orelhas submetidas a níveis de pressão sonora elevada.

SKELLET et al. (1998) expuseram um grupo de cobaias a um estímulo sonoro de banda de oitava, com a freqüência central 1,0-2,0kHz, emitido segundo dois protocolos: 95 dBNPS por 6 horas por dia durante 11 dias; e 89 dBNPS por 24 horas por dia durante 11 dias. Os autores não observaram nenhum efeito protetor com a exposição contínua.

WHITE et al. (1998) em um estudo similar, também expuseram um grupo de gerbils a um estímulo sonoro de oitava de banda com a freqüência central em $2 \mathrm{kHz}$, emitido de acordo com os seguintes protocolos: $74 \mathrm{dBA}$ por 24 horas por dia durante 10 dias e $80 \mathrm{dBA}$ por 6 horas por dia durante 10 dias, antes de expô-los a um ruído traumático (107dBA por 24 horas por dia durante 48 horas) de mesmo espectro sonoro. Segundo os autores, a exposição contínua prévia com um estímulo de baixo nível reduziu as alterações transitórias e permanentes da audição e a perda de células ciliadas decorrentes da posterior exposição traumática. Já o protocolo de exposições 
interrompidas teve o efeito de reduzir as perdas temporárias e de diminuir discretamente a perda de células ciliadas após a exposição traumática. Nenhum dos dois protocolos preveniu a redução na amplitude dos produtos de distorção das emissões otoacústicas.

Segundo YOSHIDA e LIBERMAN (2000), o protocolo convencional adotado em várias pesquisas utiliza o período de uma semana para o condicionamento das orelhas antes da exposição traumática. Mais recentemente, estes autores idealizaram uma pesquisa para estudar a efetividade de um período bem mais curto de condicionamento antecedendo a introdução do estímulo traumático em orelhas de ratos.

Os ratos foram previamente expostos a dois protocolos de investigação, ambos com estímulos condicionantes de moderada intensidade emitidos continuamente: 81 dBNPS por uma semana e 89 dBNPS por 15 minutos. Foram utilizadas as medidas dos componentes dos potenciais de ação para avaliar as alterações permanentes após a exposição traumática (8-16kHz a 100dBNPS por 2 horas). Nenhum dos dois estímulos usados provocou alterações nos limiares auditivos durante o condicionamento das orelhas, embora ambos os protocolos tenham aumentado a amplitude dos produtos de distorção das emissões otoacústicas (PDOEAs) quando os animais foram condicionados, mas não traumatizados. Ambas as exposições condicionantes conseguiram reduzir as perdas permanentes, subseqüentes à exposição traumática, comparativamente ao grupo controle, não exposto ao condicionamento prévio. O máximo efeito protetor para a exposição condicionante mais curta (15 minutos) ocorreu quando o intervalo entre a exposição condicionante e a exposição traumática foi de 24 horas, desaparecendo quando se aumentou este intervalo para 48 horas. Os autores atribuíram este resultado à síntese de proteínas necessária para a expressão do efeito protetor das orelhas. Creditam também na melhora na amplitude das PDOEASs, 
observada somente na condição de condicionamento, ao efeito deste na função das CCE.

O condicionamento prévio com um estímulo moderado também parece aumentar a resistência das orelhas quando o estímulo traumatizante é um ruído de impacto. MACFADDEN et al. (2000), expuseram chinchilas machos e fêmeas a um estímulo de oitava de banda com a freqüência central em $0,5 \mathrm{khz}$ por 6 horas por dia durante 5 dias. Após cinco dias de recuperação, os animais foram expostos a um ruído de impacto de 150 dBNPS. Os animais condicionados apresentaram menor perda auditiva e menor lesão nas células ciliadas do que o grupo controle não exposto ao estímulo condicionante. Comparativamente aos machos, as fêmeas apresentaram perda auditiva significantemente menor nas baixas freqüências e maior na freqüência de $16 \mathrm{khz}$.

Para AHROON et al. (2000), a habilidade do sistema auditivo em desenvolver resistência ao ruído, tem sido pouco explorada em orelhas com perdas pré-existentes. Em um trabalho realizado com chinchilas, ele pesquisou o efeito do "toughening" em um grupo de animais com perda auditiva induzida por ruído. $\mathrm{O}$ "toughening" foi produzido por um estímulo de impacto, de banda estreita de freqüência centrado em $1000 \mathrm{~Hz}$ e emitido a 115 dBNPS por 10 dias, 6 horas por dia, e o trauma foi produzido pelo mesmo estímulo sonoro, porém emitido a 121 dBNPS por 5 dias, 24 horas por dia. O grupo 1 foi exposto a um ruído traumatizante que provocou uma perda auditiva moderada em uma faixa larga de freqüência e, após 30 dias de intervalo, foi submetido a uma estimulação conhecida pela capacidade de produzir o "toughening" em orelhas normais de chinchilas. O grupo 2 foi submetido ao mesmo estimulo que produz “toughening" e, 30 dias após, foi exposto ao mesmo ruído traumatizante. No grupo 1 (com perda), nenhum efeito "toughening" foi constatado, enquanto que no grupo 2 
(sem perda), o efeito "toughening" foi verificado em uma larga faixa de freqüência. Segundo observação dos autores, parece que as cócleas danificadas não desenvolvem "toughening".

Os resultados das várias pesquisas vêm comprovando a eficiência dos métodos que propõem a exposição prévia a estímulos sonoros específicos para aumentar a resistência das orelhas expostas a níveis elevados de pressão sonora. NIU e CANLON (2002) assim resumiram a revisão das pesquisas referentes a estes mecanismos protetores: “As evidências acumuladas demonstram a importância da redução dos efeitos deletérios das exposições traumáticas utilizando-se som condicionante. O condicionamento por som é um processo ativo induzido por um estímulo de baixa intensidade, não danoso e que produz uma proteção de longo termo que previne várias formas de trauma por ruído. Este fenômeno é conhecido por ocorrer em uma variedade de mamíferos incluindo gerbils, chinchilas, cobaias, coelhos, ratos e na espécie humana. Diferentes paradigmas de condicionamento por som tem sido comprovados na prevenção de alterações patológicas no sistema auditivo”. 


\section{3 - CASUÍSTICA E MÉTODOS}

\section{1 - Casuística}

A casuística desta pesquisa foi inicialmente constituída por 48 pacientes, de ambos os gêneros, recrutados entre os pacientes inscritos no Programa de Doação de Próteses Auditivas do Hospital Regional da Zona Sul. Todos apresentavam perdas auditivas neurossensoriais bilaterais de grau moderado a profundo e estavam na faixa etária de 6 a 29 anos.

Deste total, 25 pacientes, ou 42 orelhas, foram incluídas na análise estatística deste estudo. Dezessete pacientes da amostra foram avaliados com próteses auditivas binaurais e, portanto tiveram as duas orelhas $(n=34)$ estudadas. Oito pacientes foram avaliados com próteses auditivas monoaurais, tendo, portanto somente uma das orelhas $(n=8)$ incluída no estudo.

Dos vinte e cinco pacientes estudados, treze indivíduos estavam incluídos no Grupo Experimental (GE), e doze indivíduos no Grupo Convencional (GC).

No Grupo Convencional (GC), três pacientes eram do gênero feminino e nove do gênero masculino. Oito destes tiveram as duas orelhas incluídas no estudo (8 binaurais), e, em quatro destes, somente uma das orelhas foi avaliada (4 unilaterais). Das 20 orelhas analisadas no $\mathrm{GC}$, nove eram orelhas direita $(\mathrm{OD}=9)$ e onze eram orelhas esquerda $(\mathrm{OE}=11)$.

No Grupo Experimental (GE), sete pacientes eram do gênero feminino e seis do gênero masculino. Nove destes tiveram as duas orelhas incluídas no estudo (9 binaurais), e em quatro destes somente uma das orelhas foi avaliada (4 unilaterais). Das 
22 orelhas analisadas no GE, onze eram orelhas direita $(\mathrm{OD}=11)$ e onze eram orelhas esquerda $(\mathrm{OE}=11)$.

A média da faixa etária para os pacientes incluídos no GE foi de 16,9 anos e para os incluídos no GC, de 13,9 anos.

Considerando na classificação da perda auditiva por orelha estudada, as médias para tons puros de 500 a $2000 \mathrm{~Hz}$, determinada segundo os critérios estabelecidos por Davis e Silvermann (1970), ficaram assim distribuídos as 22 orelhas incluídas no GE e as 20 orelhas incluídas no GC quanto à média da perda auditiva: perda auditiva moderada: GE (1) e GC (4); perda auditiva severa: GE (6) e GC (8); perda auditiva profunda: GE (15) e GC (8).

Quanto ao tempo de estimulação prévia das orelhas estudadas, ou seja, o período de uso da prótese auditiva antes dos 25 pacientes serem incluídos aos grupos de estudo, a composição da amostra foi a seguinte: menos de 1 mês: GE (5) e GC (4); 1 a 2 meses: GE (1) e GC (2); 2 a 3 meses: GE (4) e GC (3); 3 a 4 meses: GE (0) e GC (2); 4 a 5 meses: GE (2) ; GC (1); 5 a 6 meses: GE (1) e GC (0).

Quanto à tecnologia das próteses auditivas adaptadas nas 22 orelhas incluídas no GE, oito eram digitais e quatorze eram analógicas ou programáveis. Nas 20 orelhas incluídas no GC, dez das próteses auditivas adaptadas eram digitais e dez eram programáveis ou analógicas.

No Grupo Experimental (GE) ficaram incluídas as 22 orelhas com maior mudança temporária no limiar auditivo (TTS), medida na etapa pré-experimental deste estudo, e no Grupo Convencional, as 20 orelhas com menor mudança temporária no limiar auditivo (TTS), medida nesta mesma etapa. 
Nas orelhas analisadas no GE (n=22), a amplificação "usual" das próteses auditivas adaptadas foi alterada (reduzida) na etapa experimental desta pesquisa durante um período de 60 a 90 dias, e, nas orelhas analisadas no GC (n=20), a amplificação usual das próteses auditivas adaptadas não foi modificada durante o período integral deste estudo.

As medidas "in situ" com as Próteses Auditivas testadas foram realizadas em 35 orelhas $(\mathrm{OD}=18$ e $\mathrm{OE}=17)$, das 42 que participaram deste estudo. Dezoito delas $(\mathrm{OD}=$ 9 e $\mathrm{OE}=9)$ estavam incluídas no $\mathrm{GE}$ e dezessete $(\mathrm{OD}=9$ e $\mathrm{OE}=8)$ estavam incluídas no GE.

Em sete das 42 orelhas estudadas não foram realizadas as medidas "in situ" por questões técnicas.

Os percentuais referentes ao gênero, orelha testada e tempo de estimulação prévia com a prótese auditiva (anterior ao inicio da pesquisa), para os pacientes incluídos no GE e no GC, e a classificação da média da perda auditiva por orelha testada, podem ser verificados nas Figura 1A e 1B.

A distribuição individual da amostra estudada (25 pacientes) quanto à idade, gênero, média da perda auditiva para tons puros (Classificação de Davis e Silvermann, 1970), orelha testada, tempo de estimulação prévia, modelo, marca e tecnologia da prótese auditiva adaptada, estão discriminados nos anexos.

As médias das medidas "in situ" foram incluídos nos resultados e os valores individuais das medidas para trinta e cinco orelhas testadas estão inseridos nos anexos do trabalho. 


\subsection{1 - Critérios Gerais de Inclusão no Estudo}

Para os paciente incluídos nos dois grupos de estudo:

a) Portador de perda auditiva neurossensorial bilateral de grau moderado a profundo;

b) Sem evidências de doenças de orelha externa ou média;

c) Resíduos auditivos presentes em qualquer uma das orelhas, em pelo menos duas das freqüências de 250 a $4000 \mathrm{~Hz}$;

d) Pacientes adaptados há menos de 6 meses com próteses auditivas binaurais ou monoaurais, de qualquer tecnologia, tipo ou marca;

e) Fazer uso sistemático das próteses auditivas durante o período deste estudo.

\subsection{2 - Critérios Específicos de Inclusão nos Dois Grupos Distintos}

\subsubsection{1 - Grupo Experimental (GE)}

1- Apresentar diferença superior a $2 \mathrm{~dB}$ na faixa de freqüência de 250 a $2000 \mathrm{~Hz}$, entre as alterações induzidas nas orelhas providas de suas próteses auditivas e as alterações induzidas nas orelhas desprovidas de suas próteses auditivas medidas na etapa pré-experimental.

2- Ter no mínimo oito medidas das mudanças temporárias induzidas nos limiares auditivos (TTS) durante o período do estudo;

3- Usar próteses auditivas de moderada à alta potência, desde que dotadas de controle externo de volume;

4- Concordar em usar suas próteses auditivas com a amplificação reduzida durante um período pré-determinado para este estudo;

5- Estar ciente da importância de não alterar a posição do controle externo de volume em benefício do estudo. 


\subsubsection{2 - Grupo Convencional (GC)}

1- Não apresentar diferença superior a $2 \mathrm{~dB}$ na faixa de freqüência de 250 a 2000 $\mathrm{Hz}$, entre as alterações induzidas nas orelhas providas de suas próteses auditivas e as alterações induzidas nas orelhas desprovidas de suas próteses auditivas medidas na etapa pré-experimental.

2- Ter no mínimo oito medidas das mudanças induzidas nos limiares auditivos (TTS), durante o período da pesquisa.

\subsection{3 - Critérios de Exclusão}

a) Falta de colaboração, baixa atenção ou imprecisão nas respostas a audiometria tonal liminar;

b) Perda auditiva flutuante;

c) Não estar fazendo uso regular da prótese auditiva;

d) Não concordar ou não obedecer aos critérios de inclusão 4 e 5 determinados para os pacientes incluídos no GE;

e) Ter menos do que as oito medidas das mudanças induzidas nos limiares auditivos (TTS) durante o período do estudo. 


\subsection{4 - Distribuição Percentual das Características Gerais da Amostra} Estudada
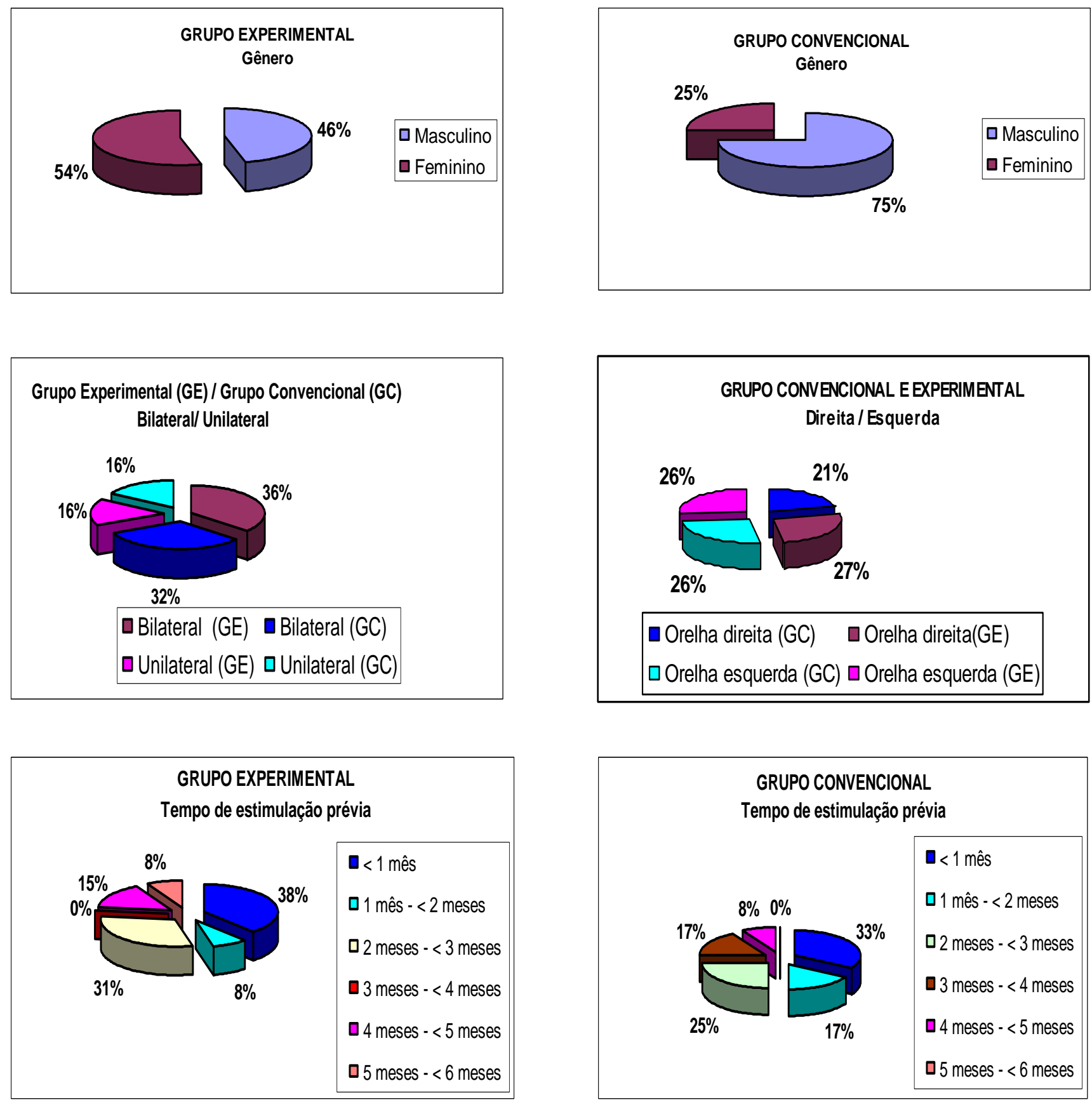

Figura 1A - Distribuição percentual das características gerais da amostra estudada para os pacientes incluídos no GE ( $n=13)$ e no GC ( $n=12)$, quanto ao Gênero dos Sujeitos, Orelha(s) incluída(s) na pesquisa e Tempo de Estimulação com a(s) Prótese(s) Auditiva(s), anterior a inclusão da orelha testada nos grupos de estudo. 


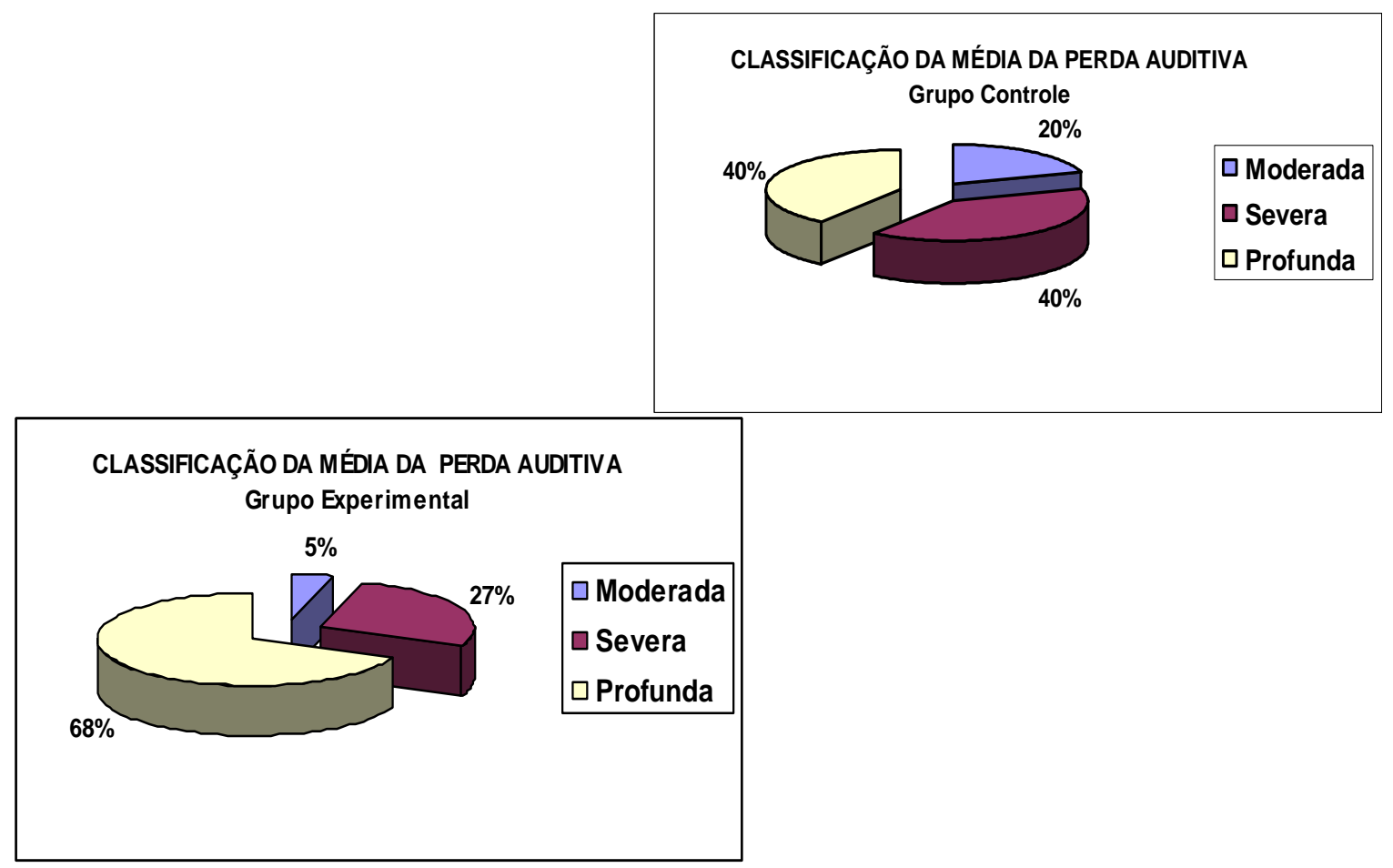

Figura 1B - Distribuição percentual das orelhas incluídas no $G E(n=22)$ e no $G C(n=20)$, quanto à média das perdas auditivas segundo a Classificação de Davis e Silvermann (1970).

\section{2 - Aprovação da Comissão de Ética}

Esta pesquisa foi aprovada pela Comissão de Ética para Análise de Projetos de Pesquisa — CAPPesq — da Diretoria Clínica do Hospital das Clínicas e da Faculdade de Medicina da Universidade de São Paulo em 20.11.02 — Protocolo de Pesquisa $\mathrm{n}^{\circ}$ $547 / 02$

\section{3 - Termo de Consentimento Livre e Esclarecido}

Todos os pacientes que integraram a amostra selecionada foram anteriormente esclarecidos de que se tratava de um trabalho de pesquisa, não havendo, portanto obrigatoriedade na participação. Os termos de consentimento assinado pelos pacientes ou por seus responsáveis, encontram-se nos arquivos da pesquisadora. 


\section{4 - Local da Pesquisa}

Esta pesquisa foi conduzida no Setor de Audiometria do Ambulatório Regional de Especialidades (ARES) do Hospital Regional da Zona Sul, localizado na Avenida Adolfo Pinheiros, 244, Santo Amaro, São Paulo, Capital.

O período da coleta dos dados extendeu-se de outubro de 2001 a dezembro de 2003.

\section{5 - Procedimentos Preliminares}

Todo o processo de pré-seleção, seleção, indicação, adaptação, orientação do uso, fornecimento e manutenção das próteses auditivas usadas nos pacientes da amostra estudada foram realizados no DERDIC.

Portanto, foram efetuadas somente as avaliações audiológicas necessárias à pesquisa ou alguns testes básicos (audiometria tonal liminar, logoaudiometria e imitânciometria), quando estes não estavam disponíveis ou atualizados no prontuário do paciente.

O desempenho acústico das próteses auditivas adaptadas também foi avaliado individualmente nesta etapa preliminar do estudo. Isto foi necessário para que pudéssemos identificar que nível de amplificação estava efetivamente estimulando as orelhas protetizadas no uso regular de suas próteses auditivas, antes dos pacientes serem integrados aos grupos de estudo.

Fez parte das avaliações audiológicas e do desempenho das próteses auditivas em uso nesta etapa preliminar:

a) Determinação dos limiares auditivos tonais por via aérea realizados nas freqüências de 250 a $8000 \mathrm{~Hz}$, com pesquisa da audibilidade mínima para tons puros 
mensuradas de 2 em $2 \mathrm{~dB}$, segundo a técnica ascendente do método psicométrico dos limites;

b) Pesquisa do desconforto realizada com fones, para a fala e para os tons puros nas frequiências de 500 a 4000Hz;

c) Medida do ganho funcional da prótese auditiva em uso, realizada em campo livre nas freqüências de 500 a $4000 \mathrm{~Hz}$;

d) Avaliação da adequação da saída máxima da prótese auditiva, realizada de maneira informal, mediante a exposição do paciente a estímulos sonoros comuns variados e de alta intensidade, emitidos bem próximos às orelhas adaptadas com as próteses auditivas.

Para as medidas do ganho funcional e para a avaliação da saída máxima, foram respeitados os controles internos e externos das próteses auditivas previamente ajustadas para os pacientes. No caso das próteses auditivas dotadas de controle externo de volume, as duas medidas acima (c e d), foram realizadas com os controles de volume ajustados na posição de preferência do paciente, ou na que foi prescrita pelo profissional responsável pela indicação e adaptação da prótese auditiva.

Isto significa que a avaliação preliminar do desempenho das próteses auditivas em uso foi realizada na amplificação prescrita para a sua perda auditiva, quando a prótese foi adaptada, ou na que estava sendo utilizada pelo paciente, de acordo com a sua preferência pessoal. Denominamos esta condição, de amplificação ou volume "usual”.

Esta amplificação ou volume "usual", definido na etapa preliminar, foi anotado na ficha de acompanhamento e serviu como referência para as outras etapas da pesquisa. 


\section{6 - Metodologia}

Esta metodologia permitiu avaliar a evolução das mudanças temporárias nos limiares auditivos (TTS) nos dois grupos distintos de orelhas formados para este estudo.

Várias medidas dos TTS foram realizadas periodicamente no decorrer do estudo e medidas durante os períodos em que as orelhas, inicialmente desprovidas das próteses auditivas e posteriormente adaptadas com as suas próteses auditivas, permaneciam expostas à ação de um ruído característico de um ambiente acústico comum.

Durante o período em que foram medidos os TTS nas mesmas condições experimentais determinadas para os dois grupos de orelhas estudados, os pacientes integrados a estes grupos usavam regularmente as suas próteses auditivas dentro dos critérios distintos determinados para cada grupo.

Para que este estudo fosse possível, os dois grupos foram avaliados durante as três etapas distintas, definidas nesta pesquisa como: etapa pré-experimental ou prétreinamento; etapa experimental ou de treinamento; e etapa pós-experimental ou póstreinamento.

Para medir as alterações nos limiares auditivos em uma condição experimental controlada, foi determinado que todos os pacientes deveriam permanecer em um mesmo ambiente, expostos à ação do ruído presente neste local durante um período contínuo de 2 a 2 1/2 horas. O ambiente designado para este propósito foi o próprio ambulatório onde esta pesquisa foi conduzida.

Este procedimento ocorreu em oito dias distintos, definindo as oito medidas das mudanças temporárias nos limiares auditivos (TTS), estudadas nesta pesquisa . 
A seguir será discutida a metodologia integrada, elaborada para a pesquisa da evolução das mudanças temporárias dos limiares auditivos durante o período de estudo. As oito medidas dos TTSs foram avaliadas nas orelhas incluídas aos dois grupos quando expostas às mesmas condições acústicas, enquanto faziam o uso regular de suas próteses auditivas em condições acústicas distintas.

\title{
3.6.1 - Representação Esquemática da Metodologia Integrada
}

\section{Etapa Pré-Experimental ou Pré -Treinamento}

\author{
AMOSTRA GERAL $=48$ PACIENTES \\ AMOSTRA ESTUDADA $=25$ PACIENTES
}

TTS 0 (primeira medida)

(Orelhas desprovidas das Próteses Auditivas durante o $1^{\circ}$ dia de permanência no Ambulatório por 2 a $2 \frac{1}{2} 2$ horas)

TTS 1 e TTS 2 (segunda e terceira medida)

(Orelhas adaptadas com suas Próteses Auditivas na amplificação ou volume "usual" durante o $2^{\circ}$ e o $3^{\circ}$ dia de permanência no Ambulatório por 2 a 2 1/2 horas)

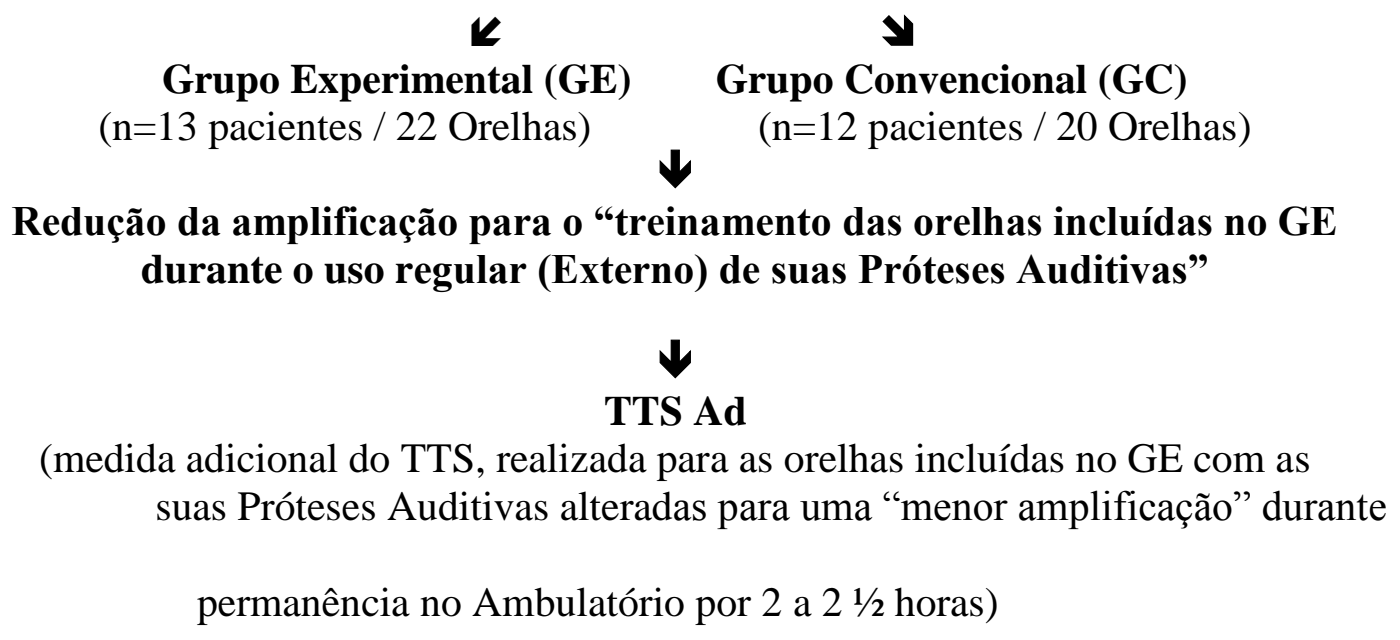

(medida adicional do TTS, realizada para as orelhas incluídas no GE com as suas Próteses Auditivas alteradas para uma "menor amplificação" durante

permanência no Ambulatório por 2 a $2 \frac{112}{2}$ horas)

\section{$\underline{\text { Etapa Experimental ou de Treinamento }}$}

Inicio do Treinamento (60 a 90 dias) 
Grupo Experimental (GE)

Grupo Experimental / Grupo Convencional

(Orelhas adaptadas com suas Próteses Auditivas na amplificação "usual" durante a permanência no Ambulatório por 2 a $2 \frac{1}{2}$ horas)

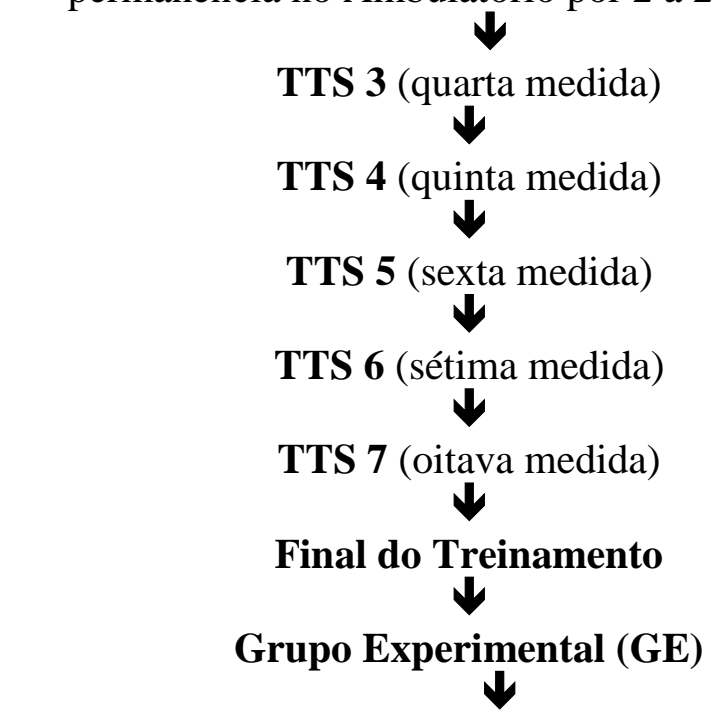

Retorno à amplificação "usual" para o uso externo /regular das Próteses Auditivas adaptadas nos pacientes do GE

\section{Etapa Pós-Experimental ou Pós-Treinamento}

Grupo Experimental / Grupo Convencional

(Orelhas adaptadas com suas Próteses Auditivas na amplificação "usual” durante a permanência no ambulatório por 2 a $2 \frac{1}{2} 2$ horas)

TTS 7 (oitava medida)

\subsection{2 - Descrição da Metodologia}

Durante as três etapas deste estudo, os pacientes vinham ao ambulatório a cada 15 ou 20 dias para os testes.

Nestes dias, eles permaneciam uma média de duas a duas horas e meia expostos à ação do ruído ambiente presente no local (ambulatório), para que fosse possível medir as alterações em seus limiares auditivos em condições acústicas controladas. 
Esse ruído ambiente convencional constituiu o estímulo - teste da pesquisa. Para facilitar a referência a este estímulo, passaremos a denominá-lo de Ruído Ambiente Específico (RAE).

$\mathrm{Na}$ etapa pré-experimental, foram realizadas três medidas controladas das alterações dos limiares auditivos durante três dias distintos.

A Primeira Medida (TTS 0) foi realizada sem a interferência das próteses auditivas, ou seja, os pacientes permaneceram expostos a ação do RAE durante 2 a 2 1⁄2 horas com as orelhas desprovidas de suas próteses auditivas.

Para determinar a Segunda (TTS 1) e a Terceira Medida (TTS 2), os pacientes permaneceram durante igual período ( 2 a $2 \frac{1}{2}$ horas) expostos a ação do RAE com as suas próteses auditivas reguladas na amplificação prescrita ou preferencial denominada de "usual".

No final da etapa pré-experimental, foram definidos os dois grupos de estudo. Os pacientes que, após a introdução da amplificação prescrita ou preferencial das próteses auditivas adaptadas, apresentaram uma alteração inicial nos seus limiares auditivos superior a $2 \mathrm{~dB}$ nas faixa de freqüência de 250 a $2000 \mathrm{~Hz}$, integraram o Grupo Experimental (GE), e os pacientes que apresentaram uma alteração inicial menor do que $2 \mathrm{~dB}$ na mesma faixa, integraram o Grupo Convencional (GC).

Os pacientes integrados ao GE tiveram, neste momento, a amplificação "usual” de suas próteses auditivas reduzidas para o uso externo (fora do ambulatório) por um período de 60 a 90 dias, proposto para o treinamento das orelhas na etapa experimental.

Uma Medida Adicional (TTS Ad) das alterações induzidas nos limiares auditivos das orelhas incluídas no GE foi realizada na amplificação reduzida. As orelhas adaptadas com suas próteses auditivas reguladas no volume mais baixo, determinado 
para o uso externo (fora do ambulatório) durante a etapa de treinamento, permaneceram no ambulatório expostas à ação do RAE por um período de 2 a 2 1⁄2 horas.

Na etapa experimental ou de treinamento foram realizadas a Quarta (TTS 3), Quinta (TTS 4), Sexta (TTS 5) e a Sétima Medida (TTS 6) das alterações induzidas nos limiares auditivos para os pacientes incluídos nos dois grupos de estudo.

Durante as quatro medidas do TTS realizadas no ambulatório na etapa de treinamento, as próteses auditivas adaptadas nos pacientes do GE voltavam a amplificação "usual”, definida para a pesquisa das alterações induzidas nos seus limiares auditivos.

Terminada a medida, a amplificação das próteses auditivas adaptadas no GE era novamente reduzida para a continuidade do treinamento.

Após a Sétima Medida (TTS 6) da etapa experimental, as próteses auditivas adaptadas nas orelhas incluídas no GE voltaram definitivamente a amplificação "usual", definindo o término do treinamento.

$\mathrm{Na}$ etapa pós-experimental, os pacientes integrados aos dois grupos de estudo permaneceram no ambulatório pela última vez, quando se procedeu a Oitava Medida (TTS 7) das alterações induzidas nos limiares auditivos durante o período de exposição contínua ( 2 a 2 1⁄2 horas) ao RAE com suas próteses auditivas reguladas na amplificação "usual".

\subsection{3 - Redução da Amplificação "Usual” para o Treinamento das Orelhas Incluídas no GE Durante a Etapa Experimental}

Para tornar esta condição mais eficiente e prática, optou-se por reduzir o ganho acústico ou a amplificação "usual" de uma forma mais homogênea e em toda a faixa de 
freqüência. Esta redução foi praticada alterando-se a posição do controle manual de volume das próteses auditivas adaptadas.

Considerando o fato de que a grande maioria já havia iniciado o uso regular de suas próteses auditivas ajustadas para uma maior amplificação acústica, e que, portanto, se ressentiriam de uma redução muito drástica nesta amplificação, foram estabelecidos alguns critérios para a redução na amplificação "usual”.

Estabelecemos que os controles externos de volume das próteses auditivas deveriam ser mantidos em uma posição que permitisse a detecção de um sinal normal de fala.

Procedemos, para isto, a seguinte avaliação:

O paciente era colocado dentro da cabina, posicionado entre as duas caixas acústicas, formando um ângulo de incidência com relação às orelhas de $0 / 45^{\circ}$ de azimute. Com a(s) prótese(s) adaptada(s), procedemos à pesquisa do limiar de detecção da fala (LDF), iniciando a avaliação com o controle de volume na posição mais baixa, alternadamente nas duas orelhas (pacientes binaurais), ou do lado protetizado (pacientes monoaurais). Usamos o microfone do audiômetro para emitir a voz em campo livre, aumentando-a gradualmente até o nível de 60dBNA. Se o LDF fosse detectado neste volume durante a apresentação de um estímulo de fala (/pa /, /pa/, /pa/) emitido a viva voz, em técnica ascendente até a intensidade de 60 dBNA, esta posição seria mantida. Caso contrário, o volume seria aumentado gradualmente, até que o LDF para uma intensidade até 60dBNA fosse alcançado.

Depois de determinada a condição de treinamento, o paciente era esclarecido de que deveria passar a fazer uso externo de seu aparelho auditivo, regulado neste volume 
mais baixo (amplificação reduzida), e de que não poderia, sob qualquer hipótese, alterálo durante o período que nós havíamos previamente estabelecido para a pesquisa.

Para garantir que não haveria mudanças durante o uso externo, os controles de volume das próteses auditivas de todos os pacientes do GE, foram fixados nesta posição com o auxílio uma fita adesiva, durante todo o período de treinamento.

\subsection{4 - Orientação Para o Uso Externo das Próteses Auditivas Durante a Etapa Experimental e Pós-Experimental}

Foi determinado, nos critérios de inclusão, que todos os pacientes incluídos nos dois grupos de estudo fizessem uso regular de suas próteses auditivas.

Para que pudéssemos ter um controle desta condição, elaboramos um protocolo de acompanhamento do uso da prótese auditiva que foi entregue para cada paciente no início da etapa experimental e que foi preenchido regularmente pelo próprio paciente ou por seu responsável. Neste protocolo foi anotada, diariamente, a hora em que o paciente colocava e em que retirava a prótese auditiva, durante toda a etapa experimental e pósexperimental. A análise destes protocolos fez parte integrante deste estudo e os dados extraídos destes controles diários serão analisados nos resultados. O modelo do protocolo utilizado encontra-se nos anexos.

\section{7 - Padronização dos Testes e Equipamentos}

\subsection{1 - Equipamentos}

a) Audiômetro clínico modelo AD-28 da Interacoustics, acoplado a um par de fones TDH39 e calibrado segundo os padrões internacionais da norma ISO 1987;

b) Imitanciômetro clínico modelo S-25 da Interacoustic, provido de fones e sonda, calibrado segundo padrões internacionais ISO 1987; 
c) Sistema de amplificação para campo livre da CAS Produtos Médicos, calibrado segundo padrão ISO 1987;

d) Sistema para as medidas "In Situ" da Madsen, modelo Aurical Audiodiagnostic Fitting System, integrado ao software NOAH e acoplado a um microprocessador Pentium;

e) Dosímetro Digital modelo CEL 460, com calibrador CEL 282, integrado ao software aplicatico dB 12, para a transferência dos dados armazenados durante as medidas das doses de ruído;

f) Analisador de áudio-freqüência em 1/3 de oitavas de banda da Neutrik Instruments, modelo NC10 (Basic Package V1.3).

\subsection{2 - Medida das Mudanças Temporárias Induzidas nos Limiares Auditivos (TTS)}

Para determinar as alterações temporárias nos limiares auditivos (TTS), induzidas após cada período contínuo de exposição ao ruído ambiente específico (RAE), duas audiometrias tonais por via aérea, eram efetuadas no mesmo dia.

A primeira medida audiométrica, ou audiometria do pré-uso (ou da préexposição), era realizada sempre pela manhã, depois de um período prolongado de repouso acústico (sem a estimulação acústica da prótese auditiva), e antes do paciente iniciar o uso de sua prótese auditiva naquele dia.

A segunda medida audiometrica ou audiometria do pós-uso (ou da pósexposição), era efetuada após um período contínuo de estimulação acústica das orelhas com suas próteses auditivas adaptadas (exceto a $1^{\text {a }}$ medida induzida / TTS 0 , que foi realizada após um período contínuo de estimulação acústica com as orelhas desprovidas de suas próteses auditivas). 
Os pacientes permaneciam na sala de espera do ambulatório de 2 a 2 1/2 horas, expostos à ação do ruído ambiente específico (RAE), tempo necessário para a indução de alterações em seus limiares auditivos. Após este período, eram colocados dentro da cabina, suas próteses auditivas eram removidas, os fones colocados e, após 2 minutos de repouso acústico, procedíamos a uma nova medida audiometrica (audiometria do pósuso ou pós-exposição) .

O estímulo utilizado para determinar os limiares audiométricos, foi o tom puro pulsado emitido em intervalos de 2 em 2 dBNA, e em intensidade variáveis até 120 dBNA, avaliados sempre nesta ordem de freqüências: $1000 \mathrm{~Hz}, 2000 \mathrm{~Hz}, 3000 \mathrm{~Hz}$, $4000 \mathrm{~Hz}, 6000 \mathrm{~Hz}, 8000 \mathrm{~Hz}, 500 \mathrm{~Hz}$ e $250 \mathrm{~Hz}$.

Para a pesquisa dos limiares psicoacústicos mínimos, foi utilizado o método dos limites, em técnica ascendente (CARHART e JERGER, 1959).

Para melhorar a sensitividade do teste, duas medidas consecutivas dos limiares auditivos eram efetuadas em cada audiometria, sendo os fones removidos e recolocados entre elas (DE VITTO, 2000).

Este critério de executar duas medidas consecutivas para determinar os limiares auditivos por frequiência, foi adotado para todas as audiometrias do pré e do pós-uso (ou da pré e da pós-exposição), efetuadas para medir as alterações induzidas nos limiares auditivos das orelhas estudadas .

\subsection{3 - Medidas "In Situ” das Próteses Auditivas}

As medidas "in situ" foram realizadas em sala não tratada acusticamente, com o paciente posicionado no meio desta e sentado a um metro de distância do alto falante, a 0/0 grau de azimute. 
Utilizamos, como estímulo acústico, o tom modulado em freqüência, emitido a 70 dBNPS .

Foram consideradas, na análise do desempenho das próteses auditivas adaptadas, as seguintes medidas "in situ"

1- Real Ear Insertion Response (REIR) ou resposta de inserção, efetuada para medir o ganho acústico/amplificação $(\mathrm{dB})$ por freqüência, avaliada em duas posições distintas do controle externo de volume: com as próteses auditivas ajustadas na amplificação ou no volume usual (maior amplificação) para as orelhas incluídas no GE e no GC, e com as próteses auditivas ajustadas na amplificação ou no volume reduzido (menor amplificação) para as orelhas incluídas no GE.

2- Real Ear Aided Response (REAR) ou resposta com a prótese auditiva na orelha externa, efetuada para a medida do nível da pressão sonora de saída (dBNPS) por freqüência, com as próteses auditivas mantidas nas mesmas posições distintas do controle externo de volume descritas nas medidas do REIR.

\subsection{4 - Medida dos Parâmetros Acústicos do Estímulo-Teste (Ruído Ambiente Específico)}

\subsubsection{1 - Análise do Espectro de Freqüências do Ruído Ambiente Específico (RAE)}

O espectro acústico do ruído ambiente específico (RAE), ou do estímulo-teste, foi identificado na etapa pré-experimental.

Utilizamos para esta finalidade o analisador de audio-freqüências digital, modelo NC-10 da Neutrik Instruments, cedido pela Escola Politécnica da Universidade de São Paulo. 
A coleta das amostras do ruído ambiente presente do local (Ambulatório do Hospital Regional da Zona Sul) foi executada pela própria pesquisadora.

O equipamento utilizado é um sistema de processamento digital que permite várias análises acústicas. Foi utilizado na coleta das amostras do ruído ambiente específico (RAE), o método de análise acústica em 1/3 de bandas de oitavas de freqüência.

O equipamento foi adaptado a um microfone analógico, que permitia medidas do nível de pressão sonora, variáveis de 18 a 137dBNPS.

Após a devida calibragem, o microfone foi adaptado a um suporte próprio e posicionado na sala de espera do ambulatório, voltado para o local de maior concentração de pacientes.

Para a coleta e o registro das medidas do ruído, foram seguidas corretamente as instruções do manual que acompanhava o equipamento.

O equipamento foi programado para coletar as amostras por curtos períodos de tempo (de cinco a dez minutos). Várias amostras foram coletadas durante três dias e em momentos distintos.

Os dados armazenados foram posteriormente transferidos pela interface serial para um personal computer (PC), através de um programa de comunicação específico que acompanha o equipamento. Isto permitiu a leitura das medidas coletadas e a posterior formatação destas no padrão Windows. 
3.7.4.2 - Registro dos Níveis de Pressão Sonora e do Tempo de Exposição ao Ruído Ambiente Específico (RAE)

Os outros dois parâmetros acústicos variáveis do ruído, ou seja, o nível da pressão sonora e o tempo de exposição das orelhas, foram registrados todas as vezes que os pacientes permaneceram expostos à ação do RAE.

Para a medida e o registro destes dois parâmetros foi utilizado o dosímetro digital, modelo CEL-460.

Este equipamento foi ajustado para operar em uma faixa dinâmica de 50 a 120 dBNPS e calibrado a 113,6 dBNPS. Utilizou-se, nas medidas dosimétricas, o filtro acústico A, um tempo lento de resposta e um fator de correção (q) ou fator de dobragem, igual a $3 \mathrm{~dB}$.

O dosímetro foi utilizado sistematicamente nas três etapas deste trabalho. Ele era acionado sempre no inicio do período de exposição dos pacientes à ação do RAE, e desligado no final deste período.

Estas dosimetrias foram realizadas durante os períodos diários, em que os pacientes permaneceram no ambulatório para a indução das mudanças temporárias ou alterações nos limiares auditivos (TTS).

\section{8 - Esquema Geral da Metodologia Para a Análise Estatística}




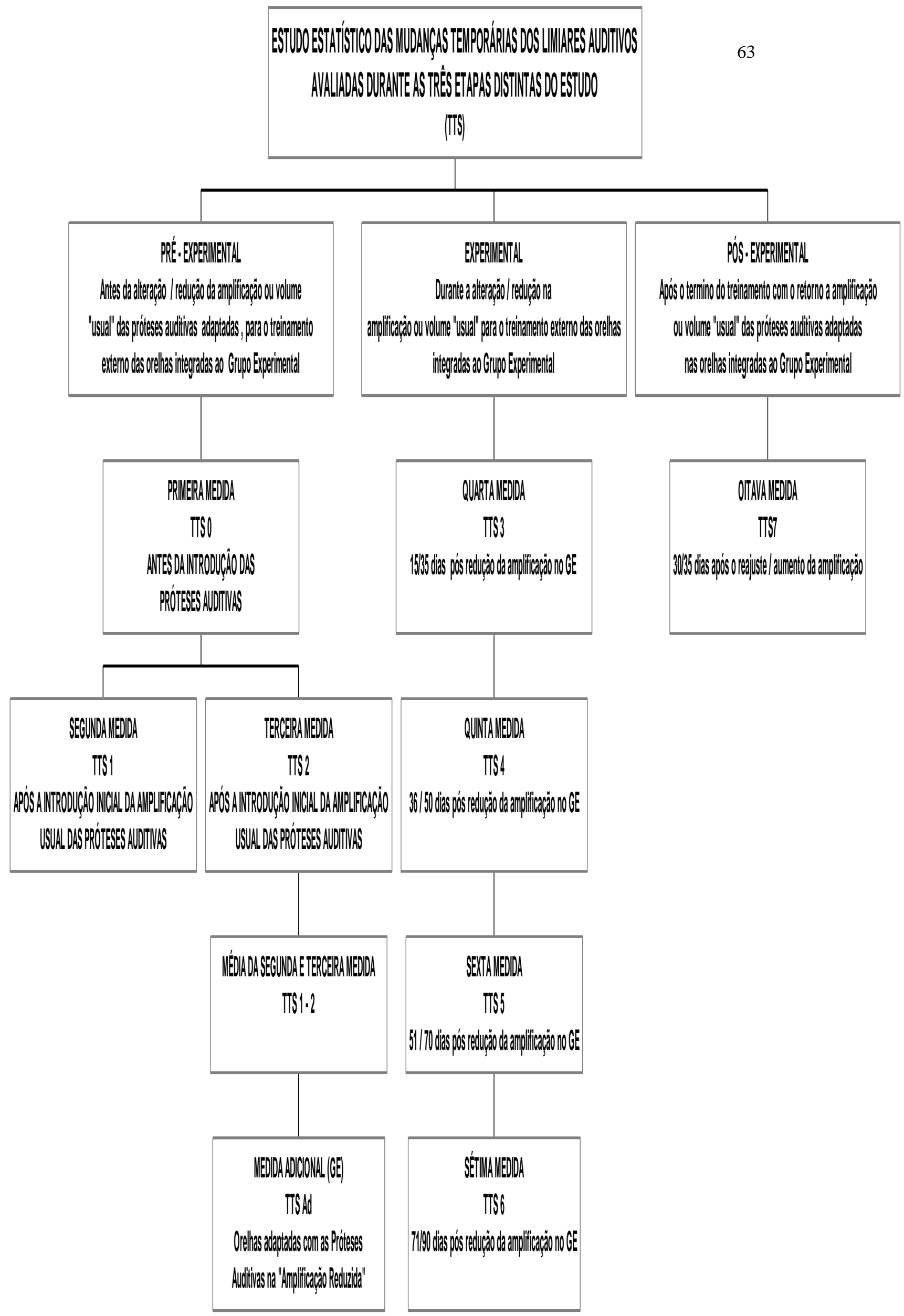




\subsection{1 - Descrição da Metodologia Estatística}

$\mathrm{Na}$ Etapa Pré-Experimental, antes dos pacientes serem integrados aos dois grupos de estudo, foram analisadas as três primeiras medidas dos TTS: Primeira Medida/TTS 0 (com as 42 orelhas desprovidas de suas próteses auditivas), Segunda medida/TTS 1 e Terceira Medida/TTS 2 (após a introdução das Próteses Auditivas adaptadas nas 42 orelhas estudadas). Para a análise estatística foram extraídas as médias da Segunda e a Terceira Medida, que passaram a constituir o TTS 1-2.

Na Etapa Experimental, após os pacientes serem divididos em dois grupos de estudo, analisou-se as quatro medidas,subseqüentes dos TTS para cada grupo.

Os pacientes integrados ao Grupo Experimental (GE), iniciaram, nesta etapa, o “treinamento de suas orelhas", por um período determinado de 60 a 90 dias.

A Quarta (TTS 3), Quinta (TTS 4), Sexta (TTS 5) e Sétima Medidas (TTS 6) realizadas nesta etapa, ocorreram respectivamente em média: 15/35 dias, 36/50 dias, 51 a 70 dias e 71/90 dias, contados a partir da redução da amplificação para o uso externo das próteses auditivas nas orelhas integradas ao GE.

$\mathrm{Na}$ Etapa Pós-Experimental, última etapa do estudo, os pacientes que integraram o Grupo Experimental, já estavam utilizando externamente ou regularmente as suas próteses auditivas reajustadas na amplificação ou no volume "usual".

A última medida ou a Oitava Medida (TTS 7) ocorreu em média 30/35 dias após o término da etapa experimental, ou seja, após a Sétima Medida (TTS 6).

A análise estatística das Medidas Adicionais/TTS Ad, efetuada nas orelhas incluídas no GE, também fez parte deste estudo. 
3.8.2 - Cálculo do Valor Médio em dB dos Limiares Auditivos e das Mudanças Temporárias (TTS) Induzidas nos Limiares Auditivos por Frequiência

Inicialmente foram extraídas as médias aritméticas das duas medidas consecutivas dos limiares auditivos efetuadas em cada audiometria.

Isto determinou o "valor médio em dB" dos limiares auditivos por frequiência, em cada audiometria realizada.

$\mathrm{O}$ valor médio em $\mathrm{dB}$ dos limiares auditivos por freqüência, obtidos na "segunda audiometria" do dia ou na audiometria do pós-uso (ou da pós-exposição), foram extraídos do valor médio dos limiares auditivos por freqüência, obtidos na "primeira audiometria" do mesmo dia ou audiometria do pré-uso (ou da pré-exposição).

Esta diferença determinou, para cada freqüência, o "valor médio em dB da magnitude do TTS" em cada uma das oito medidas e para a medida adicional induzidas durante o período de estudo.

\subsection{3 - Critérios da Avaliação Estatística}

Para a análise estatística do comportamento dos TTSs induzidos durante as três etapas desta pesquisa para as orelhas incluídas nos dois grupos de estudo, foram consideradas as médias em dB da magnitude do TTS obtido nas oito medidas induzidas para cada uma das frequiências analisadas, seguindo o seguinte critério: Primeira Medida (TTS 0); Média da Primeira e da Segunda Medida (TTS 1 - 2); Quarta Medida (TTS 3); Quinta Medida (TTS 4) ; Sexta Medida (TTS 5); Sétima Medida (TTS 6) ; Oitava Medida (TTS 7). 
A análise estatística da Medida Adicional (TTS Ad), realizada para as orelhas integradas ao Grupo Experimental, foi estudada a parte.

Dois testes não paramétricos foram utilizados na análise dos resultados.

O teste da Analise de Variância (ANOVA), que é indicado quando se quer comparar 3 ou mais grupos de informações com nível de mensuração numérica em amostras independentes e/ou pareadas, e se deseja saber se em média os grupos são diferentes. Nesta avaliação é possível também se testar mais de um efeito com um único modelo (MAXWELL e SATAKE, 1997).

Foi utilizado também no estudo, o teste de Comparações Múltiplas, quando se detectou diferença significante na estatística de $F$ ou na significância de $F(p)$, na Análise de Variância (ANOVA), ou ainda quando houve indícios de diferença (por exemplo, quando p é maior que 0,05 , mas menor que 0,10 ). As comparações múltiplas permitiram identificar diferenças entre duas categorias ou grupos de categorias presentes nos efeitos estudados no ANOVA (MAXWELL e SATAKE, 1997).

Considerou-se, na avaliação dos resultados, um nível de significância menor ou igual a $5 \%$. 


\section{4 - RESULTADOS}

\section{1 - Análise Geral}

A pesquisa das mudanças transitórias nos limiares auditivos (TTS) das 42 orelhas analisadas neste estudo foi realizada no período de outubro de 2001 a dezembro de 2003. Cada paciente estudado foi acompanhado durante um período médio de 3 a 4 meses.

A analise estatística deste trabalho só foi possível porque as mudanças temporárias dos limiares auditivos (TTS) dos pacientes que integraram os dois grupos distintos de orelhas, foram avaliadas em tempos iguais durante o período deste estudo.

As três medidas iniciais ocorreram na etapa pré-experimental para as 42 orelhas selecionadas. O TTS 0 e o TTS 1-2 foram medidos antes da inclusão das orelhas nos distintos grupos de estudo .

$\mathrm{Na}$ etapa experimental, foram realizadas mais quatro medidas. A quarta medida ou o TTS 3, ocorreu em média 15 / 35 dias; a quinta medida ou o TTS 4, em média 36 / 50 dias; a sexta medida ou TTS 5, em média 51 / 70; e a sétima medida ou TTS 6, em média 71 / 90 dias após o inicio do treinamento para as orelhas integradas ao GE.

A oitava e última medida do estudo (TTS 7), foi realizada na etapa pósexperimental, quando os pacientes incluídos no GE passaram a usar regularmente as suas próteses auditivas na amplificação "usual”, o que ocorreu, portanto, em média 30 135dias após a término do treinamento.

A média do número total (dias e horas) do uso regular das próteses auditivas registrados nas etapas experimental e pós-experimental do estudo, segundo as anotações dos pacientes incluídos no GE foi de 111 dias (1079,5 horas) e para os pacientes 
integrados ao GC, foi de 110 dias (1154 horas). A média de uso diário das próteses auditivas usadas regularmente durante as etapas experimental e pós-experimental foi de 10 horas, para os 13 pacientes incluídos no GE, e de 10 1/2 horas, para os 12 pacientes integrados ao GC.

O espectro acústico do ruído presente no ambulatório (RAE), usado como o estímulo indutor dos TTS e registrado durante três dias distintos, permitiu caracterizá-lo como um ruído intermitente de moderada intensidade e de banda larga de freqüência, com uma maior concentração de energia nas freqüências inferiores a $1000 \mathrm{~Hz}$.

A Figura 2, é a representação gráfica de três das amostras do ruído, coletadas, respectivamente, $2 \mathrm{a}(30 / 10 / 02), 2 \mathrm{~b}(6 / 11 / 02)$ e $2 \mathrm{c}(13 / 11 / 02)$, no Ambulatório do Hospital Regional da Zona Sul .

Os Leqs mínimos, médios e máximos foram registrados em 1/3 de oitavas de bandas de frequiências. Os resultados dos Leqs registrados nas outras amostras coletadas durante os três dias foram muito similares.

Um total de 67 medidas dosimetricas do ruído presente no ambulatório foram armazenadas durante este período. O menor nível de pressão sonora registrado foi de 67,8 dBA e o maior de 99,3 dBA. Durante $69 \%$ do tempo de registro, a variação no nível da pressão sonora do ruído situou-se entre 70 e 80 dBA.

A Figura 3a representa os valores mínimos e máximos dos Leqs (Níveis Equivalentes de Pressão Sonora) e a Figura 3 b representa a média percentual da variação dos níveis de pressão sonora em função do tempo de registro das medidas. $\mathrm{O}$ registro completo das 67 medidas dosimétricas efetuadas no período de 2001 a 2003 encontram-se nos anexos. 
O tempo de exposição das orelhas à ação do ruído ambiente específico (RAE), usado neste estudo como o estímulo-teste, que induziu alterações nos limiares auditivos das orelhas protetizadas, foi de 2 horas e 29 minutos. A Figura 4 representa a média da duração destas exposições (tempo em horas e minutos), registradas no Ambulatório do Hospital Regional da Zona Sul em 2001, 2002 e 2003, e a média geral durante o período de pesquisa na amostra estudada (2001 a 2003).

As medidas "in situ”, com as Próteses Auditivas testadas, foram realizadas em 35 orelhas $(\mathrm{OD}=18$ e $\mathrm{OE}=17)$. Para as orelhas incluídas no GC, a média do HEIR na amplificação "usual” foi de: $250 \mathrm{~Hz}(13 \mathrm{~dB}), 500 \mathrm{~Hz}(23 \mathrm{~dB}), 1000 \mathrm{~Hz}(34 \mathrm{~dB}), 2000 \mathrm{~Hz}$ (34 dB), $3000 \mathrm{~Hz}(27 \mathrm{~dB}), 4000 \mathrm{~Hz}(22 \mathrm{~dB}), 6000 \mathrm{HZ}$ (17dB), e a média do HEAR: 250 $\mathrm{Hz}(83 \mathrm{~dB}), 500 \mathrm{~Hz}(95 \mathrm{~dB}), 1000 \mathrm{~Hz}(110 \mathrm{~dB}), 2000 \mathrm{~Hz}(113 \mathrm{~dB}), 3000 \mathrm{~Hz}(111 \mathrm{~dB})$, $4000 \mathrm{~Hz}(105 \mathrm{~dB}), 6000 \mathrm{HZ}(87 \mathrm{~dB})$.

Para as orelhas incluídas no GE, a média do HEIR na amplificação "usual” e na amplificação "reduzida" foi, respectivamente, de: $250 \mathrm{~Hz}(35 / 21 \mathrm{~dB}), 500 \mathrm{~Hz}(47$ / $33 \mathrm{~dB}), 1000 \mathrm{~Hz}(54 / 41 \mathrm{~dB}), 2000 \mathrm{~Hz}(48 / 36 \mathrm{~dB}), 3000 \mathrm{~Hz}(35 / 24 \mathrm{~dB}), 4000 \mathrm{~Hz}$ (23dB / $18 \mathrm{~dB}), 6000 \mathrm{~Hz}(14$ / $0 \mathrm{~dB})$; e a média do HEAR foi, respectivamente, de: 250 $\mathrm{Hz}(105 / 91 \mathrm{~dB}), 500 \mathrm{~Hz}(119 / 103 \mathrm{~dB}), 1000 \mathrm{~Hz}(125 / 112 \mathrm{~dB}), 2000 \mathrm{~Hz}(124 / 112$ dB), $3000 \mathrm{~Hz}(119$ / 108 dB), $4000 \mathrm{~Hz}(112$ / 96 dB), $6000 \mathrm{~Hz}(82$ / 72 dB).

A média do HEIR (dB) e do HEAR (dBNPS), medidos com as próteses auditivas adaptadas nas orelhas incluídas no GC na amplificação "usual” e para as orelhas incluídas no GE na amplificação "usual" e na amplificação "reduzida", podem ser visualizadas nas Figuras 5a e 5b 


\subsection{1 - Gráficos Representativos da Análise Geral}
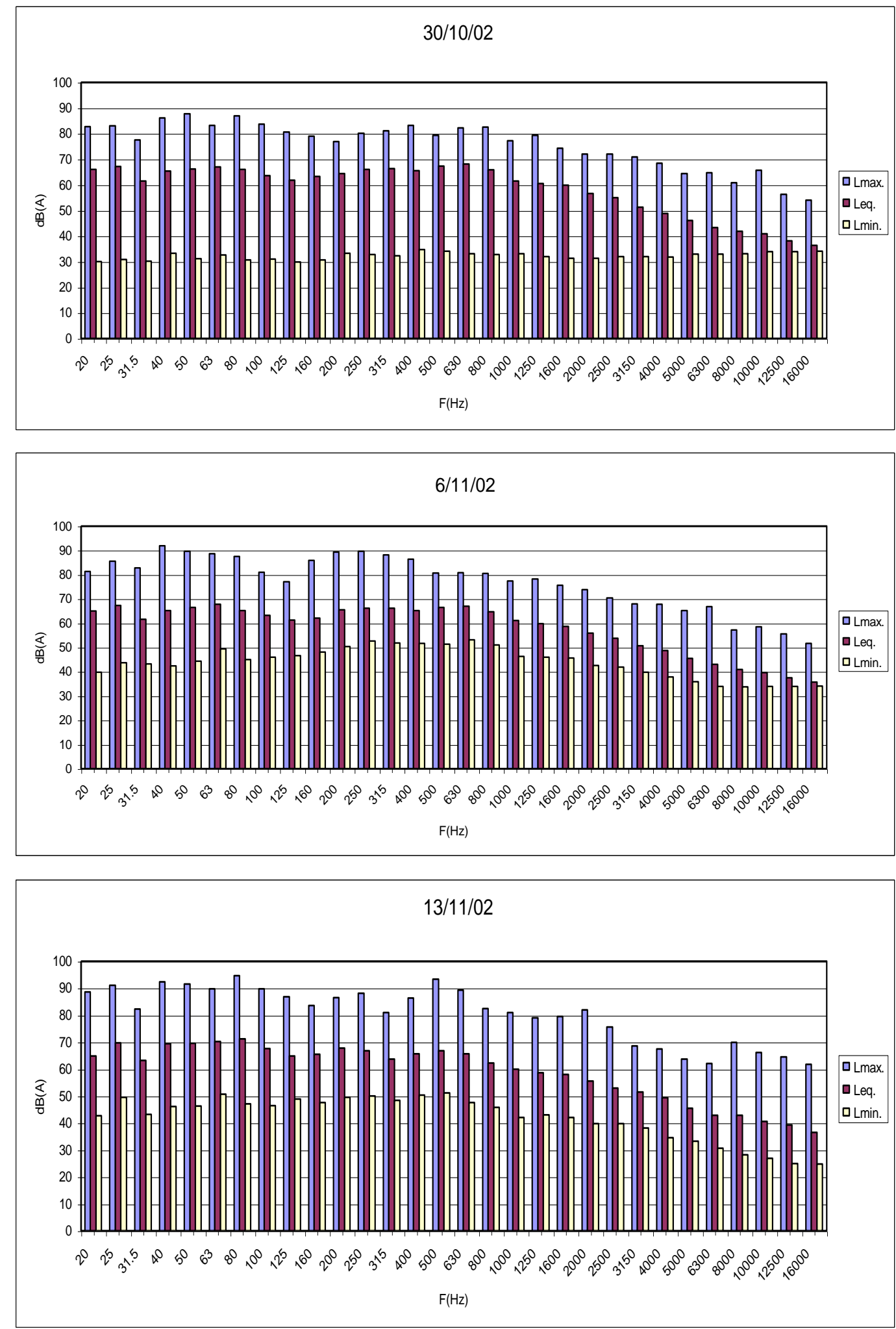
Figura 2 - Representação dos Níveis Equivalentes de Pressão Sonora (Leqs) Máximo, Médios e Mínimos registrados em 1/3 de oitava da banda de freqüência do Ruído Ambiente Específico (RAE), coletadas em 30/10/02, 6/11/02 e 13/11/02, no Ambulatório de Especialidades do Hospital Regional da Zona Sul, utilizando o analisador digital de áudio-freqüência modelo NC-10 da Neutrics Instruments.

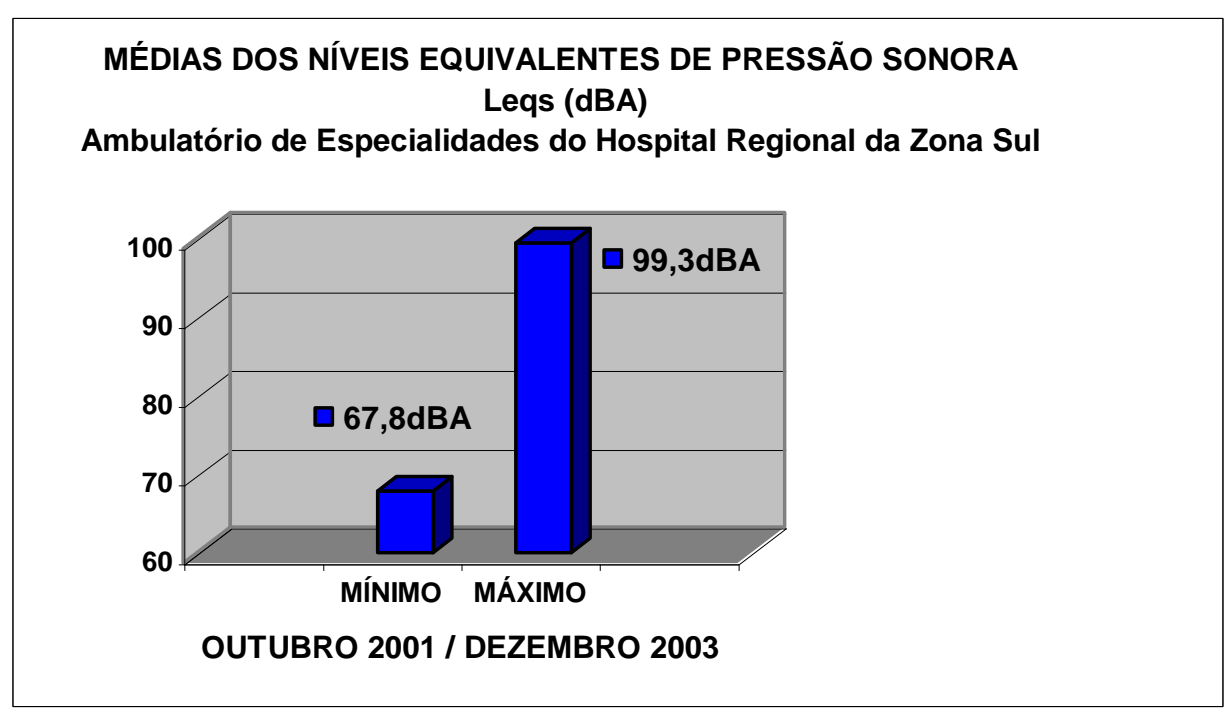

Figura 3a - Valores Mínimos e Máximos dos Leqs (níveis equivalentes de pressão sonora em dBA), do estímulo-teste ou Ruído Ambiente Específico (RAE), registrados nas dosimetrias efetuadas de outubro de 2001 a dezembro de 2003, durante os períodos de permanência dos pacientes para a pesquisa das alterações induzidas nos seus limiares auditivos, utilizando o dosímetro digital modelo CEL 460 da Cel Instruments.

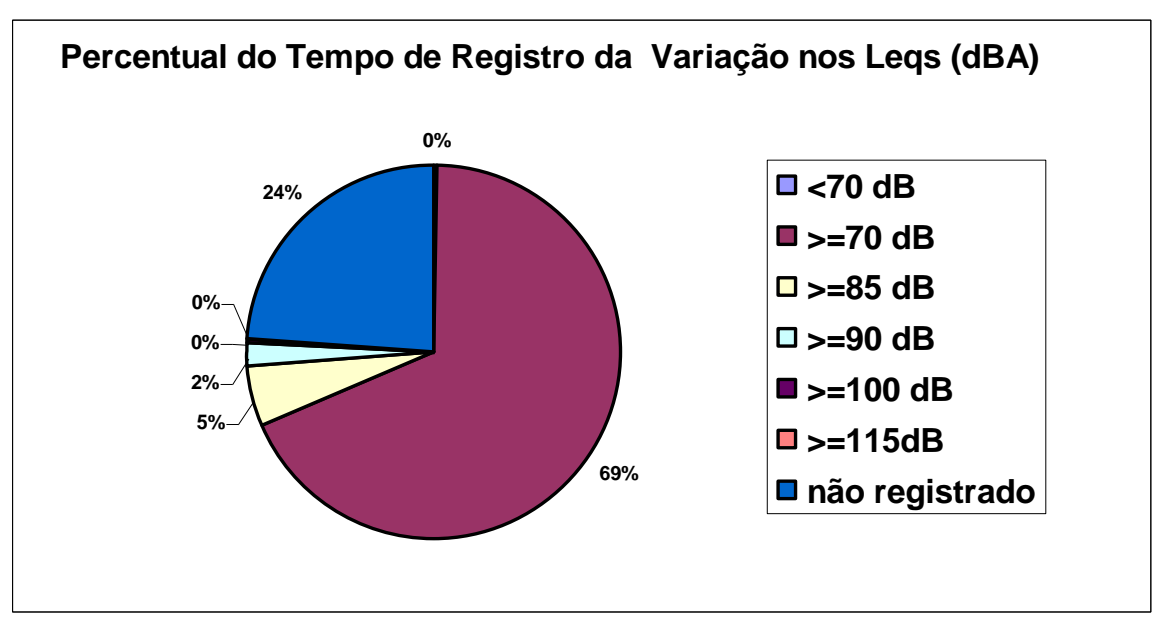

Figura 3b - Percentual do Tempo de Registro em função da Variação nos Níveis Equivalentes (Leqs) de Pressão Sonora do estímulo-teste ou Ruído Ambiente Específico (RAE), extraído das medidas dosimétricas registradas pelo dosímetro CEL 460 da Cel Instruments de outubro de 2001 a dezembro de 2003, no Ambulatório de Especialidades do Hospital Regional da Zona Sul. 


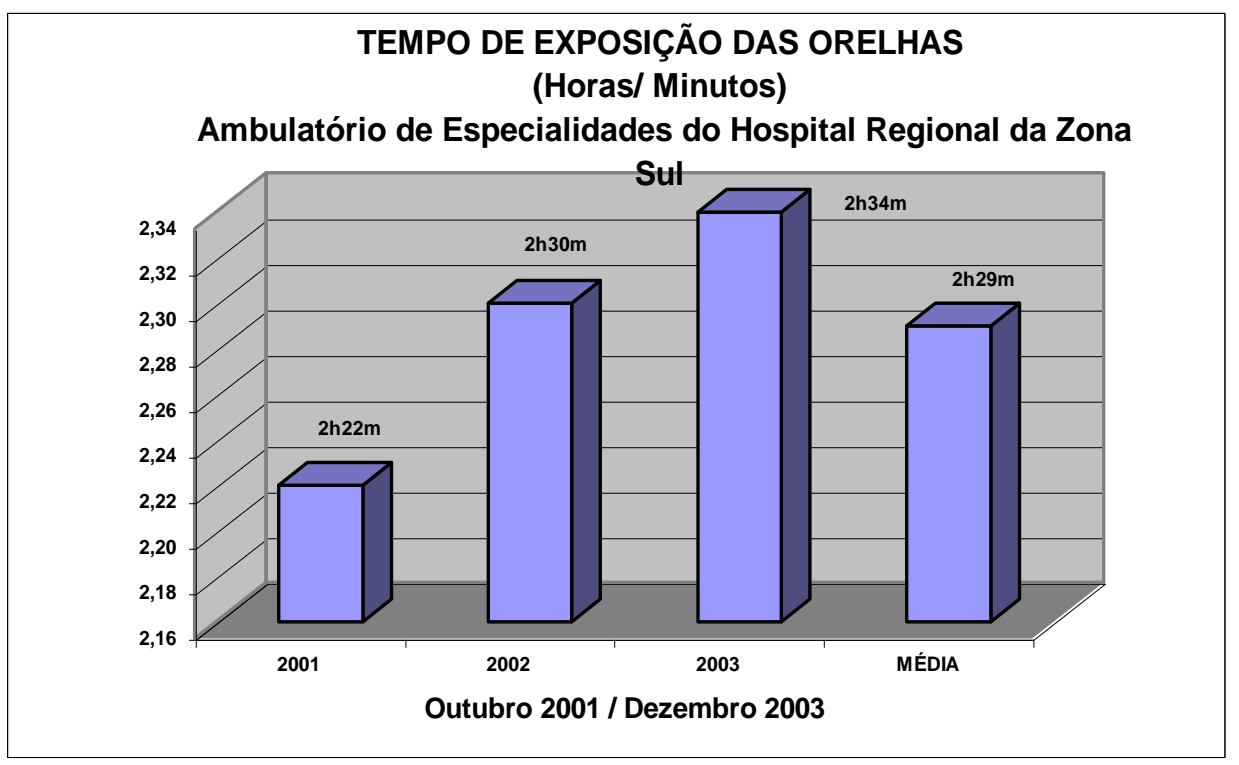

Figura 4 - Média do Tempo de Exposição ao estímulo-teste ou Ruído Ambiente Específico (RAE), registrado durante a permanência dos pacientes no Ambulatório de Especialidades do Hospital Regional da Zona Sul. A média a direita (2 horas e 29 meses), representa o tempo médio de exposição das orelhas, medido nos períodos de pesquisa das alterações induzidas nos limiares auditivos e registrado pelo dosímetro CEL 460 da Cel Instruments de outubro de 2001 a dezembro de 2003.

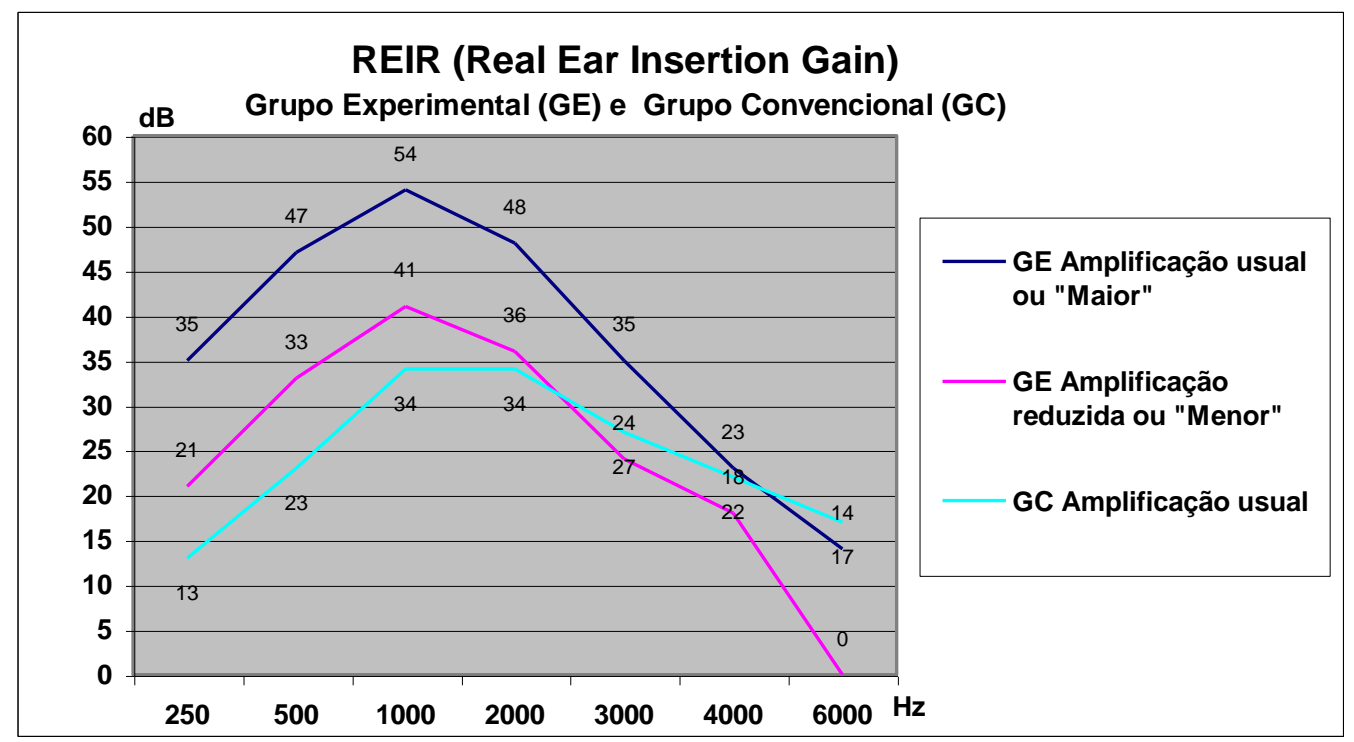

Figura 5a - Média do Ganho Acústico/Amplificação (dB), por freqüência das medidas "in situ" para as orelhas incluídas no GE ( $n=18)$ e para as orelhas incluídas no $G C(n=17)$. 


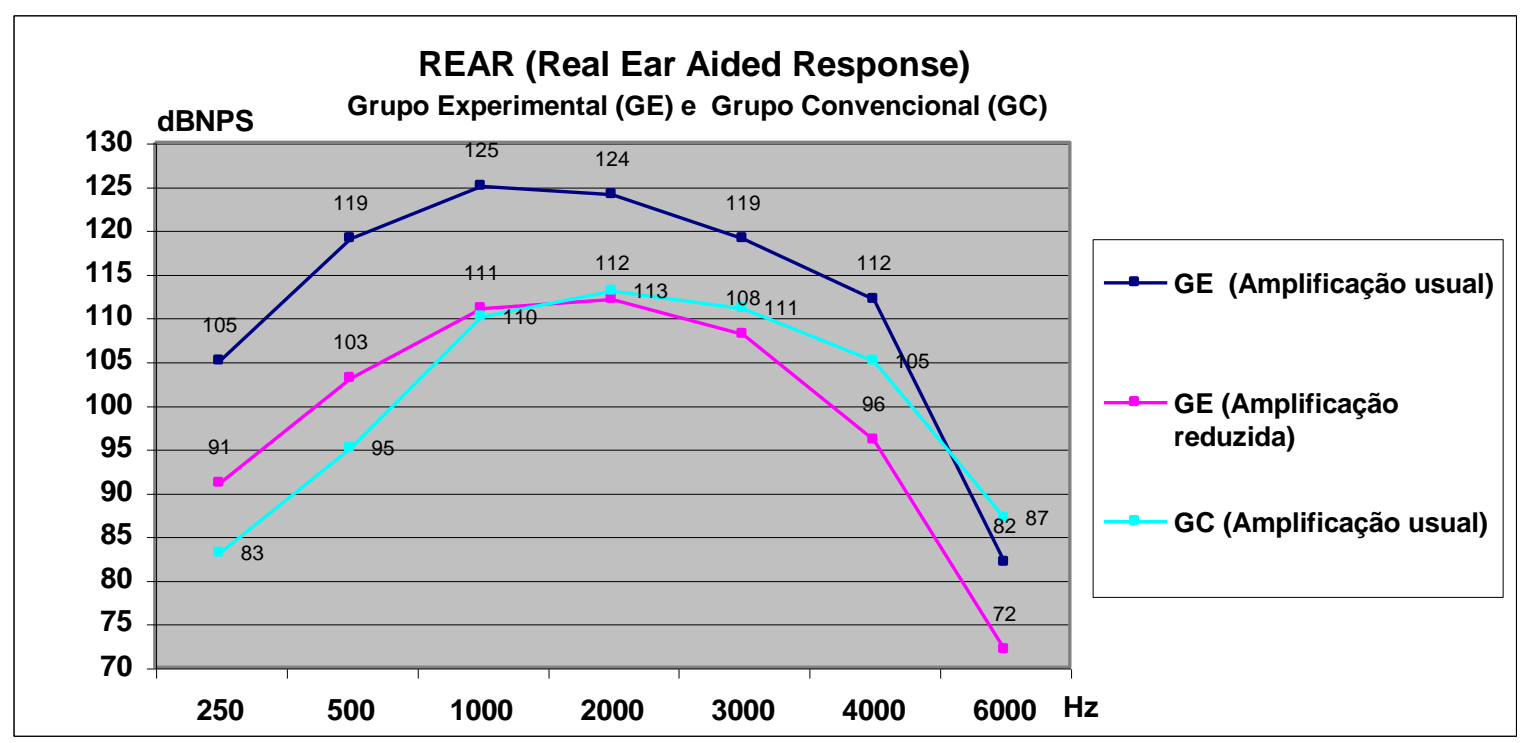

Figura 5b - Média Pressão Sonora de Saída (dBNPS), por freqüência das medidas "in situ" para orelhas incluídas no GE $(n=18)$ e para as orelhas incluídas no $G C(n=17)$.

\section{2 - Análise Estatística}

\subsection{1 - Estudos Preliminares}

Integração dos Pacientes Monoaurais

Procedeu-se, inicialmente, a uma avaliação estatística preliminar, para determinar se os oito pacientes avaliados com próteses auditivas monoaurais poderiam ser incluídos neste estudo. Para isto, avaliou-se os dezessete pacientes adaptados com próteses auditivas binaurais, para verificar se haviam diferenças estatisticamente significantes entre as duas orelhas destes pacientes incluídas nos dois grupos estudados.

Foi aplicado, nesta pesquisa, o teste de Análise de Variância (ANOVA) nos nove pacientes do GE (n=9) e nos oito pacientes do GC $(n=8)$, para os quatro efeitos estudados: 1-Grupo; 2- Medidas; 3- Orelha; e 4- Freqüência, considerando-se um nível de significância menor ou igual a 5\%. 
Como, de um modo geral, a avaliação não mostrou diferenças estatisticamente significante nos dois grupos para o efeito orelha, os oito pacientes adaptados com próteses auditivas monoaurais, foram incluídos nos grupos correspondentes para os estudos posteriores.

\subsection{2 - Estudos Direcionados}

Para direcionar os resultados da pesquisa, optou-se por comparar inicialmente a média dos limiares ou das perdas auditivas por freqüência nas 22 orelhas selecionadas para integrar o GE, com a média das 20 orelhas selecionadas para integrar o GC. Foram comparadas também as médias dos TTSs iniciais induzidos nestas orelhas durante a etapa pré-experimental.

Na sequiência deste estudo direcionado, os TTSs induzidos antes da inclusão das orelhas nos grupos de estudo (etapa pré-experimental), foram comparados aos induzidos após a inclusão das orelhas nos grupos de estudo (etapas experimental e pósexperimental).

Para finalizar, a análise direcionada comparou os TTSs induzidos na primeira etapa do estudo (pré-experimental), com os TTS induzidos última etapa do estudo (pósexperimental).

\subsection{3 - Análise Estatística da Média dos Limiares/Perdas Auditivas nas} Orelhas Incluídas no GE e no GC

Para esta análise, foram considerados os limiares auditivos da pré-exposição medidos na primeira audiometria efetuada para a determinação da Primeira Medida (TTS 0). 
Tabela 1 - Médias e desvio-padrão dos Limiares / Perdas Auditivas das orelhas incluídas no GE (N=22) e das orelhas incluídas no $\mathrm{GC}(\mathrm{N}=20)$.

\begin{tabular}{llcccccccc}
\hline & & \multicolumn{7}{c}{ Freqüências } \\
\cline { 3 - 9 } Grupos & 250 & 500 & 1000 & 2000 & 3000 & 4000 & 6000 & 8000 \\
\hline \multirow{3}{*}{ GC } & Média(dB) & 63,93 & 73,75 & 85,93 & 92,36 & 93,80 & 97,02 & 103,98 & 92,23 \\
& Desvio-padrão & 25,81 & 20,51 & 16,97 & 20,89 & 24,77 & 23,78 & 25,55 & 17,56 \\
& $N$ & 20 & 20 & 20 & 20 & 20 & 20 & 20 & 20 \\
\hline \multirow{3}{*}{ GE } & Média(dB) & 83,65 & 89,50 & 94,77 & 99,35 & 100,04 & 102,19 & 102,33 & 87,78 \\
& Desvio-padrão & 18,58 & 20,51 & 18,99 & 21,33 & 22,94 & 25,91 & 30,14 & 24,94 \\
& $N$ & 22 & 22 & 22 & 22 & 22 & 22 & 22 & 22 \\
\hline
\end{tabular}

Tabela 2 - Análise de Variância (ANOVA), comparando a média dos limiares / perdas auditivas nas orelhas incluídas no GE ( $\mathrm{N}=22)$ e nas orelhas incluídas no $\mathrm{GC}(\mathrm{N}=20)$.

\begin{tabular}{lc}
\hline Efeitos & Significância de $f(p)$ \\
\hline Grupo & 0,2334 \\
Freqüências & $<0,0001^{*}$ \\
Grupos x Freqüências & $<0,0001^{*}$ \\
\hline
\end{tabular}

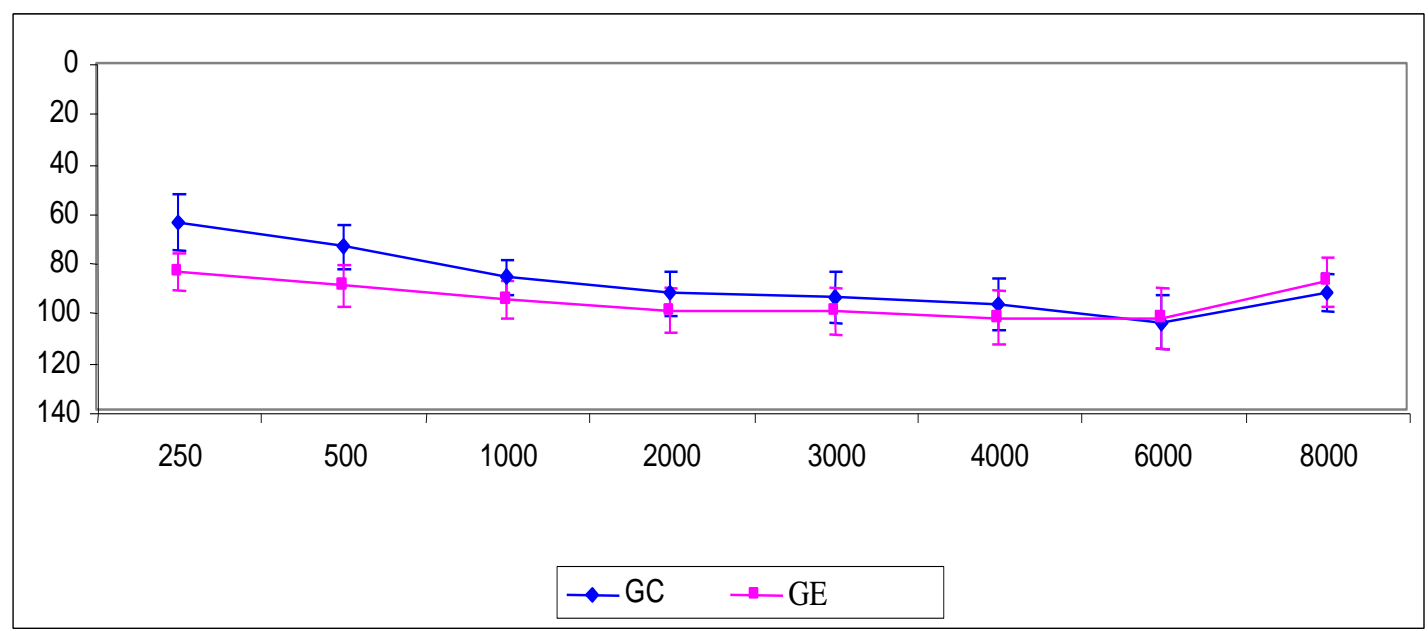

Legenda: Intervalo de confiança para a média: média $\pm 1,96$ * desvio-padrão $/ \sqrt{ }(n-1)$

Figura 6 - Comparação da Média $(\mathrm{dB})$ dos Limiares / Perdas Auditivas por freqüência $(\mathrm{Hz})$ nas orelhas incluídas no GE ( $n=22)$ e nas orelhas incluídas no $G C(n=20)$. 


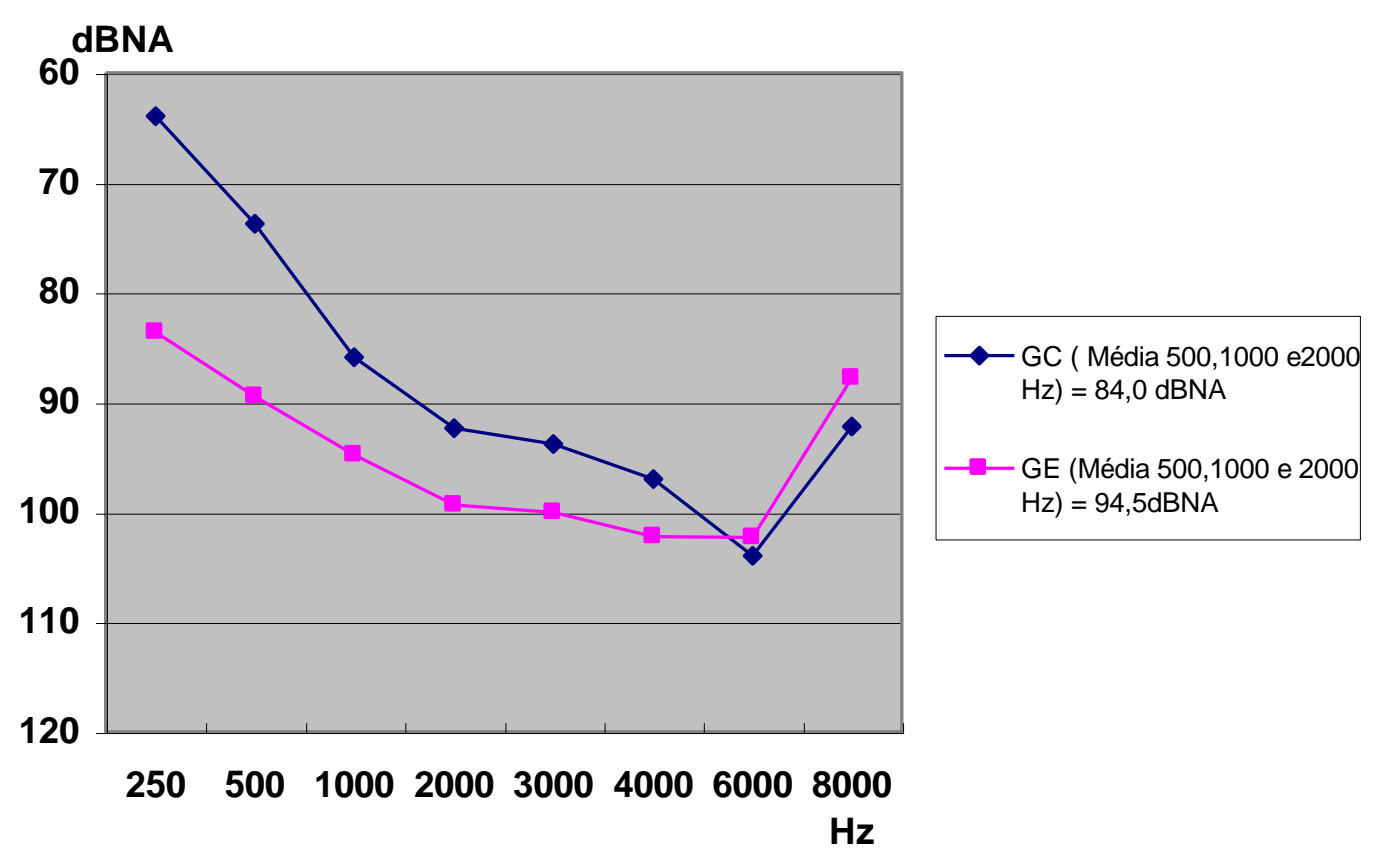

Figura 7 - Audiograma representando a média dos Limiares /Perdas Auditivas (dBNA) por Freqüência $(\mathrm{Hz})$ das 22 Orelhas integradas ao Grupo Experimental (GE) e das 20 Orelhas integradas ao Grupo Convencional (GC).

A Tabela 1 mostra as médias em dB e o desvio-padrão dos limiares/perdas auditivas nos dois grupos estudados. Considerando um nível de significância de 5\%, podemos verificar que houve significância para os efeitos Frequiência e interação entre Grupo x Freqüência, e não significância para o efeito Grupo (Tabela 2).

Como houve uma significância expressiva para o efeito Freqüência e para o efeito integrado Grupo x Freqüência $(<0,0001)$, procedeu-se ao teste de comparações múltiplas, tendo verificado que o GE apresentou perdas auditivas significantemente maiores entre as freqüências de 250 a $2000 \mathrm{~Hz}$. Na Figura 6, é possível visualizar esta diferença.

O Audiograma (Figura 7), representa a média por frequiência dos limiares/perdas auditivas das 42 orelhas incluídas neste estudo medidos na primeira audiometria.

Conforme é possível observar (Figura 7), considerando-se as médias das perdas auditivas nas frequiências 500,1000 e $2000 \mathrm{~Hz}$, as 20 orelhas posteriormente integradas ao Grupo Convencional, apresentavam na média uma perda auditiva 10,5 dB menor do que a das 22 orelhas posteriormente incluídas no Grupo Experimental. 


\subsection{4 - Análise Estatística dos TTSs Medidos com as Orelhas Desprovidas das Próteses Auditivas nas Orelhas Incluídas no GE e nas Orelhas Incluídas no GC}

Para esta análise, foram comparados os valores obtidos na Primeira medida (TTS 1), para as 22 orelhas incluídas posteriormente no GE e para as 20 orelhas incluídas posteriormente no GC.

Procedeu-se no estudo a Análise da Variância (ANOVA), considerando um nível de significância de $5 \%$.

Tabela 3 - Médias e desvio-padrão dos valores dos TTSs para as Orelhas incluídas no GE ( $n=22)$ e para as Orelhas incluídas no GC ( $\mathrm{N}=20)$ na Primeira Medida (TTS0).

\begin{tabular}{clcccccccc}
\hline \multirow{3}{*}{ Grupo } & & \multicolumn{7}{c}{ Freqüência $(\mathrm{Hz})$} \\
\cline { 3 - 10 } & & 250 & 500 & 1000 & 2000 & 3000 & 4000 & 6000 & 8000 \\
\hline \multirow{3}{*}{ GC } & Média (dB) & $-1,45$ & 0,90 & 0,58 & 0,00 & $-0,01$ & $-0,55$ & $-0,33$ & 0,00 \\
& Desvio-padrão & 5,52 & 4,05 & 2,20 & 2,09 & 4,04 & 4,89 & 3,13 & 3,96 \\
& $\mathrm{~N}$ & 20 & 20 & 20 & 20 & 20 & 20 & 20 & 20 \\
\hline \multirow{3}{*}{$\mathrm{GE}$} & Média(dB) & $-0,59$ & $-0,71$ & $-0,50$ & 0,00 & $-2,39$ & $-3,43$ & $-0,52$ & $-1,30$ \\
& Desvio-padrão & 6,63 & 5,90 & 4,38 & 6,18 & 7,70 & 11,97 & 5,20 & 5,49 \\
& $\mathrm{~N}$ & 22 & 22 & 22 & 22 & 22 & 22 & 22 & 22 \\
\hline
\end{tabular}

Tabela 4 - Análise de Variância (ANOVA) dos TTSs das Orelhas incluídas no GE $(n=22)$ e das Orelhas incluídas no $\mathrm{GC}(\mathrm{N}=20)$ na Primeira Medida (TTS 0).

\begin{tabular}{cc}
\hline Efeitos & Significância de $f(p)$ \\
\hline Grupos & 0,4060 \\
Freqüências & 0,2946 \\
Grupos x Freqüências & 0,5327 \\
\hline
\end{tabular}




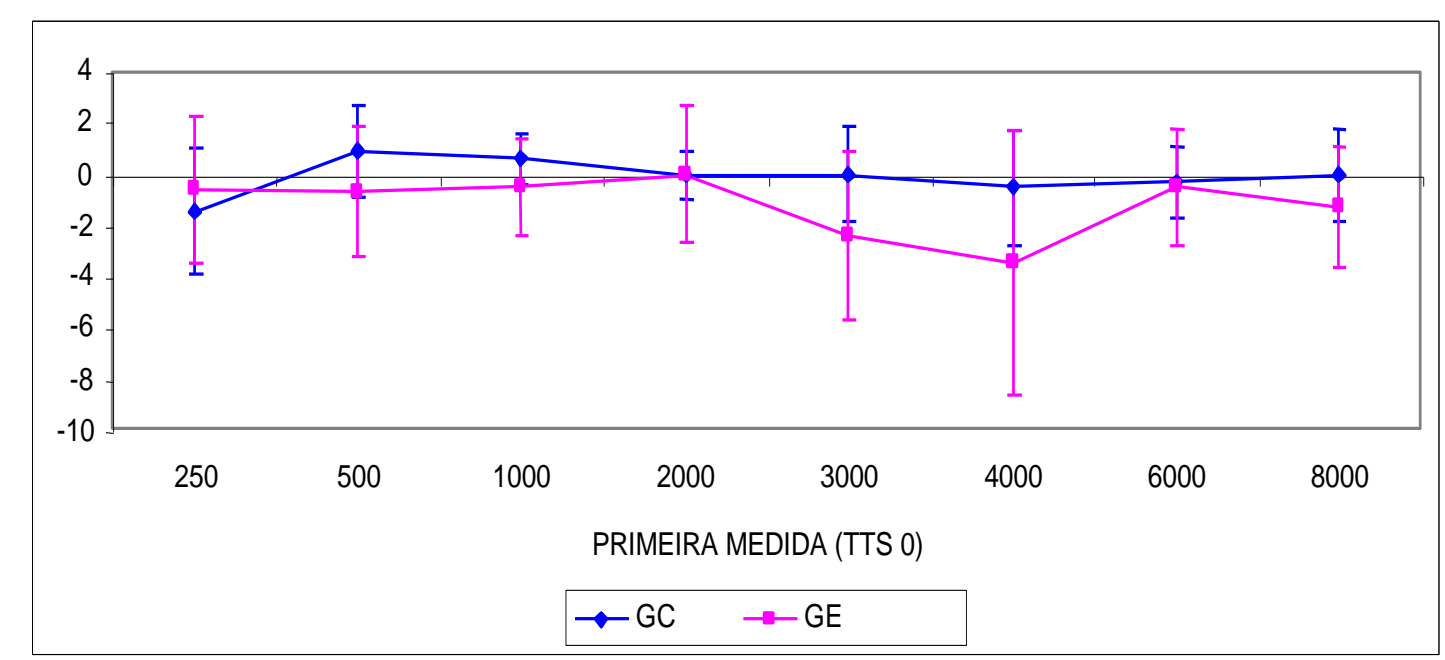

Legenda: Intervalo de confiança para a média: média $\pm 1,96$ * desvio-padrão / $\sqrt{ }(n-1)$

Figura 8 - Comportamento dos TTSs nas Orelhas incluídas no GE (N=22) e nas Orelhas incluídas no GC $(\mathrm{N}=20)$ na Primeira Medida (TTS 0).

Considerando-se um nível de significância de 5\%, é possível verificar, na Primeira Medida (Tabela 3 e 4), que não houve diferenças estatisticamente significantes nos três efeitos estudados (Grupo, Freqüência e Grupo x Freqüência). Analisando a Figura 8, podemos verificar que não houve diferenças nos TTS 0 induzidos nas orelhas posteriormente integradas aos dois grupos distintos, antes da introdução da amplificação de suas próteses auditivas.

4.2.5. - Análise Estatística dos TTSs Induzidos nas Orelhas Desprovidas e Providas de suas Próteses Auditivas no Grupo Experimental e no Grupo Convencional

Para esta análise, procedeu-se a comparação da Primeira Medida (TTS 0) com a média da Segunda e da Terceira Medida (TTS 1-2), separadamente nas orelhas integradas a cada grupo distintos de estudo. 
$\underline{\text { Orelhas Integradas ao Grupo Experimental }}$

Tabela 5 - Médias e desvio-padrão da Primeira Medida / TTS 0 (orelhas desprovidas das Próteses Auditivas) e da média da Segunda e da Terceira Medida / TTS 1-2 (orelhas providas de suas Próteses Auditivas ) para as orelhas integradas ao GE $(n=22)$.

\begin{tabular}{|c|c|c|c|c|c|c|c|c|c|}
\hline \multirow[b]{2}{*}{ Medidas } & & \multicolumn{8}{|c|}{ Freqüências } \\
\hline & & 250 & 500 & 1000 & 2000 & 3000 & 4000 & 6000 & 8000 \\
\hline & Média(dB) & $-0,59$ & $-0,71$ & $-0,50$ & $-0,02$ & $-2,39$ & $-3,43$ & $-0,52$ & $-1,30$ \\
\hline $1^{\mathrm{a}}$ Medida & Desvio-padrão & 6,63 & 5,90 & 4,38 & 6,18 & 7,70 & 11,97 & 5,20 & 5,49 \\
\hline TTS 1 & $\mathrm{~N}$ & 22 & 22 & 22 & 22 & 22 & 22 & 22 & 22 \\
\hline Média da $1^{a}$ & Média(dB) & 5,05 & 5,34 & 3,73 & 3,07 & 1,86 & 0,40 & 1,68 & 0,96 \\
\hline e $2^{\mathrm{a}}$ Medida & Desvio-padrão & 5,22 & 4,12 & 4,96 & 2,69 & 5,03 & 4,90 & 5,06 & 3,41 \\
\hline TTS 1-2 & $\mathrm{N}$ & 22 & 22 & 22 & 22 & 22 & 22 & 22 & 22 \\
\hline
\end{tabular}

Tabela 6 - Análise de Variância (ANOVA) da Primeira Medida (TTS 0) e da média da Segunda e da Terceira Medida (TTS1/2) para as orelhas integradas ao GE $(n=22)$.

\begin{tabular}{lc}
\hline Efeitos & Significância de $f(p)$ \\
\hline Medidas & $0,0007^{*}$ \\
Freqüências & $0,0017^{*}$ \\
Medidas x Freqüências & 0,0997 \\
\hline
\end{tabular}

Orelhas Integradas ao Grupo Convencional

Tabela 7 - Médias e Desvio Padrão da Primeira Medida / TTS 0 (orelhas desprovidas das Próteses Auditivas) e da média da Segunda e da Terceira Medida / TTS 1-2 (orelhas providas de suas Próteses Auditivas) para as orelhas integradas ao $G C(n=20)$.

\begin{tabular}{|c|c|c|c|c|c|c|c|c|c|}
\hline \multirow[b]{2}{*}{ Medida } & & \multicolumn{8}{|c|}{ Freqüências } \\
\hline & & 250 & 500 & 1000 & 2000 & 3000 & 4000 & 6000 & 8000 \\
\hline & Média & $-1,45$ & 0,90 & 0,58 & 0,00 & $-0,08$ & $-0,55$ & $-0,33$ & 0,03 \\
\hline $1^{\text {a }}$ Medida & Desvio-padrão & 5,52 & 4,05 & 2,20 & 2,09 & 4,04 & 4,89 & 3,13 & 3,96 \\
\hline TTS 1 & $\mathrm{~N}$ & 20 & 20 & 20 & 20 & 20 & 20 & 20 & 20 \\
\hline Média da & Média & 2,15 & 1,28 & 1,26 & 1,53 & 0,93 & 0,85 & 0,04 & $-0,10$ \\
\hline $1^{\mathrm{a}} \mathrm{e} 2^{\mathrm{a}}$ & Desvio-padrão & 3,37 & 3,70 & 3,10 & 3,16 & 2,20 & 2,68 & 2,79 & 0,74 \\
\hline TTS 1-2 & $\mathrm{N}$ & 20 & 20 & 20 & 20 & 20 & 20 & 20 & 20 \\
\hline
\end{tabular}

Tabela 8 - Análise de Variância (ANOVA da Primeira Medida (TTS 0) e da média da Segunda e da Terceira Medida (TTS 1-2) para as orelhas integradas ao GC $(n=20)$.

\begin{tabular}{lc}
\hline Efeitos & Significância de $\mathrm{f}(\mathrm{p})$ \\
\hline Medida & 0,0669 \\
Freqüências & 0,6219 \\
Medidas x Freqüências & 0,2049 \\
\hline
\end{tabular}


A Tabela 5 mostra as diferenças das médias e o desvio-padrão do TTS 0 e da média TTS 1-2 para o GE . A Tabela 7 mostra as mesmas diferenças para o GC.

Comparando-se os dois valores, é possível verificar, pela Análise de Variância, que o GE (Tabela 6) apresentou significância para os dois efeitos: Medida e Frequiência, enquanto que no GC (Tabela 8) não houve diferenças significantes para os três efeitos estudados.

Como para as orelhas integradas ao GE houve uma diferença estatisticamente significante nos efeitos Medida e Freqüência, foi usado o teste de comparações múltiplas para verificar onde estariam as diferenças. O que se pode observar é que a média TTS 1-2 aumentou em todas as freqüências comparada as medidas do TTS 1.

As orelhas incluídas no GC não apresentaram diferenças estatisticamente significantes para os três efeitos estudados. No entanto, para o efeito medida, o valor da variância foi inferior a $0,10(\mathrm{f}=0,0669)$. O teste de comparações múltiplas permitiu observar que, embora a característica geral das orelhas incluídas no GC seja de não variação entre o TTS 0 e o TTS 1-2, houve um pequeno indicio de diferença entre essas suas medidas na freqüência de $250 \mathrm{~Hz}$.

Nas Figuras 9 e 10, é possível visualizar este comportamento diferenciado antes e logo após a introdução da amplificação das próteses auditivas nas orelhas incluídas no GE (Figura 9) e nas orelhas incluídas no GC (Figura 10). 


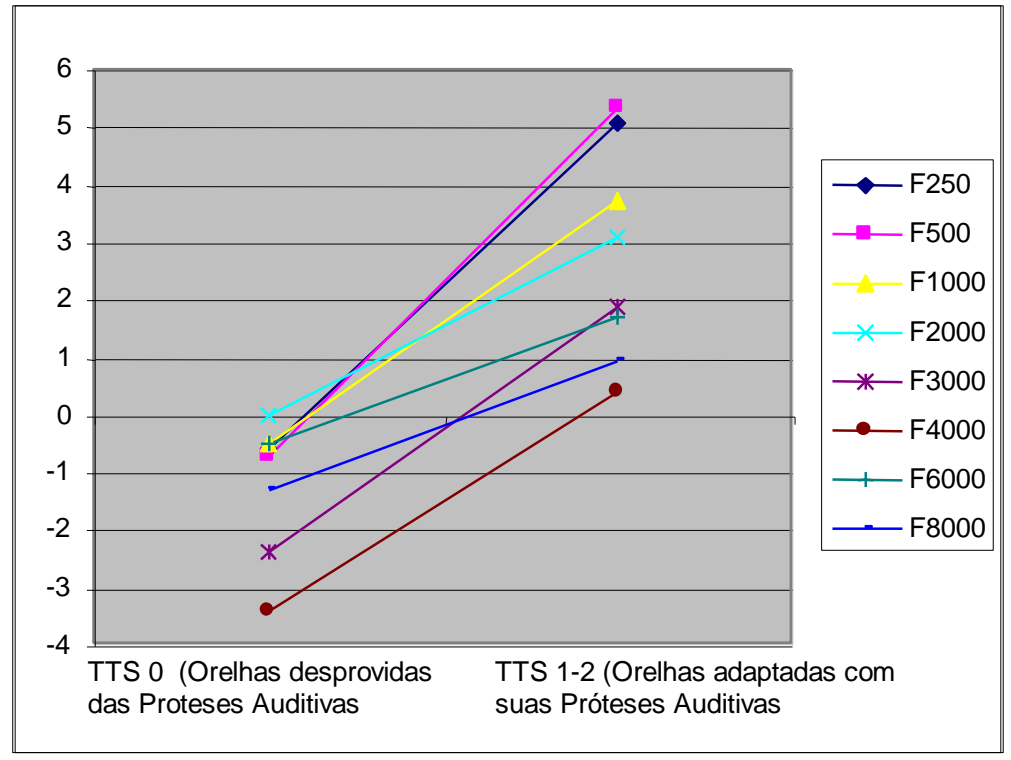

Figura 9 - Comportamento dos TTSs antes da introdução da amplificação das Próteses Auditivas e logo após a introdução da amplificação das Próteses Auditivas para as 22 orelhas integradas ao GE.

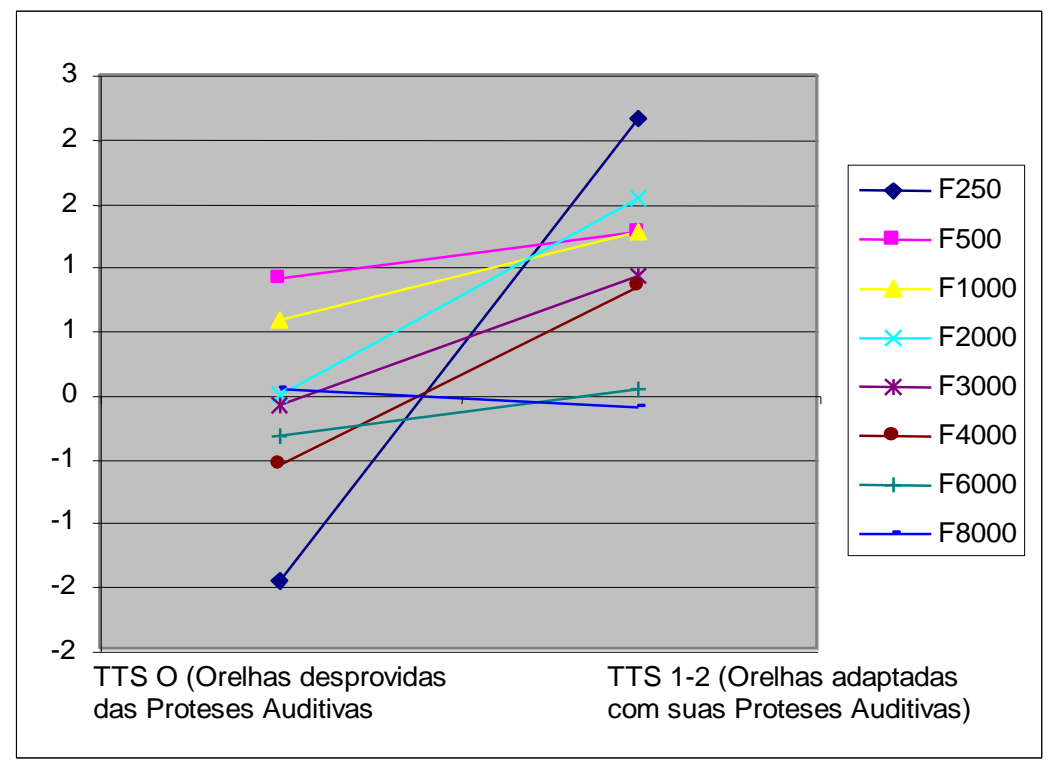

Figura 10 - Comportamento dos TTSs antes da introdução da amplificação das Próteses Auditivas e logo após a introdução da amplificação das Próteses Auditivas para as 20 orelhas integradas ao GC.

Comparando-se os TTSs medidos na etapa pré-experimental, podemos visualizar que, para as 22 orelhas integradas ao GE (Figura 9), houve um aumento significante dos 
TTS 1-2 em todas as freqüências com a introdução da amplificação das próteses auditivas adaptadas agindo nas orelhas protetizadas.

No entanto, a mesma comparação para as 20 orelhas incluídas no GC (Figura 10), mostra que os TTS 1-2 medidos após a introdução inicial da amplificação das próteses auditivas adaptadas agindo nas orelhas protetizadas, apresentaram um aumento muito pequeno em quase todas as frequiências analisadas, com exceção de $250 \mathrm{~Hz}$, onde se pode constatar um aumento visível nas orelhas adaptadas com suas próteses auditivas.

4.2.6 - Análise Estatística dos TTSs nas Orelhas Integradas ao GE com as Próteses Auditivas Reguladas na Maior Amplificação (Amplificação "Usual") e na Menor Amplificação (Amplificação "Reduzida / Treinamento")

Para esta análise, foram consideradas a média TTS 1 - 2 e o TTS Ad, efetuada em 18 das vinte e duas orelhas integradas ao GE .

Foi aplicado na análise estatística das diferenças, a Variância de ANOVA com um nível de significância de 5\%.

Tabela 9 - Médias e desvio-padrão das medidas dos TTSs das Orelhas integradas ao GE (N=18) com as Próteses Auditivas ajustadas na Maior Amplificação (TTS 1-2) e na Menor Amplificação (TTS Ad).

\begin{tabular}{clcccccccc}
\hline Amplificação & & \multicolumn{7}{c}{ Freqüências } \\
\cline { 3 - 10 } & 250 & 500 & 1000 & 2000 & 3000 & 4000 & 6000 & 8000 \\
\hline Maior & Média (dB) & 5,44 & 6,00 & 4,83 & 3,65 & 3,11 & 1,26 & 2,72 & 1,46 \\
Amplificação & Desvio-padrão & 5,51 & 4,09 & 4,77 & 2,62 & 3,36 & 4,07 & 4,35 & 3,42 \\
TTS 1-2 & N & 18 & 18 & 18 & 18 & 18 & 18 & 18 & 18 \\
\hline Menor & Média (dB) & $-0,69$ & 1,06 & 3,08 & 1,22 & 0,19 & $-0,36$ & $-0,75$ & 0,28 \\
Amplificação & Desvio-padrão & 8,17 & 6,08 & 3,78 & 3,35 & 4,48 & 3,89 & 4,16 & 1,53 \\
TTS Ad & $N$ & 18 & 18 & 18 & 18 & 18 & 18 & 18 & 18 \\
\hline
\end{tabular}


Tabela 10 - Análise de Variância (ANOVA) para as Orelhas integradas ao GE $(\mathrm{N}=18)$ com as Próteses Auditivas ajustadas na Maior Amplificação (TTS 1-2) e na Menor Amplificação (TTS Ad).

\begin{tabular}{lc}
\hline Efeitos & Significância de f $(p)$ \\
\hline Amplificação & $0,0003^{*}$ \\
Freqüências & $0,0065^{*}$ \\
Amplificação x Freqüências & 0,0665 \\
\hline
\end{tabular}

A Tabela 9 mostra as diferenças das médias e o desvio-padrão com as mesmas próteses auditivas reguladas em diferentes níveis de amplificação, para as 18 orelhas integradas ao GE.

$\mathrm{Na}$ análise da variância (Tabela 10), podemos verificar que houve diferenças estatisticamente significantes para os efeitos Amplificação $(0,0003 *)$ e Freqüência $\left(0,0065^{*}\right)$, e não significante para a interação Amplificação x Freqüência $(0,0665)$.

Como a significância para os dois efeitos isolados foi expressiva, procedeu-se ao teste de comparações múltiplas, que mostrou um decréscimo na magnitude dos TTSs das freqüências mais baixas para as mais altas com as próteses auditivas reguladas nos diferentes níveis de amplificação. Também foi possível determinar, por comparações múltiplas, que a magnitude do TTS foi maior com as próteses auditivas ajustadas na condição de “maior” amplificação/TTS 1-2 (amplificação “usual”). É possível verificar esses resultados analisando a Figura 11. 


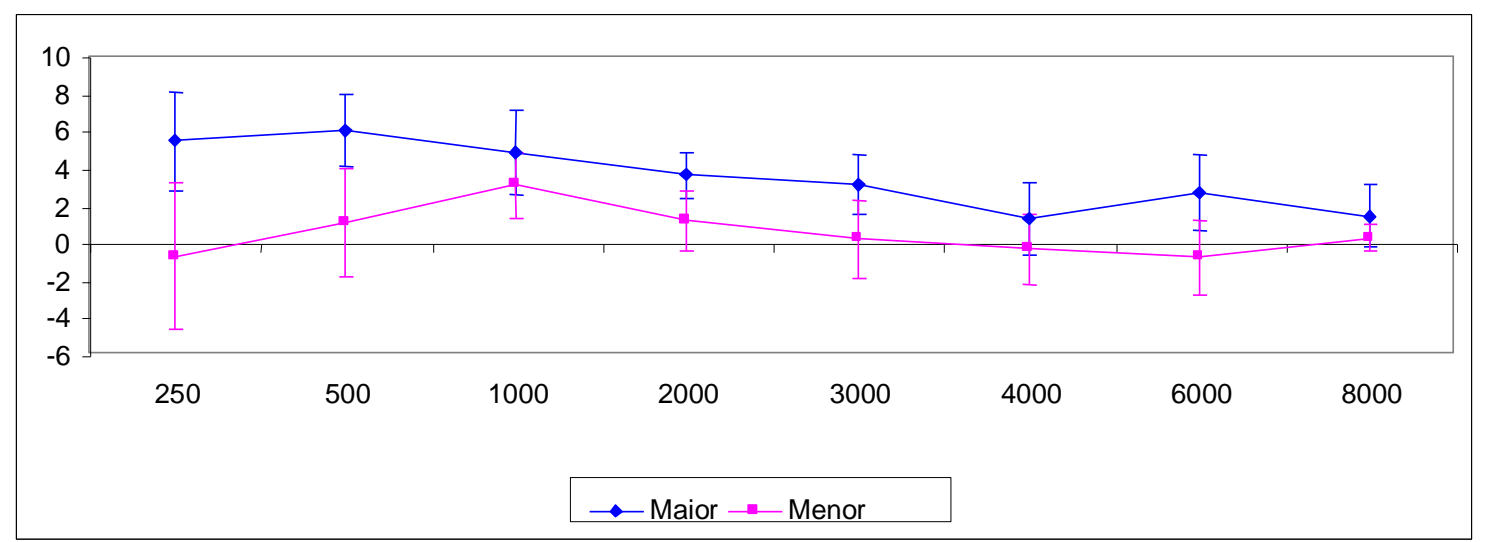

Legenda: Intervalo de confiança para a média: média $\pm 1,96$ * desvio-padrão / $\sqrt{ }(\mathrm{n}-1)$

Figura 11 - Comparação dos TTS 1-2 e TTS Ad medidos nas 18 orelhas do GE com as Próteses Auditivas reguladas na Maior Amplificação (amplificação "usual") e na Menor Amplificação (amplificação reduzida usada no treinamento).

Podemos observar diferenças visíveis entre os TTSs nas 18 orelhas incluídas no GE quando as suas próteses auditivas foram reguladas em diferentes níveis de amplificação. Na condição de "maior" amplificação (TTS 1-2), estas diferenças são maiores nas freqüências inferiores a $1000 \mathrm{~Hz}$, reduzindo nas freqüências mais altas.

\subsection{7 - Análise Estatística do Comportamento dos TTS para as Orelhas Integradas ao GE Durante as Três Etapas do Estudo}

Para esta análise, foram consideradas todas as medidas do TTSs obtidas durante o estudo para as oito freqüências nas orelhas integradas ao GE $(n=22)$.

Foi aplicado no estudo a análise da Variância de ANOVA para os efeitos Frequiência e Medida, considerando-se um nível de significância de 5\%. 
Tabela 11 - Médias e desvio-padrão dos TTSs induzidos nas 22 orelhas incluídas no GE para as freqüências de 250 a $8000 \mathrm{~Hz}$ durante o período de estudo.

\section{FREQÜÊNCIAS (Hz)}

\begin{tabular}{|c|c|c|c|c|c|c|c|c|c|}
\hline MEDIDAS & & 250 & 500 & 1000 & 2000 & 3000 & 4000 & 6000 & 8000 \\
\hline & Média(dB) & $-0,59$ & $-0,71$ & $-0,50$ & $-0,02$ & $-2,39$ & $-3,43$ & $-0,52$ & $-1,30$ \\
\hline $1^{\text {a }}$ Medida & Desvio-padrão & 6,63 & 5,90 & 4,38 & 6,18 & 7,70 & 11,97 & 5,20 & 5,49 \\
\hline TTS 0 & $\mathrm{n}$ & 22 & 22 & 22 & 22 & 22 & 22 & 22 & 22 \\
\hline Média da & Média (dB) & 5,05 & 5,34 & 3,73 & 3,07 & 1,86 & 0,40 & 1,68 & 0,96 \\
\hline $2^{a}$ e $3^{a}$ Medida & Desvio-padrão & 5,22 & 4,12 & 4,96 & 2,69 & 5,03 & 4,90 & 5,06 & 3,41 \\
\hline TTS 1-2 & $\mathrm{n}$ & 22 & 22 & 22 & 22 & 22 & 22 & 22 & 22 \\
\hline & Média $(\mathrm{dB})$ & 5,55 & 6,68 & 5,23 & 4,66 & 2,61 & 2,14 & 0,50 & 0,64 \\
\hline $4^{\text {a }}$ Medida & Desvio-padrão & 8,17 & 7,09 & 5,94 & 5,35 & 4,63 & 3,93 & 6,32 & 2,59 \\
\hline TTS 3 & $\mathrm{n}$ & 22 & 22 & 22 & 22 & 22 & 22 & 22 & 22 \\
\hline & Média(dB) & 4,16 & 3,64 & 4,82 & 3,32 & 1,09 & 1,05 & 1,14 & 0,16 \\
\hline $5^{\text {a }}$ Medida & Desvio-padrão & 6,42 & 7,14 & 7,21 & 4,05 & 5,23 & 4,83 & 7,24 & 6,19 \\
\hline TTS 4 & $\mathrm{n}$ & 22 & 22 & 22 & 22 & 22 & 22 & 22 & 22 \\
\hline & Média(dB) & 3,32 & 4,46 & 6,11 & 3,55 & 2,32 & 1,68 & $-0,02$ & 1,46 \\
\hline $6^{\mathrm{a}}$ Medida & Desvio-padrão & 5,76 & 5,19 & 6,24 & 4,05 & 4,31 & 4,22 & 5,40 & 4,41 \\
\hline TTS 5 & $\mathrm{n}$ & 22 & 22 & 22 & 22 & 22 & 22 & 22 & 22 \\
\hline & Média(dB) & 3,96 & 3,71 & 3,86 & 4,41 & 3,02 & 1,02 & 1,16 & 2,16 \\
\hline $7^{\text {a }}$ Medida & Desvio-padrão & 6,88 & 4,12 & 7,79 & 8,97 & 7,79 & 6,33 & 6,82 & 4,45 \\
\hline TTS 6 & $\mathrm{n}$ & 22 & 22 & 22 & 22 & 22 & 22 & 22 & 22 \\
\hline & Média(dB) & $-0,23$ & 2,11 & 2,09 & 2,39 & $-0,09$ & $-0,73$ & $-0,25$ & $-1,11$ \\
\hline $8^{\mathrm{a}}$ Medida & Desvio-padrão & 5,77 & 6,21 & 4,63 & 5,23 & 4,53 & 2,68 & 6,27 & 3,99 \\
\hline TTS 7 & & 22 & 22 & 22 & 22 & 22 & 22 & 22 & 22 \\
\hline
\end{tabular}

Tabela 12 - Análise de Variância (ANOVA) da média dos TTSs induzidos nas 22 orelhas incluídas no Grupo Experimental comparando os três efeitos estudados: Medidas, Freqüências e interação Medidas e Freqüências.

\begin{tabular}{lc}
\hline Efeitos & Significância de f (p) \\
\hline Medidas & $<0,0001^{*}$ \\
Freqüências & $<0,0001^{*}$ \\
Medidas x Freqüências & 0,2166 \\
\hline
\end{tabular}

A Tabela 11 representa a média em dB e o desvio-padrão dos TTSs induzidos nas 22 orelhas incluídas no GE nas três etapas do estudo.

A Tabela 12 representa a Análise de Variância dos três efeitos estudados. Conforme é possível visualizar, os dois efeitos, Freqüência e Medida, apresentaram variações estatisticamente significantes $(<0,0001)$, e a interação Medida e Freqüência, 
apresentou variação não significante $(0,2166)$ para as 22 orelhas incluídas no Grupo Experimental.

Considerando-se que, para as orelhas integradas ao GE houve uma expressiva significância nos dois efeitos, Freqüência e Medida, foi realizado o teste de comparações múltiplas para verificar onde estariam essas diferenças. O que se pode observar por comparações múltiplas é que o TTS 3. comparado a média TTS 1-2, apresentou um incremento em todas as frequiências analisadas. A partir do TTS 3, ocorreu uma redução gradual nos TTSs subseqüentes (TTS 4 a TTS 7). Com exceção dos TTS 0 (orelhas desprovidas das próteses auditivas), os TTS 7 medidos na etapa pósexperimental foram os mais baixos para as orelhas incluídas no GE.

As freqüências mais alteradas foram as de 250 a $2000 \mathrm{~Hz}$, tendo as demais apresentado pequenas alterações em todos as medidas induzidas.

A seguir, podemos visualizar o comportamento das oito freqüências analisadas (Figura 12) e o comportamento de todos os TTSs induzidos durante o período integral deste estudo (Figura 13) para as 22 orelhas incluídas no GE.

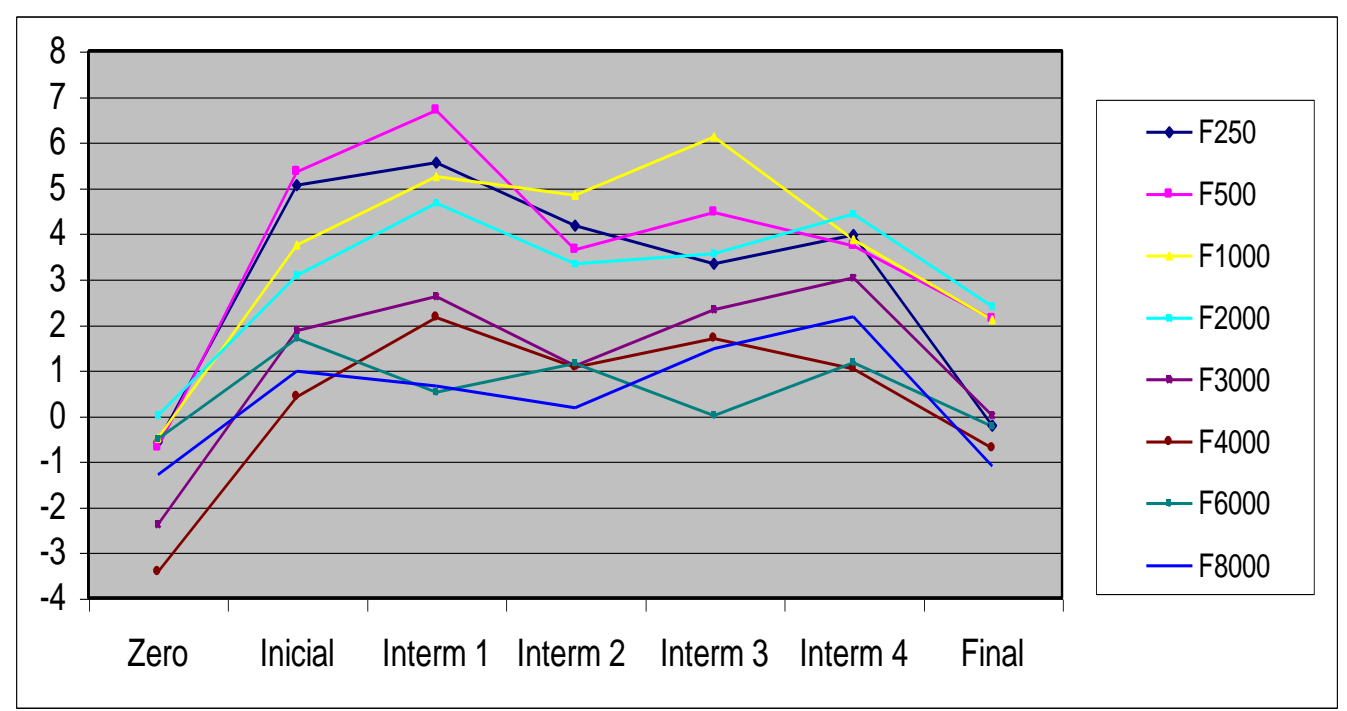

Figura 12 - Comportamento das freqüências analisadas $(250$ a $8000 \mathrm{~Hz})$ nas etapas pré-experimental, experimental e pós-experimental para as 22 orelhas incluídas no Grupo Experimental.

OBS: onde lê-se: zero, inicial, interm.1, interm.2, interm 3, interm 4 , final , leia-se: TTS 0 , TTS 1-2, TTS 3, TTS 4, TTS 5 , TTS6, TTS 7 


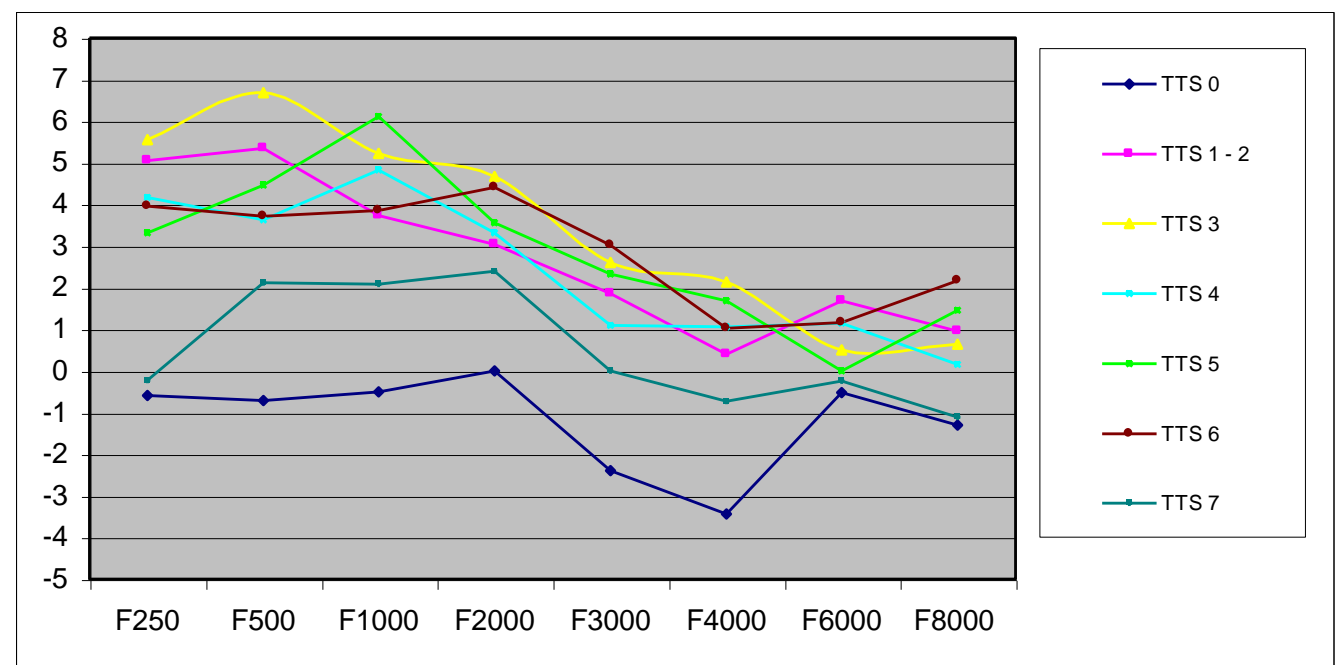

Figura 13 - Comportamento dos TTSs induzidos nas etapas pré-experimental, experimental e pósexperimental para as 22 orelhas incluídas no Grupo Experimental.

Analisando a Figura 12 e a Figura 13, é possível visualizar que os TTSs medidos durante o estudo tiveram um comportamento bastante regular em todas as frequiências analisadas .

Se atentarmos para a Figura 13, veremos que inicialmente se verificou um crescimento visível nos TTSs das orelhas incluídas no GE da primeira medida ou no TTS 0 (antes da introdução da amplificação das próteses auditivas), para a segunda e terceira medida ou TTS 1-2 ( logo após a introdução da amplificação das próteses auditivas). Este aumento ocorreu em toda a faixa de freqüência pesquisada (250 a 8000 $\mathrm{Hz})$.

Do TTS 1-2 para o TTS 3 (15/35 dias após o inicio do treinamento), houve mais um aumento nas alterações induzidas nos limiares auditivos, de 250 a 4000Hz (Figura 13).

A partir do aumento verificado no TTS 3, ocorreu um decréscimo gradual até o TTS 7 em toda a faixa de freqüência analisada (Figura 13). 
A faixa de frequiência de 250 a $2000 \mathrm{~Hz}$ (Figura 12), foi onde ocorreu a maior magnitude do TTSs. A partir desta frequiência, a magnitude dos TTSs tendeu a se reduzir, principalmente nas frequiências mais altas. $\mathrm{O}$ mesmo padrão pode ser observado nas oito medidas.

Com exceção da primeira medida (TTS 0), avaliada antes da introdução da amplificação das próteses auditivas, nota-se que a oitava medida (TTS 7) é a que apresentou as menores alterações em todas as frequiências analisadas para as orelhas protetizadas incluídas no GE (Figura 13).

Se compararmos as alterações observadas no final do treinamento (TTS 6), com as alterações observadas antes do treinamento (TTS1-2), para as orelhas incluídas no GE (Tabela 11), pode ser verificado que a redução ocorreu inicialmente nas frequências inferiores a $1000 \mathrm{~Hz}$. Para $250 \mathrm{~Hz}$ houve uma redução de 1,09dB (5,05/3.96dB) e para $500 \mathrm{~Hz}$ de 1,63 dB (5,34/3,71dB). Considerando o valor médio das reduções observadas nestas duas frequências igual a 1,36dB , chegamos a um percentual de $26 \%$ de redução nos TTS para as frequências inferiores a $1000 \mathrm{~Hz}$.

Se compararmos as alterações observadas após o treinamento (TTS7) com as observadas antes do treinamento (TTS1-2), para as frequências de 250 a $2000 \mathrm{~Hz}$, podemos observar que houve uma redução em todas elas .Em 250 ocorreu uma redução de 5,28dB (5,05/-0,23), em 500 de 3,23 dB (5,34/2,11db), em $1000 \mathrm{~Hz}$ de 1,64 dB $(3,73 / 2,09 \mathrm{db})$ em $2000 \mathrm{~Hz}$ de $0,68 \mathrm{~dB}(3,07 / 2,39 \mathrm{db})$. Considerando a média da redução nestas quatro frequências igual a $2,7 \mathrm{~dB}$, podemos chegar a um percentual de $62 \%$ de redução dos TTS das orelhas incluídas no GE na etapa pós-experimental, na faixa de 250 a $2000 \mathrm{~Hz}$. 


\subsection{8 - Análise Estatística dos TTSs Induzidos nas Orelhas Incluídas no GC Durante as Três Etapas do Estudo}

Para esta análise, foram considerados todos os TTS medidos nas oito frequiências analisadas para as orelhas integradas ao $\mathrm{GC}(\mathrm{n}=20)$ durante o estudo integral.

Foi aplicado no estudo a análise da Variância de ANOVA para os efeitos Freqüência e Medida, considerando-se um nível de significância de 5\%.

Tabela 13 - Médias e desvio-padrão dos TTSs medidos nas freqüências de 250 a $8000 \mathrm{~Hz}$, durante as etapas pré-experimental, experimental e pós-experimental para as 20 orelhas incluídas no GC.

MEDIDAS FREQÜÊNCIAS ( $\mathrm{Hz})$

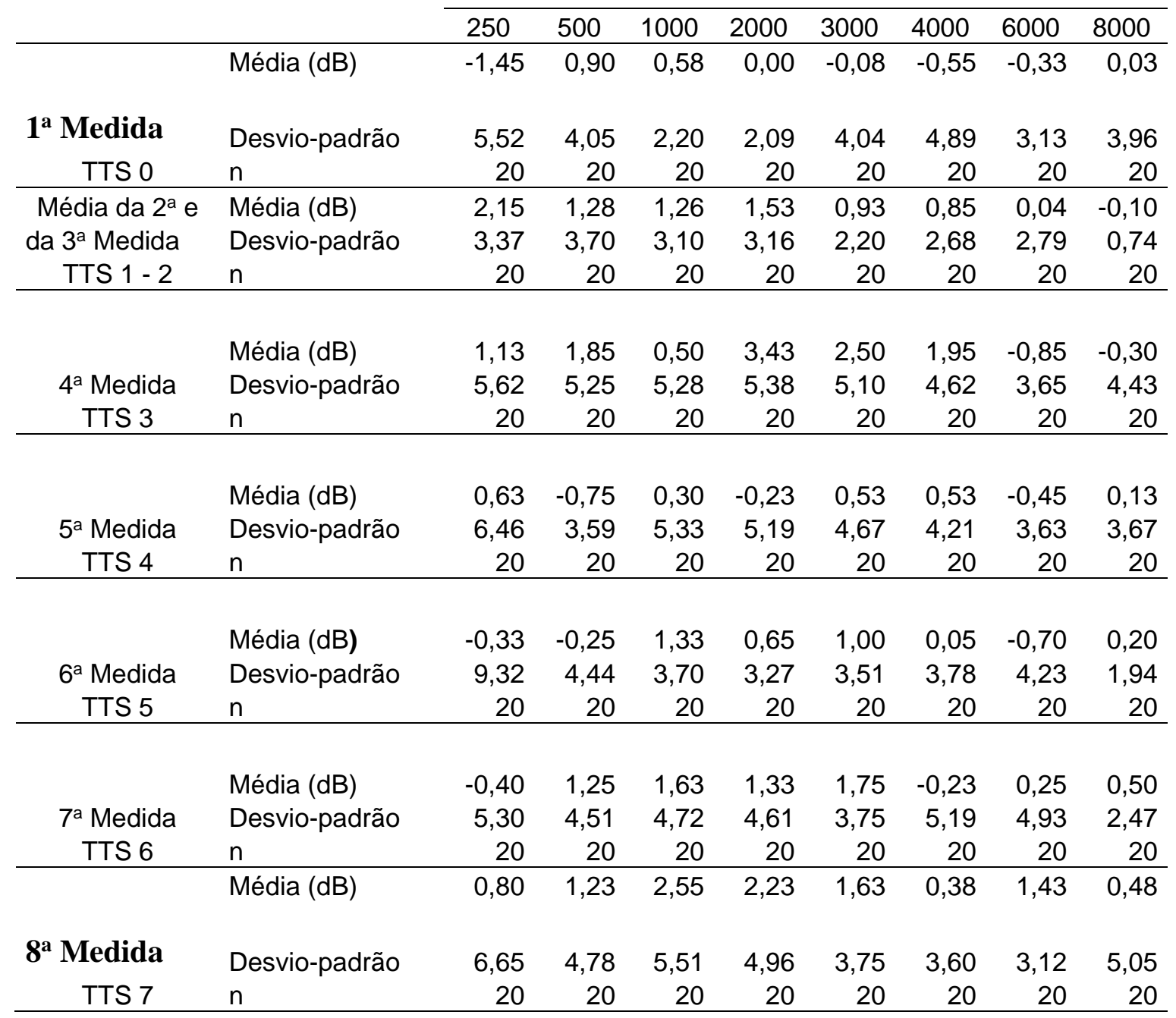


Tabela 14 - Análise da Variância (ANOVA) comparando os três efeitos estudados: Medidas, Freqüências e interação Medidas e Freqüências nas 20 orelhas incluídas no Grupo Convencional.

\section{Efeitos}

Medidas

Significância de $\mathbf{f}(\mathbf{p})$

Freqüências

0,1245

Medidas x Freqüências

0,0957

0,9123

A Tabela 13 mostra a média em dB e o desvio-padrão dos TTSs induzidos nas 20 orelhas incluídas no Grupo Convencional durante o período integral deste estudo.

Se analisarmos a Tabela 14, poderemos verificar que, nas 20 orelhas incluídas no Grupo Convencional, não houve alteração estatisticamente significante para nenhum dos três efeitos estudados: Medidas $(0,1245)$, Frequiência $(0,0957)$ e interação entre Medidas e Freqüência $(0,9123)$.

Embora as orelhas incluídas no GC não tenham apresentado diferenças significantes nos três efeitos estudados, para o efeito freqüência a variância foi menor que $0,10(f=0,0957)$.

Por esta razão, procedeu-se ao teste de comparações múltiplas para verificar onde estariam essas diferenças. O que se pode observar por comparações múltiplas é que, embora a característica seja de não alteração nos TTSs nas oito medidas realizadas, há um pequeno indício de maior alteração nos TTSs induzidos nas freqüências inferiores $(250$ a $3000 \mathrm{~Hz})$, do que nas freqüências superiores.

A seguir, podemos visualizar o comportamento das oito freqüências estudadas (Figura 14), e o comportamento dos TTSs analisados (Figura 15) durante o período integral deste estudo. 


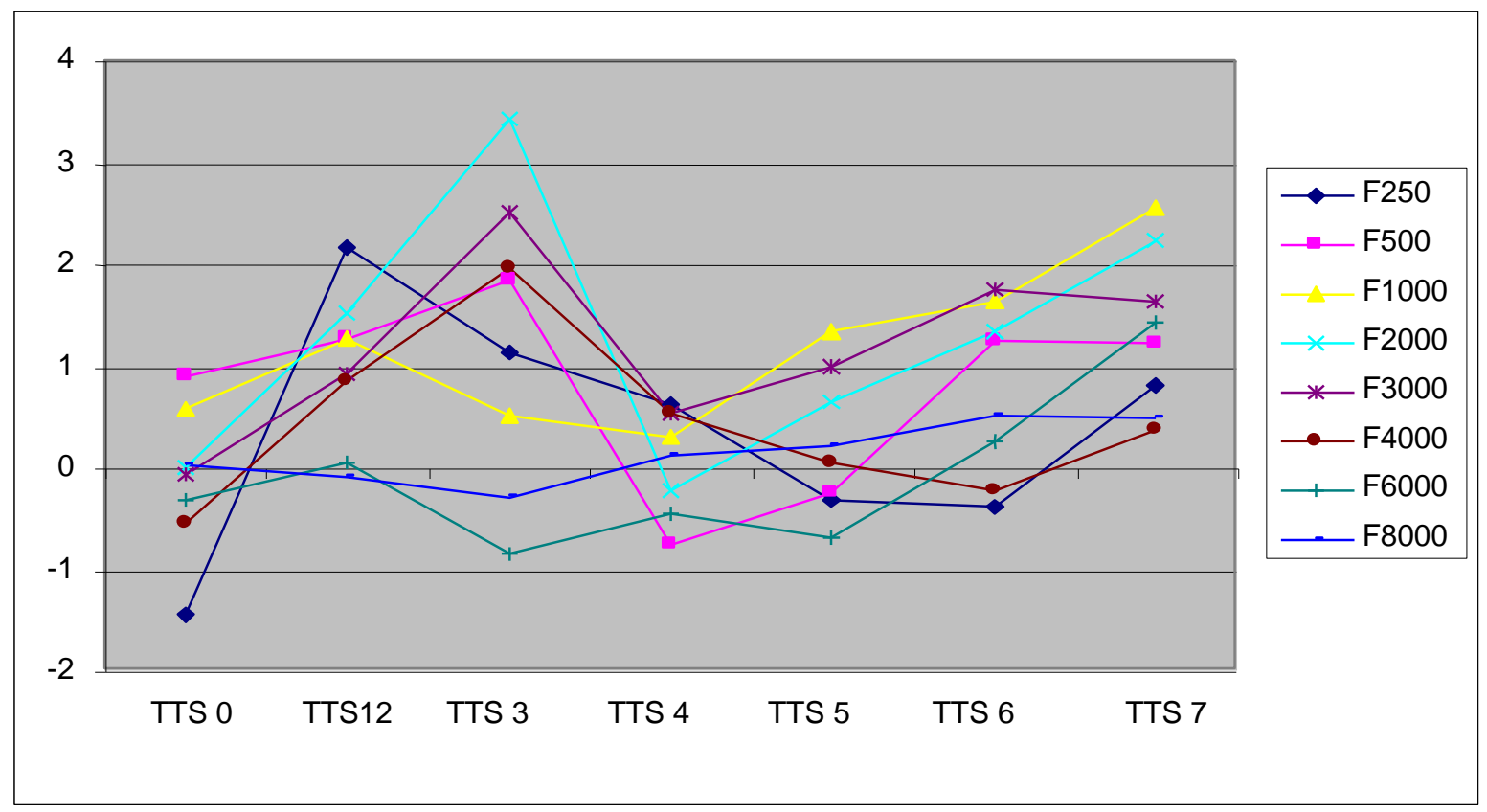

Figura 14 - Comportamento das freqüências analisadas (250 a $8000 \mathrm{~Hz})$ nas etapas pré-experimental, experimental e pós-experimental para as 20 orelhas incluídas no Grupo Convencional.

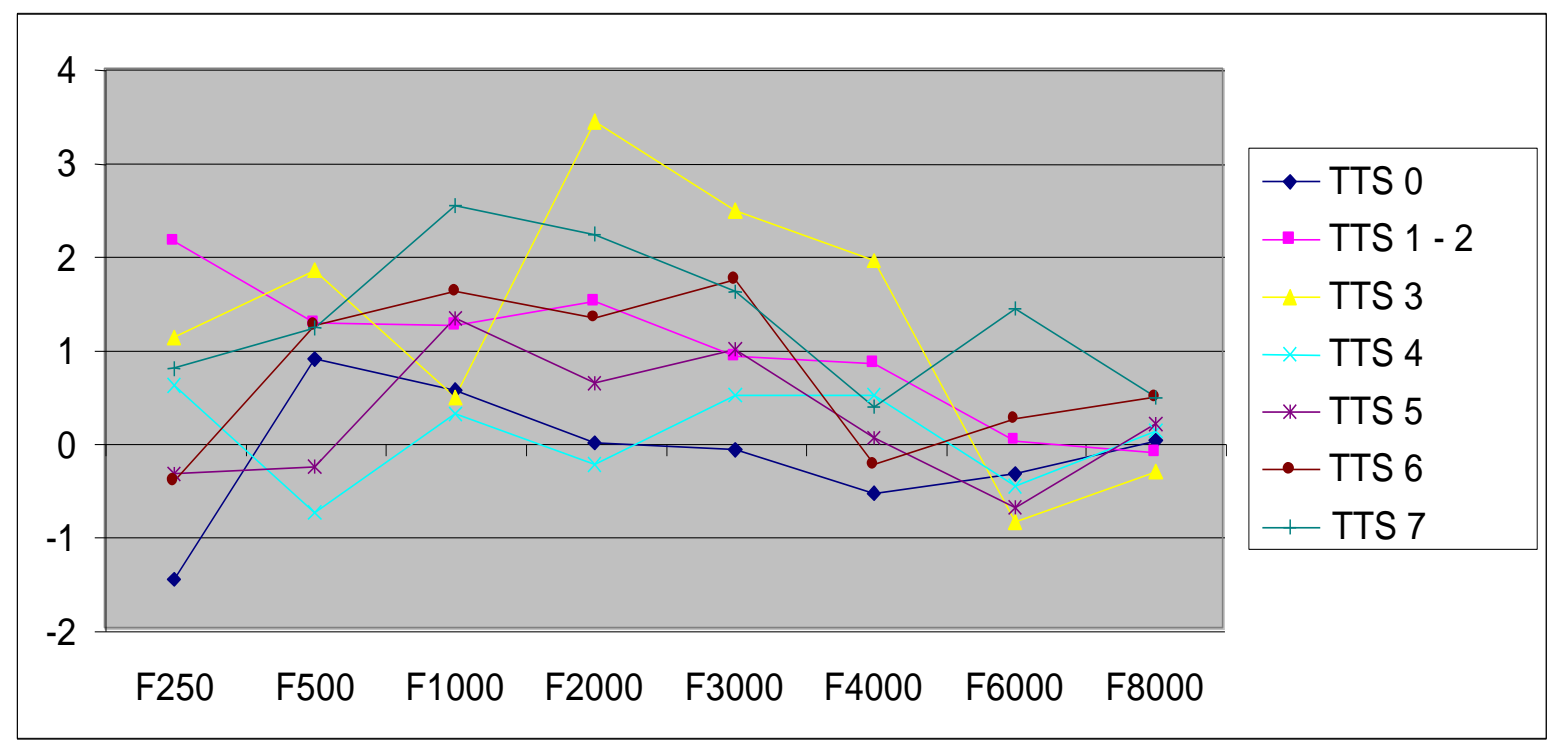

Figura 15- - Comportamento dos TTSs induzidos nas etapas pré-experimental, experimental e pósexperimental para as 20 orelhas incluídas no Grupo Convencional.

Analisando as Figuras 14, poderemos visualizar que as 20 orelhas incluídas no GC mostraram um comportamento menos regular ao longo da faixa de freqüência analisada durante o período deste estudo. Em algumas frequiências os TTS tiveram uma redução precoce: na freqüência de $250 \mathrm{~Hz}$ a redução iniciou a partir do TTS 1- 2 e foi gradual 
até o TTS 6. Em outras freqüências houve uma elevação do TTS 1- 2 para o TTS 3 (500, 2000, 3000 e 4000 Hz), ou uma redução (1000, 6000 e $8000 H z)$. A partir do TTS 1- 2 o comportamento das freqüências foi variado, tendo apresentado momentos de elevação ou de redução nas medidas subseqüentes dos seus TTSs.

Quanto à evolução nos TTSs ao longo do estudo, podemos observar algumas diferenças com relação ao comportamento do GE.

Observando a Figura 15, podemos ver que do TTS 0 (antes da introdução da amplificação das próteses auditivas) para os TTS 1- 2 (após a introdução da amplificação das próteses auditivas), houve também um aumento nos TTSs até 6000 $\mathrm{Hz}$, porém bem menor do que o verificado para as orelhas incluídas no GE, com exceção da freqüência de $250 \mathrm{~Hz}$, onde este aumento foi mais expressivo.

Do TTS 1- 2 para o TTS 3 (Figura 15), também houve um aumento, porém em uma faixa de freqüência mais estreita $(2000$ a $4000 \mathrm{~Hz})$ do que a observada nas orelhas do GE, onde se verificou um aumento em uma faixa mais larga $(250 \mathrm{a} 4000 \mathrm{~Hz})$.

Do TTS 3 para o TTS 4 (Figura 15), pode ser visualizada uma nítida redução em quase todas as freqüências $(250 \mathrm{a} 4000 \mathrm{~Hz})$.

A partir TTS 4 até o TTS 7, o padrão do comportamento das alterações transitórias induzidas nos limiares auditivos foi o inverso do observado nas orelhas integradas ao GE, ou seja, houve tendência a um aumento (Figura 15).

Excetuando o TTS induzido na frequiência de $250 \mathrm{~Hz}$, que teve uma redução gradual a partir do TTS 1- 2 até o TTS 6 , aumentando discretamente no final do estudo (TTS 7), mas se mantendo inferior ao TTS inicial (TTS 1), nas demais freqüências os TTSs induzidos no final do estudo (TTS 7) foram praticamente iguais ou mais elevados 
do que os induzidos no inicio (TTS 1). Este comportamento pode ser visualizado na Figura 14.

\subsection{9 - Análise Estatística dos TTSs Induzidos nas Orelhas Incluídas nos Dois Grupos na Etapa Pré-Experimental}

Comparou-se, para esta análise, os (TTS 1-2) das 22 orelhas incluídas no GE, com os (TTS 1-2) das 20 orelhas incluídas no GC.

Tabela 15 - Médias e desvio-padrão do TTS induzidos na Etapa Pré-Experimental (TTS 1-2) para as 20 Orelhas incluídas no Grupo Convencional e as 22 orelhas incluídas no Grupo Experimental nas freqüências de 250 a $8000 \mathrm{~Hz}$.

\begin{tabular}{|c|c|c|c|c|c|c|c|c|c|}
\hline \multirow[b]{2}{*}{ Grupo } & & \multicolumn{8}{|c|}{ Momentos } \\
\hline & & 250 & 500 & 1000 & 2000 & 3000 & 4000 & 6000 & 8000 \\
\hline & Média & 2,15 & 1,28 & 1,26 & 1,53 & 0,93 & 0,85 & 0,00 & $-0,10$ \\
\hline CG & Desvio-padrão & 3,37 & 3,70 & 3,10 & 3,16 & 2,20 & 2,68 & 2,79 & 0,74 \\
\hline (TTS 1-2) & $\mathrm{n}$ & 20 & 20 & 20 & 20 & 20 & 20 & 20 & 20 \\
\hline & Média & 5,05 & 5,34 & 3,73 & 3,07 & 1,86 & 0,40 & 1,68 & 0,96 \\
\hline $\begin{array}{l}\text { GE } \\
\text { (TTS 1-2) }\end{array}$ & $\begin{array}{c}\text { Desvio-padrão } \\
n\end{array}$ & $\begin{array}{c}5,22 \\
? ?\end{array}$ & 4,12 & $\begin{array}{l}4,96 \\
? ?\end{array}$ & $\begin{array}{l}2,69 \\
2 ?\end{array}$ & 5,03 & $\begin{array}{c}4,90 \\
0 ?\end{array}$ & 5,06 & $\begin{array}{c}3,41 \\
? ?\end{array}$ \\
\hline
\end{tabular}

Tabela 16 - Análise da Variância (ANOVA) comparando os três efeitos estudados: Grupos, Freqüências e interação Grupos e Freqüências, na Etapa Pré-Experimental (TTS 1-2 ) para as 20 orelhas incluídas no GC e as 22 orelhas incluídas no GE.

\begin{tabular}{lc}
\hline Efeitos & Significância de $f(p)$ \\
\hline Grupos & $0,0231^{*}$ \\
Freqüências & $0,0001^{*}$ \\
Grupos x Freqüências & 0,0545 \\
\hline
\end{tabular}

A Tabela 15 representa a média e o desvio-padrão dos TTS induzidos na etapa pré-experimental (antes da inclusão das orelhas nos grupos de estudo) para as 20 orelhas incluídas no GC e para 22 orelhas incluídas no GE. 
Na análise de Variância (Tabela 16) dos TTS 1-2, medidos nas orelhas incluídas em cada grupo de estudo, foi encontrada uma diferença estatisticamente significante para o efeito grupo $\left(0,0231^{*}\right)$ e freqüência $\left(<0,0001^{*}\right)$.

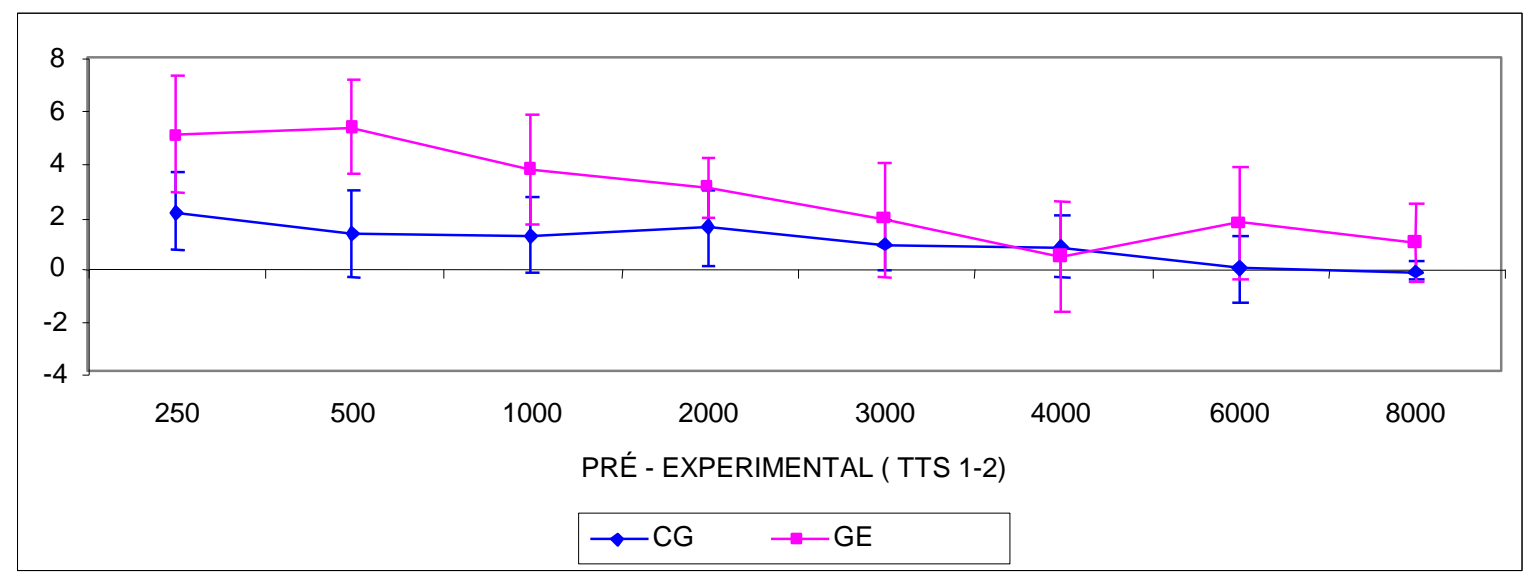

Figura 16 - Comportamento na Etapa Pré-Experimental (TTS 1-2) nas oito freqüências analisadas, para as 20 orelhas incluídas no Grupo Convencional e para as 22 orelhas incluídas no Grupo Experimental.

Por comparações múltiplas, verificou-se que houve diferenças significantes nas alterações induzidas inicialmente nas orelhas incluídas nos dois grupos distintos de estudo, nas três primeiras frequiências analisadas $(250$ a 1000Hz). A partir daí, com a redução nas alterações induzidas nos limiares auditivos nas frequiências superiores verificada nas orelhas dos dois grupos, esta diferença deixou de existir. Este comportamento diferenciado, verificado no início do estudo entre as orelhas incluídas nos dois grupos distintos, pode ser visualizado na Figura 16.

\subsubsection{0 - Análise Estatística dos TTSs Induzidos nas Orelhas Incluídas nos Dois Grupos na Etapa Pós-Experimental}

Comparou-se, para esta análise, os TTS 7 nas 22 orelhas incluídas no GE com os TTS 7 nas 20 orelhas incluídas no GC. 
Tabela 17 - Médias e desvio-padrão do TTS induzidos na Etapa Pós-Experimental (TTS 7) para as 20 Orelhas incluídas no Grupo Convencional e as 22 orelhas incluídas no Grupo Experimental nas freqüências de 250 a $8000 \mathrm{~Hz}$.

\begin{tabular}{ccccccccccc}
\hline & & \multicolumn{7}{c}{ Momentos } \\
\cline { 3 - 10 } Grupo & 250 & 500 & 1000 & 2000 & 3000 & 4000 & 6000 & 8000 \\
\hline & Média & 0,80 & 1,23 & 2,55 & 2,23 & 1,63 & 0,38 & 1,43 & 0,48 \\
GC & Desvio-padrão & 6,65 & 4,78 & 5,51 & 4,96 & 3,75 & 3,60 & 3,12 & 5,05 \\
(TTS 7) & $\mathrm{n}$ & 20 & 20 & 20 & 20 & 20 & 20 & 20 & 20 \\
\hline GE & Média & $-0,23$ & 2,11 & 2,09 & 2,39 & 0,00 & $-0,73$ & $-0,25$ & $-1,11$ \\
(TTS 7) & Desvio-padrão & 5,77 & 6,21 & 4,63 & 5,23 & 4,53 & 2,68 & 6,27 & 3,99 \\
\hline
\end{tabular}

Tabela 18 - Análise de Variância (ANOVA) comparando os três efeitos estudados: Grupos, Freqüências e interação Grupos e Freqüências, na Etapa Pós-Experimental (TTS 7) para as 20 orelhas incluídas no GC e as 22 orelhas incluídas no GE.

\begin{tabular}{cc}
\hline Efeitos & Significância de $\mathrm{f}(\mathrm{p})$ \\
\hline Grupos & 0,3283 \\
Freqüências & $0,0240^{*}$ \\
Grupos x Freqüências & 0,8511 \\
\hline
\end{tabular}

As Tabelas 17 e 18 comparam as alterações induzidas nos limiares auditivos na última etapa do estudo, para as orelhas integradas ao GC e ao GE.

A Tabela 17 representa a média e os desvio-padrão para as 20 orelhas incluídas no GC e para as 22 orelhas incluídas no GE na etapa pós-experimental (TTS 7).

Pela analise de variância (Tabela 18), verificou-se diferenças significantes no efeito freqüência $\left(0,0240^{*}\right)$ e não significantes para o efeito grupo e para a interação grupo e freqüência. 


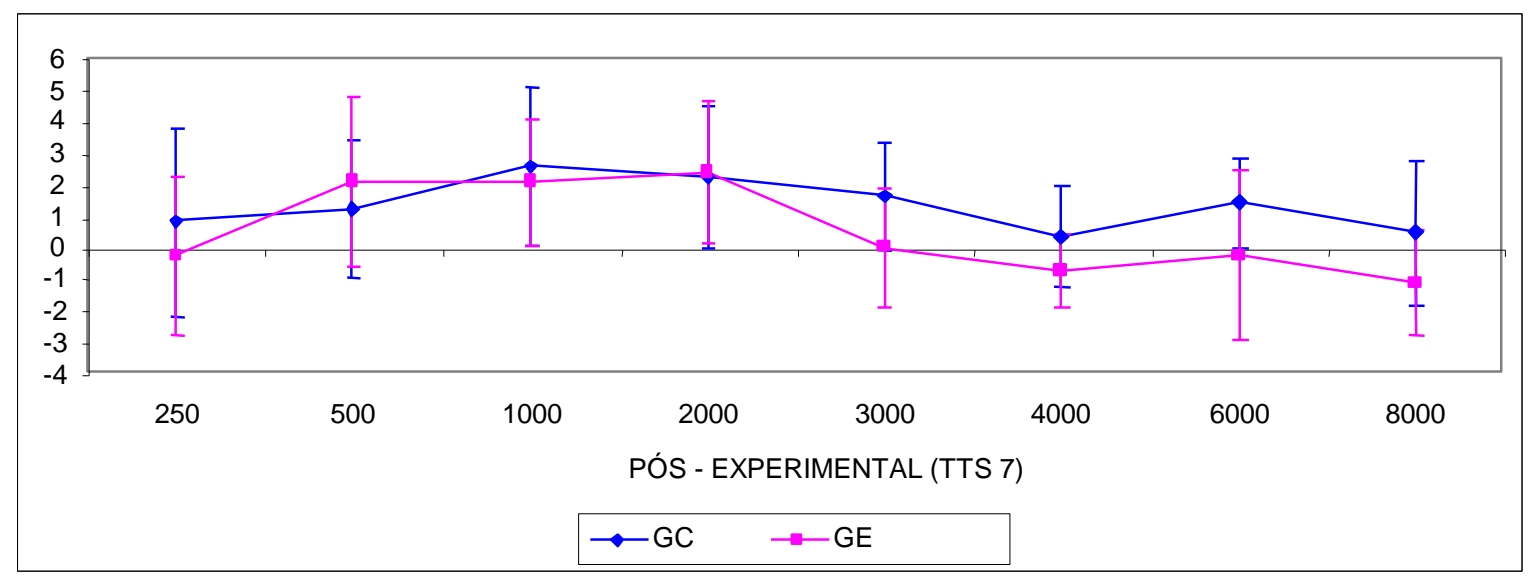

Figura 17 - Comportamento na Etapa Pós-Experimental (TTS 7) nas oito freqüências analisadas, para as 20 orelhas incluídas no Grupo Convencional e para as 22 orelhas incluídas no Grupo Experimental.

Por comparações múltiplas, observou-se um comportamento decrescente das alterações induzidas nos limiares auditivos das orelhas do GE no sentido das altas freqüências.

Observando a Figura 17, podemos verificar que quase não há diferença nos TTS 7 entre as orelhas incluídas nos distintos grupos nas freqüências abaixo de $2000 \mathrm{~Hz}$. Esta diferença passa a ocorrer a partir de 2000 Hz, devido à redução nas alterações induzidas nos limiares auditivos nas altas freqüências, verificado nas orelhas incluídas no GE no final do estudo. 


\section{5- DISCUSSÃO}

Este trabalho foi concebido com o objetivo de investigar a hipótese do desenvolvimento do efeito da resistência ou do "toughening" em orelhas com perdas auditivas pré-existentes quando sistematicamente expostas aos níveis elevados de pressão sonora, gerada durante o uso contínuo de próteses auditivas.

Para isto, as medidas das mudanças temporárias nos limiares auditivos (TTS), induzidas nas orelhas após um período determinado de exposição à ação de um ruído característico de um ambiente específico, foram usadas como método de investigação do fenômeno pesquisado.

O ruído presente neste ambiente comum, eleito como ambiente-teste deste experimento (ambulatório), se mostrou adequado como um estímulo não padronizado indutor de alterações nos limiares auditivos.

Isto pode ser comprovado porque os três parâmetros acústicos do ruído, frequiência, intensidade e duração (Figuras 2, 3 a, 3b e 4 ), que interferem na variação das mudanças temporárias dos limiares auditivos (MILLS et al, 1981; MELNICK, 1991), mantiveram uma relativa estabilidade durante os períodos controlados de exposição das orelhas à sua ação.

A pesquisa foi realizada em três etapas distintas e a análise estatística direcionada procurou identificar o comportamento dos TTSs medidos em cada uma destas etapas para os dois grupos de orelhas formados para este estudo.

Para organizar a discussão dos resultados, vamos ordená-la por etapas: 


\section{1 - Etapa Pré-Experimental}

As 42 orelhas estudadas foram inicialmente avaliadas sem a interferência da estimulação eletrônica de suas próteses auditivas. Esta medida nos permitiu observar a susceptibilidade das orelhas antes da inclusão nos dois grupos distintos, quando estas foram expostas pela primeira vez durante o estudo à ação isolada do ruído presente no ambiente-teste.

A primeira medida induzida (TTS 0) foi obtida após o primeiro período contínuo de exposição das orelhas ao ruído, desprovidas do efeito da amplificação de suas próteses auditivas. Se analisarmos esta medida (Tabela 3 e 4; Figura 8), poderemos verificar que os limiares auditivos em todas as freqüências estudadas $(250$ a $8000 \mathrm{~Hz}$ ) não se alteraram após as 2 a $2 \frac{1}{2}$ horas em que essas 42 orelhas permaneceram expostas ao estímulo-teste (RAE).

Isto veio a comprovar que a atuação isolada do ruído não foi capaz de provocar alterações estatisticamente significantes $(\mathrm{f}<0,05 \%)$ nas orelhas dos pacientes antes destes serem integrados aos dois grupos de estudo.

Ficou evidenciado também que a susceptibilidade das orelhas, posteriormente incluídas no GE, não foi diferente da observada nas orelhas posteriormente incluídas no GC, quando se considerou o efeito do estímulo-teste agindo nestas orelhas sem a interferência da amplificação das próteses auditivas adaptadas.

É admitido que os ruídos de banda larga de freqüência, como se caracterizou o estímulo-teste usado nesta pesquisa (Figura 2), não são capazes de provocar alterações transitórias significativas nos limiares auditivos das orelhas normais quando emitidos a intensidade moderadas, inferior a $76 \mathrm{dBA}$ (WARD et al,1976) . 
Segundo os dados extraídos das 67 medidas registradas sistematicamente pelo dosímetro, os níveis equivalentes de pressão sonora do estímulo-teste (RAE) mantiveram-se entre 70 a 80 dBA durante $69 \%$ do tempo de exposição das orelhas para a indução das alterações mensuradas nos limiares auditivos (Figura 3 B).

Destes dados, podemos inferir que essas 42 orelhas com perdas auditivas préexistentes, quando desprovidas do efeito de amplificação das próteses auditivas adaptadas, não demonstraram mais susceptibilidade à ação do estímulo-teste do que seria esperado encontrar nas orelhas normais se expostas às mesmas condições de estimulação.

Essa inferência tem seu suporte nos trabalhos de MILLS (1973; 1981), quando pesquisou as alterações dos limiares auditivos induzidos por um ruído de oitava de banda de freqüência, emitido durante 5 dias a uma intensidade de 80 dBNPS, em um grupo de chinchilas de audição normal e em um grupo de chinchilas com perda préexistente de aproximadamente $30 \mathrm{~dB}$ em altas freqüências. Ele encontrou menor alteração no limiar auditivo pós-exposição (threshold shift), no grupo com perda préexistente, quando comparada ao grupo normal. Entretanto, o nível da pressão sonora necessário para a detecção do estímulo pós-exposição ou o limiar alterado (shift threshold), foi o mesmo em ambos os grupos. Estes resultados, segundo o autor, confirmam a hipótese de que as orelhas com perdas neurossensoriais pré-existentes, não são mais susceptíveis aos efeitos do ruído do que as orelhas normais.

Embora os resultados tenham comprovado que as orelhas integradas aos dois grupos distintos não eram susceptíveis a ação específica deste ruído, já que este não foi capaz de alterar os seus limiares auditivos após um período contínuo de estimulação, o 
mesmo não se pode dizer quando a amplificação das próteses auditivas adaptadas foi inicialmente introduzida nas 42 orelhas estudadas.

As orelhas integradas ao GE apresentaram alterações significantes ( $f<0,05^{*}$ para o efeito medida e frequiência) nos seus limiares auditivos quando expostas à ação do ruído potencializado pela amplificação "usual” das próteses auditivas. Já para as orelhas integradas ao GC, estas alterações, embora tenham ocorrido, não foram estatisticamente significantes ( $f>0,05$ ) para os efeitos Medida, Freqüência e interação Medida e Freqüência.

Isto significa que as orelhas estudadas reagiram de modo diferenciado quando estimuladas pela amplificação gerada pelas próteses auditivas adaptadas, nesta etapa inicial do estudo.

As 22 orelhas, posteriormente integradas ao GE, apresentaram, na etapa préexperimental, mudanças temporárias nos limiares auditivos (TTS 1- 2) em uma larga faixa de freqüência $(250$ a $2000 \mathrm{~Hz}$ ), enquanto que, nas 20 orelhas integradas ao GC, só houve evidências de alterações (TTS 1-2) em uma faixa restrita às frequiências mais baixas $(250 \mathrm{~Hz})$.

Estes resultados preliminares nos permitiram identificá-las como dois grupos distintos de orelhas quanto à susceptibilidade provocada por suas próteses auditivas, quando usadas na amplificação prescrita ou preferencial.

Se a presença de alterações temporárias nos limiares auditivos por um período curto de estimulação pode ser associada às alterações permanentes possíveis de ocorrer com o uso freqüente de próteses auditivas (MACRAE, 1995), podemos considerar que as 22 orelhas integradas ao GE formaram um grupo de orelhas de risco devido a 
superamplificação gerada pelas próteses auditivas quando usadas na amplificação prescrita ou preferencial.

Portanto, no final da etapa pré-experimental, foram formados dois grupos diferenciados de orelhas para o estudo: um grupo de 22 orelhas com risco (GE) e um grupo de 20 orelhas sem risco ou com pouco risco (GC) de agravamento da perda auditiva pré-existente, atribuída a amplificação gerada pelas próteses auditivas.

Ainda na etapa pré-experimental, quando foram comparadas as médias por freqüência dos limiares auditivos dos dois grupos distintos de orelhas, verificou-se que as 22 orelhas incluídas no GE apresentavam perdas auditivas iniciais (antes da introdução das próteses auditivas), na média $10,5 \mathrm{~dB}$ superiores às das 20 orelhas incluídas no GC. Analisando os resultados, podemos observar que os limiares auditivos dos pacientes que integraram o GE eram maiores, principalmente nas frequiências de 250 a $2000 \mathrm{~Hz}$ (Figura 7).

Disto se conclui que as perdas auditivas iniciais das orelhas integradas posteriormente ao GE eram maiores do que às das orelhas integradas posteriormente ao GC. Esta diferença inicial dos limiares auditivos entre os dois grupos de orelhas também foi confirmada pelo resultado da estatística $\left(f<0,05^{*}\right.$ para os efeitos frequiências e interação grupos e frequiências).

É admitido que os limiares auditivos possam ser alterados pela amplificação gerada por próteses auditivas e que haja um incremento destes, com o aumento da potência acústica.

HUMES e BESS (1981), descreveram o efeito causado por uma prótese auditiva em limiares auditivos normais. A prótese auditiva foi testada em três níveis diferentes de amplificação (40,5; 46,2 ; 54,3 dBSPL) e de pressão sonora de saída (113; 124 e 132 
dBSPL). Eles puderam observar que as mudanças temporárias nos limiares auditivos, induzidos por um estímulo acústico de largo espectro de freqüência emitido a $70 \mathrm{dBA}$ durante 57 minutos e medidas nas freqüências de 1000 e $4000 \mathrm{~Hz}$, aumentaram com o aumento da amplificação e da pressão sonora de saída .

MACRAE (1993) estudou as diferenças nas alterações dos limiares auditivos induzidas nas orelhas protetizadas em uma estudante de 15 anos portadora de perda auditiva neurossensorial severa bilateral, observadas em dias distintos. As duas orelhas estavam adaptadas com suas próteses auditivas (modelo retroauricular Phonak PPCS), reguladas no mesmo volume (volume preferencial) durante os 5 dias de observação .Os limiares auditivos do pós-uso eram sempre medidos após um período diário de 4 horas de permanência dentro da sala de aula com as próteses auditivas em uso contínuo. O nível médio da pressão sonora, registrada por um dosímetro digital durante todo o tempo da exposição nestes cinco dias, foi de 58 dBNPS.

Segundo observações do pesquisador, ficou evidenciado que os TTSs aumentavam substancialmente nos dias em que suas próteses auditivas eram utilizadas em conjunto com um sistema FM .

Em nosso estudo anterior (DE VITTO, 2000) a correlação estatística estudada, ou seja, a média das mudanças temporárias nos limiares auditivos encontrados nas orelhas de 27 pacientes usuários monoaurais de próteses auditivas e a média da potência acústica gerada por suas próteses auditivas, foi fraca (coeficiente de Person $<0,40$ ). No entanto, quando comparamos os resultados das medidas "in situ", das médias da pressão sonora de saída e do ganho acústico por frequiência, pudemos observar que houve uma tendência ao aumento nos TTSs das orelhas protetizadas quando essas duas medidas acústicas aumentavam. 
ROSS e LERMANN (1967), ao compararem as perdas permanentes da audição, verificadas em um grupo de 18 indivíduos protetizados unilateralmente, com a potência máxima de saída de suas próteses auditivas nas frequiências de 500 a $2000 \mathrm{~Hz}$, conforme especificação encontrada nos catálogos técnicos dos fabricantes, também não conseguiram evidenciar esta relação, tendo encontrado uma fraca correlação $(c=0,21)$.

É consensual que, para haver uma correção satisfatória da audição, é necessário que a amplificação acústica da prótese auditiva esteja adequada ao grau da perda auditiva.

Portanto, já era esperado que o grupo com perdas auditivas maiores (GE), estivessem utilizando próteses auditivas mais potentes do que o grupo com perdas auditivas menores (GC).

MACRAE (1993) concluiu, ao constatar que as alterações nos limiares auditivos da jovem eram maiores nos dias em que sua prótese auditiva era usada em conjunto com o sistema FM, que a magnitude dos TTSs pode variar em um mesmo indivíduo dependendo do nível médio da pressão sonora de saída presente no interior da orelha protetizada.

Nós concordamos com esta hipótese, porque, no nosso trabalho, esta relação ficou evidenciada. A magnitude do TTS foi comparada em 18 orelhas integradas ao GE, com suas próteses auditivas reguladas em duas posições distintas do controle de volume, gerando, portanto níveis diferentes de amplificação nas orelhas protetizadas durante iguais períodos de uso: um nível "maior", quando essas próteses auditivas foram ajustadas na denominada amplificação "usual"; e um nível "menor", quando as mesmas próteses auditivas foram ajustadas na amplificação "reduzida". Nesta comparação, ficou evidenciado que os TTS induzidos após um mesmo período de uso contínuo da prótese 
auditiva ( 2 a $2 \frac{1}{2} 2$ horas), foram nitidamente maiores em todas as frequiências analisadas (250 a $8000 \mathrm{~Hz})$, quando as próteses auditivas estavam ajustadas para uma "maior" amplificação. Estas diferenças foram estatisticamente significantes para os efeitos amplificação (f <0,05*) e freqüência $\left(\mathrm{f}<0,05^{*}\right)$.

Nas orelhas avaliadas com suas respectivas próteses auditivas ajustadas em posições distintas do controle de volume durante as medidas "in situ" (Figuras 5 A e 5 B), é possível observar que, em geral, houve um aumento no REAR (nível da pressão sonora de saída em dBNPS), conforme se aumentou o REIR (amplificação ou ganho acústico medido em dB).

Podemos então atribuir o aumento da magnitude dos TTS, verificada com as próteses auditivas ajustadas para uma maior amplificação, ao aumento do nível de pressão sonora de saída, presente no interior das orelhas investigadas.

Finalizando a análise desta primeira etapa (etapa pré-experimental), podemos observar que as alterações mensuradas nas orelhas com a introdução das próteses auditivas, embora de pequena magnitude (menor que $10 \mathrm{~dB}$ ), foram estatisticamente significantes para as orelhas incluídas no GE ( $<<0,05^{*}$ para os efeitos Medidas e Freqüências).

É possível extrair destes resultados que as próteses auditivas adaptadas, ou a superamplificação gerada por estas, foi provavelmente o fator responsável por alterações nos limiares auditivos verificadas nas orelhas protetizadas quando estimuladas por um ruído, cuja ação isolada não demonstrou ter esta capacidade.

Estas alterações, induzidas nos limiares auditivos e que foram medidas logo após a introdução das próteses auditivas, podem ser atribuídas a um efeito potencializado, resultante da interação entre os dois agentes (ruído + amplificação da prótese auditiva), 
que gerou um nível de pressão sonora suficiente para alterar os limiares nas orelhas com perdas auditivas pré-existentes.

HUMES (1984) definiu, de interação ou potencialização, ao dano maior resultante da ação conjunta de dois agentes que isoladamente teriam menor efeito.

Vale observar que os limiares auditivos abaixo de $1000 \mathrm{~Hz}$ foram os que mais se alteraram após a exposição. Isto coincide com a área de maior concentração de energia do ruído ambiente presente no local (Figura 2, espectro acústico do RAE) e com a faixa de freqüência mais amplificada pelas próteses auditivas (Figura 5A e 5B, medidas “in situ”), porém, não coincide com a região das altas frequiências, área mais afetada (Figura 7) pela perda auditiva pré-existente nas orelhas integradas aos grupos de estudo.

HUMES (1984), analisando vários estudos, realizados em orelhas humanas e de animais, referentes à interação entre a exposição ao ruído e as perdas auditivas préexistentes, concluiu que, se a região da perda pré-existente não coincide exatamente com a região afetada pelo ruído experimental, o dano total resultará da soma dos dois.

Para esclarecer, ele usou o seguinte exemplo: se um ruído A produz uma perda de $20 \mathrm{~dB}$ a 500, e um ruído B produz uma perda de $20 \mathrm{~dB}$ a $4000 \mathrm{~Hz}$, quando se apresentam juntos, resultaram em uma perda auditiva combinada de $20 \mathrm{~dB}$ em $500 \mathrm{~Hz}$ e 20 dB em 4000 Hz. Portanto, um ruído de baixa freqüência não interage com um ruído de alta frequiência e vice-versa. Desta forma, segundo ele, uma exposição a um ruído de baixa freqüência resultará em uma alteração restrita às regiões de maior sensibilidade à baixas freqüências do órgão auditivo.

As perdas permanentes da audição, verificadas em pacientes usuários freqüentes de próteses auditivas, parecem estar associadas às alterações transitórias nos limiares 
auditivos que ocorrem nas orelhas protetizadas após um período contínuo de uso diário de suas próteses auditivas.

MACRAE (1995) estudou a degeneração encontrada nos limiares auditivos de 500 a $4000 \mathrm{~Hz}$, constatada em seu estudo anterior (MACRAE, 1991), em um grupo de oito crianças, após 7 anos de uso continuo de suas próteses auditivas. Ele observou uma concordância na faixa de freqüência de 500 a $2000 \mathrm{~Hz}$ entre essas degenerações, e as alterações transitórias assimptóticas dos limiares auditivos, previstas após 8 horas de uso contínuo de suas próteses auditivas, expostas à um nível médio de ruído (Aweighted sound pressure level) de 65,5dBA, correspondente a um Leq de 82,5 dBA.

Destes dados, podemos concluir que as próteses auditivas, ou melhor, a amplificação gerada por estas, pode representar um fator inerente de risco para o aumento das lesões pré-existentes nas orelhas protetizadas.

Este risco, evidentemente, é maior quando se usam próteses auditivas mais potentes como ocorre nas orelhas de pacientes com perdas auditivas severas a profundas. Também pode existir para aqueles pacientes com perdas auditivas menores, mas que preferem usar excessiva amplificação.

Isto pode ser real, já que, na presente pesquisa, o aumento no nível da amplificação acústica gerada pelas próteses auditivas adaptadas nas orelhas integradas ao GE, pareceu aumentar significantemente as alterações induzidas nos limiares auditivos das orelhas protetizadas, quando estas permaneceram expostas à ação do estímulo-teste por períodos de tempo iguais, com suas próteses auditivas ajustadas para diferentes níveis de amplificação.

Para as orelhas integradas ao GE, é possível extrair, relacionando as Figuras 5A e 5B, que representam a média das medidas "in situ" com suas próteses auditivas 
ajustadas em duas distintas posições do controle de volume, com a Figura 11, que representa a média dos TTS induzidos nas orelhas com suas próteses auditivas ajustadas nas mesmas posições, que a potência gerada pelas próteses auditivas adaptadas nas orelhas integradas ao GE não foi capaz de induzir alterações significantes nos seus limiares auditivos quando a amplificação gerada por elas foi reduzida, ou seja, quando estas foram usadas abaixo do ganho acústico prescrito ou preferencial. No entanto, quando essas mesmas próteses auditivas foram ajustadas no ganho prescrito ou preferencial (amplificação “usual”), as alterações induzidas nos seus limiares auditivos aumentaram significantemente em todas as freqüências analisadas.

Quanto às orelhas com perdas auditivas menores (média $=87,21$ dBNA), incluídas no GC, a potência gerada por suas próteses auditivas ajustadas no ganho prescrito ou preferencial (amplificação “usual”), pareceu não causar alterações expressivas em seus limiares auditivos.

Destes dados, podemos considerar que a amplificação/ganho acústico freqüentemente usado por pacientes com perdas auditivas neurossensoriais acima de 90 dBNA, parece oferecer um risco potencial de superamplificação quando suas próteses auditivas são utilizadas em ambientes acústicos convencionais, com níveis de ruído próximos aos medidos no ambulatório (70 a 80 dBA).

Os resultados desta pesquisa parecem comprovar os estudos teóricos de MACRAE (1994), associando às mudanças transitórias assimptóticas dos limiares auditivos (ATS), que se espera ocorrer diariamente após um período contínuo (aproximadamente 8 horas) de uso de próteses auditivas, às mudanças permanentes atribuídas ao efeito cumulativo da amplificação gerada por estas. 
Neste estudo, ele concluiu que a amplificação gerada pelas próteses auditivas adaptadas para pacientes com perdas auditivas menores que 60 dBNA, dentro dos critérios recomendados pela NAL, não causam ATS (asymptotic threshold shift) nas orelhas protetizadas, se usadas em ambientes com nível de pressão sonora próximos à 61 dBNPS.

Para as perdas auditivas maiores que $60 \mathrm{dBNA}$, pequenas quantidades de ATS são esperadas de ocorrer durante o uso contínuo de próteses auditivas, mas esses são seguros, exceto para os pacientes com perdas auditivas superiores à 100 dBNA, para os quais a quantidade de amplificação requerida para a compensação adequada de suas perdas auditivas, é sempre um fator de risco.

Ele também atribuiu ao uso de próteses auditivas com excessivo REIR (real ear insertion gain), em ambientes com níveis elevados de pressão sonora, a causa provável de perdas permanentes na audição encontrada em usuários com PTAs (three frequency average pure tone thresholds) igual ou maior que $50 \mathrm{dBNA}$.

Segundo o autor, pacientes que preferem usar ganho de inserção (REIR) superior ao recomendado na regra de prescrição para o ganho acústico das próteses auditivas em função do grau da perda auditiva, desenvolvida pela NAL (National Acoustic Laboratories), deveriam evitar usá-las em ambientes com nível elevado de pressão sonora (em torno de 75 dBNPS).

Esta primeira etapa nos permitiu identificar os dois grupos distintos, formados para a continuidade deste estudo. Também definiu os parâmetros de comparação com as duas etapas subseqüentes, permitindo acompanhar o efeito ou o comportamento nas mudanças temporárias induzidas nos limiares auditivos das 42 orelhas analisadas durante o período integral este estudo. 


\section{2 - Etapa Experimental}

A partir da etapa pré-experimental, todos os pacientes do Grupo Experimental, portanto o nosso grupo de maior risco, tiveram a amplificação "usual" (ganho acústico prescrito ou preferencial) reduzida durante o período proposto para o "treinamento" das suas orelhas.

Isto significa que, durante este período (60 a 90 dias), as orelhas incluídas no Grupo Experimental, passaram a ser estimuladas regularmente em uma condição bastante similar à das orelhas integradas ao Grupo Convencional, já que a amplificação "reduzida" de suas próteses auditivas, geravam uma pressão sonora de saída equivalente à gerada nas orelhas protetizadas do GC, com suas próteses auditivas ajustadas na amplificação "usual” (medidas "in situ” Figura 5 A e 5 B).

No entanto, quando vinham ao ambulatório para as medidas das alterações induzidas em seus limiares auditivos, esta condição se diferenciava. As orelhas incluídas no GE, estimuladas durante o uso regular de suas próteses auditivas com uma “menor" amplificação, passavam a ser estimuladas durante o período de permanência no ambulatório (2 a 2 1⁄2 h), com uma "maior" amplificação.

Para as orelhas incluídas no $\mathrm{GC}$, esta diferença na estimulação foi pouco expressiva, já que se procurou manter, no ambulatório, a mesma amplificação utilizada durante o uso regular de suas próteses auditivas.

Na primeira avaliação da etapa experimental (TTS 3), os pacientes da amostra já estavam distribuídos nos seus respectivos grupos de estudo, e, portanto, já estavam recebendo uma estimulação diferenciada quando expostos às condições experimentais no ambulatório. 
Se compararmos o TTS 1-2 com o TTS 3, veremos que houve um nítido aumento nas alterações induzidas para as orelhas incluídas no GE nas frequiências de 250 a 4000 Hz e reduções nas freqüências mais altas $(6000$ e 8000 Hz).

Se analisarmos estas duas medidas (TTS 1-2 / TTS 3) para as orelhas incluídas no GC nestes mesmos momentos, veremos que houve um comportamento mais irregular, com aumentos em $500 \mathrm{~Hz}, 2000 \mathrm{~Hz}, 3000 \mathrm{~Hz}, 4000 \mathrm{~Hz}$ e reduções em $250 \mathrm{~Hz}, 1000 \mathrm{~Hz}$, $6000 \mathrm{~Hz}$ e $8000 \mathrm{~Hz}$.

Este aumento nos TTS das incluídas no GE no inicio (TTS 3) da etapa experimental, pode ser atribuída a mudança inicial no padrão de estimulação destas orelhas: as orelhas estimuladas com uma "menor" amplificação durante os primeiros 15/35 dias de treinamento (uso externo), foram estimuladas com uma "maior" amplificação durante um período de 2 a 2 1⁄2 horas de permanência no ambulatório.

Esta estimulação inicial com dois estímulos subseqüentes, um de "menor" intensidade e um de "maior" intensidade, resultou, inicialmente, em um aumento significante nas alterações induzidas nos limiares auditivos para as orelhas incluídas no GE.

VOLDRICH (1979), expôs um grupo de 10 chinchilas com perdas auditivas préexistentes, a um ruído experimental de 1/3 de oitavas, emitido a $145 \mathrm{~dB}$ por 5 minutos, e, em seguida, ao mesmo ruído emitido a $90 \mathrm{~dB}$ por 30 minutos. A metade do grupo foi exposta a ambos os ruídos e a outra metade foi exposta somente ao ruído mais intenso. Ele observou que a extensão do dano ao longo da membrana basilar foi mais aumentada no grupo exposto aos dois ruídos $(7,25 \mathrm{~mm})$, do que no grupo exposto somente ao ruído mais elevado (2,73mm). Quanto ao grupo controle, submetido somente ao ruído de 
menor intensidade (90 dB), não houve alterações significativas na área previamente lesada.

É provável que este aumento nas alterações induzidas nas orelhas incluídas no GE, verificadas no inicio da etapa experimental, possa ser resultado de um efeito similar.

As orelhas incluídas no GE estavam sendo estimuladas regularmente, com uma amplificação mais "baixa", durante o uso externo de suas próteses auditivas na etapa experimental. O efeito desta "menor amplificação", embora pareça não ter provocado alterações importantes nos seus limiares auditivos, se comparadas as alterações induzidas na "maior amplificação" (Figura 11), pode ter contribuído para aumentar inicialmente a área sensibilizada pelo ruído nas cócleas afetadas.

Isto ocorreu quando estas orelhas, estimuladas durante os primeiros 15 a 35 dias com uma "menor amplificação", foram submetidas a uma condição de "maior amplificação", gerando um maior nível de pressão sonora no interior das orelhas protetizadas.

O fato de este aumento ter ocorrido de modo expressivo no inicio da etapa experimental (TTS 3), tendendo a redução nas medidas subseqüentes (TTS $4,5,6$ ) conduz a hipótese de que, nos primeiros dias (15/35 dias), após a alteração no padrão de estimulação, o sistema auditivo das orelhas integradas ao GE estivesse ainda se reorganizando para se reajustar a esta nova mudança.

Na medida seguinte da etapa experimental (TTS 4) já se observa, para as orelhas integradas ao GE, uma tendência a redução nas alterações induzidas nos limiares auditivos de 250 a $4000 \mathrm{~Hz}$ com relação a medida anterior (TTS 3): 5,55/ 4,16 dB; 6,68/3,64 dB; 5,23/4,82 dB; 4,66/3,32 dB; 2,61/1,09 dB; 2,14/1,05 dB. Interessante é 
que esta redução ocorreu exatamente na mesma faixa de freqüência $(250$ a 4000Hz), onde foi observado, inicialmente, um aumento nestas alterações induzidas.

Se analisarmos o que ocorreu para as orelhas incluídas no GC, veremos que também houve uma redução nas alterações induzidas nos limiares auditivos neste mesmo momento (TTS 4). Esta redução ocorreu em praticamente toda a faixa de freqüência e continuou a ocorrer nas freqüências mais graves $(250 \mathrm{~Hz})$, nas medidas posteriores da etapa experimental (TTS 4,5 e 6 ).

Na amostra estudada, $72 \%$ das quarenta e duas orelhas incluídas no estudo, já utilizavam suas próteses auditivas a aproximadamente três meses antes de serem introduzidas nos seus respectivos grupos de estudo.

Considerando que a medida do TTS 4 ocorreu, em média, 36/50 dias após a introdução da amplificação "usual" das próteses auditivas adaptadas no estudo, é possível inferir que, nas orelhas adaptadas com próteses auditivas, cuja amplificação gerada não interage ou não potencializa o efeito do ruído, uma redução nos TTS induzidos inicialmente durante os períodos diários de uso contínuo das próteses auditivas poderá ocorrer já nos primeiros seis meses de aclimatização das orelhas protetizadas.

Aclimatização foi o termo definido em 1989 por Gatehouse (SAUNDERS e CIENKOWSKI, 1997) para designar o aumento dos benefícios da amplificação das próteses auditivas observados nos primeiros meses de uso.

Para as orelhas incluídas no GE, esta redução nas alterações induzidas nos limiares auditivos, iniciada após 36/50 dias de treinamento (uso regular das próteses auditivas na amplificação reduzida), parece ter se processado de um modo gradual nos momentos subseqüentes. 
MIYAKITA et al. (1992), conseguiu verificar a capacidade das orelhas humanas normais em desenvolver resistência, ou "thoughening", a estimulação sonora elevada, quando gradualmente treinada com um estimulo de menor intensidade .

O TTS foi induzido por um estímulo de banda estreita ( $1 / 3$ de oitava a $2 \mathrm{kHz})$, emitido a um nível elevado de pressão sonora (105 dBNPS), por 2 minutos.

As orelhas dos oito jovens normo-ouvintes (de 12 a 16 anos), que concluíram este experimento, apresentaram TTS mensuráveis na faixa de freqüência de 2 a $6 \mathrm{KHz}$, quando inicialmente expostos (pré-treinamento) ao estímulo usado como estímulo-teste.

Esse valor inicial do TTS obtidos antes do treinamento serviu como valorreferência e foi comparado, posteriormente, ao TTS medido durante e após a etapa de treinamento.

O treinamento das orelhas foi realizado com um estimulo sonoro de menor intensidade (70dBA) e de banda larga de freqüência (seleção musical), emitido durante exposições interrompidas de 6 horas por dia, durante nove dias consecutivos.

Uma redução estatisticamente significante $(\mathrm{p}<0,05)$ no TTSs inicial foi observada no $5^{\circ}$ dia de treinamento, correspondendo a uma redução de $3,7 \mathrm{~dB}$ ou de $25 \%$, relativo aos valores iniciais (ou referência).

Esta redução aumentou gradativamente com a continuidade do treinamento: 4,7 $\mathrm{dB}$ ou $31 \%$ ( $\left.7^{\circ} \mathrm{dia}\right)$ e $8,1 \mathrm{~dB}$ ou $54 \%$ ( $\left.9^{\circ} \mathrm{dia}\right)$. Portanto no final do treinamento havia ocorrido uma redução total de 54\% em relação ao TTSs inicial.

No $5^{\circ}$ dia de treinamento, esta redução ocorreu em uma faixa estreita de freqüências (3-3,5 kHz). Porém, no $9^{\circ}$ dia, se estendeu a uma larga faixa de freqüências (2 a $5 \mathrm{kHz})$. 
Considerando que esta redução foi estatisticamente significante no $5^{\circ}$ dia de treinamento, isto significa que, após um período relativamente curto de treino (30 horas), já se constatou uma redução expressiva na susceptibilidade das orelhas normais quando expostas repetidamente ao mesmo estímulo sonoro elevado.

Embora tenha se verificado uma redução significativa, esta se restringiu a uma faixa de freqüência menor do que a afetada originalmente pela estimulação traumática.

Com a continuidade do treinamento, verificou-se que essa redução se estendeu também para outras freqüências, afetadas inicialmente pelo ruído traumático.

Portanto, 54 horas após o inicio do treinamento $\left(9^{\circ} \mathrm{dia}\right)$, praticamente $54 \%$ da susceptibilidade das orelhas normais, quando expostas repetidamente ao mesmo estimulo traumático (105 dBNPS/10 minutos), havia se reduzido em uma larga faixa de freqüência, inicialmente afetada pela estimulação traumática.

A comparação dos estudos de MIYAKITA et al. (1992) com o presente estudo é difícil, um vez que as duas pesquisas foram realizadas em populações e em condições bem distintas.

Nosso trabalho avaliou orelhas com perdas auditivas pré-existentes e que já vinham sendo estimuladas à aproximadamente 3 meses, com níveis elevados de pressão sonora gerado por suas próteses auditivas, antes da redução do estímulo sonoro proposto para o treinamento destas orelhas.

No entanto, foi possível observar semelhanças nos resultados das duas pesquisas, o que nos permitiu traçar alguns paralelos.

O estímulo traumático (ruído ambiente potencializado pela amplificação das próteses auditivas em uso), induziu alterações transitórias significantes nos limiares auditivos (TTS) das orelhas protetizadas do GE, antes do treinamento destas. 
Este TTS inicial, observado nas orelhas protetizadas do GE na etapa préexperimental (TTS 1-2 ), ocorreram principalmente na faixa de freqüência de 250 a $2000 \mathrm{~Hz}$.

Excetuando o aumento verificado nos primeiros dias após o inicio do treinamento, o TTS das orelhas com perdas auditivas pré-existentes, quando expostas repetidamente a um mesmo estímulo traumático, também foi gradativamente se reduzindo na medida em que o treinamento se processava.

Nos estudos de MIYAKITA et al. (1992), no $5^{\circ}$ dia de treinamento, 25\% das alterações iniciais nos limiares auditivos, induzidas nos limiares auditivos dos jovens expostos ao estímulo traumático, havia se reduzido em uma faixa estreita $(3-3,5 \mathrm{kHz})$, menor do que a afetada inicialmente pelo ruído. Porém, no último dia de treinamento $\left(9^{\circ}\right.$ dia), as alterações iniciais induzidas nos limiares auditivos haviam se reduzido em $54 \%$ e se estendido em uma larga faixa de freqüência ( 2 a $5 \mathrm{kHz})$.

No presente trabalho, também foi verificada uma redução dos TTSs durante a etapa de treinamento para as orelhas incluídas no GE, porém em uma faixa mais estreita.

Na última etapa do treinamento (TTS 6), $26 \%$ das reduções nas alterações dos limiares auditivos das orelhas do GE já haviam ocorrido nas freqüências graves (abaixo de $1000 \mathrm{~Hz}$ ), portanto, em uma faixa menor do que a afetada inicialmente pela ação do ruído amplificado pela prótese auditiva $(250$ a $2000 \mathrm{~Hz})$.

\section{3 - Etapa Pós-Experimental}

Na seqüência da pesquisa de MIYAKITA et al. (1992), depois de cessado os 9 dias consecutivos de treinamento, os pacientes foram instruídos para usar tampões (ear 
plug) nas duas orelhas, durante 6 horas por dia. Isto ocorreu durante um intervalo de três dias, no qual os testes foram suspensos.

De quatro a seis dias após o termino do treinamento, ocorreu a última etapa do estudo ou o pós-treino.

Nesta etapa, os TTS nas orelhas dos 8 jovens foram novamente induzidos pelo mesmo estímulo traumático, uma vez por dia, durante cinco dias.

O que se verificou nesta etapa pós-treino foi que os TTSs aumentaram significantemente $(\mathrm{p}<0,05)$ em uma larga faixa de freqüências, quando foram comparados aos TTSs observados no último dia do treino ( $9^{\circ}$ dia), aproximado-se dos valores iniciais de referência (pré-treino).

Como o efeito do treinamento quase desapareceu quatro dias após o último dia de treinamento, os autores concluíram que o efeito do treinamento observado nas condições usadas no experimento não foi persistente.

Comparando os resultados do pós-treino, observados na pesquisa de MIYAKITA et al (1992), com resultados do presente estudo, observados na mesma etapa para as orelhas incluídas no GC (não treinadas), podemos verificar uma semelhança no comportamento dos TTS.

O TTS observado no momento final do estudo (TTS 7), para as orelhas protetizadas integradas ao GC, também aumentou (Figura 15). Embora este aumento não tenha sido estatisticamente significante ( $f>0,05$ ), ocorreu em praticamente todas as freqüências, com exceção das baixas freqüências (inferiores a $1000 \mathrm{~Hz}$ ), onde o TTS gradualmente reduzido nos momentos anteriores (TTS 3 a TTS 6) se manteve inferior ou praticamente igual ao inicial (TTS 1-2). 
Com relação às orelhas com perdas pré-existentes treinadas (GE), notou-se um comportamento bem diferenciado se comparado ao observado nas orelhas com perdas pré-existentes não treinadas (GC) e nas orelhas normais treinadas (MIYAKITA, 1992), após o término do treinamento (etapa pós-experimental ou pós-treino).

O TTS, no momento final do estudo (TTS 7), foi o mais baixo verificado desde a introdução no estudo (TTS 1-2) do efeito da amplificação “usual” gerada pelas próteses auditivas adaptadas nas orelhas integradas ao GE.

Se voltarmos nossa atenção ao que ocorreu na etapa pré-experimental deste estudo, quando não havíamos ainda introduzido a proposta de treinamento para as orelhas posteriormente incluídas no GE, poderemos observar que o TTS induzido no inicio deste estudo (TTS 1-2) nas orelhas adaptadas com suas próteses auditivas usadas na amplificação prescrita/preferencial, apresentou diferenças estatisticamente significantes entre os dois grupos de orelhas analisadas neste mesmo momento ( $<$ < $0,05^{*}$ para os efeitos grupos e freqüências). Estas diferenças resultaram do aumento do TTS verificado nas orelhas incluídas no GE, principalmente nas freqüências de 250 a 2000 Hz. (Figura 16).

As diferenças encontradas neste momento inicial do estudo foram atribuídas a maior amplificação nas baixas frequiências nas próteses auditivas adaptadas nos pacientes com perdas auditivas maiores, posteriormente incluídos no GE.

Quando, no entanto, se comparou o TTS induzidos no final (TTS 7), quando as orelhas incluídas no GE já haviam terminado o treinamento, foi possível observar que as diferenças encontradas no inicio do estudo (Figura 16) nos TTS dos dois grupos de orelhas na faixa de freqüência de 250 a $2000 \mathrm{~Hz}$, foi reduzida neste momento final (Figura 17). 
A análise estatística, comparando o momento final (TTS 7) para os dois grupos, não mostrou significância para o efeito grupo (f $>0,05^{*}$ ) e para o efeito integrado grupo e freqüência ( $\mathrm{f}>0,05^{*}$ ), mas foi significante para o efeito freqüência ( $\mathrm{f}<0,05^{*}$ ). $\mathrm{O}$ teste de comparações múltiplas, aplicado para identificar esta diferença, permitiu observar que esta ocorreu devido ao comportamento decrescente das alterações induzidas nos limiares auditivos nas altas freqüências, verificado nas orelhas incluídas no GE.

Disto podemos observar que, não só a magnitude das alterações, induzidas nos limiares auditivos na faixa de freqüência inicialmente afetada pela alta amplificação das próteses auditivas (250 a $2000 \mathrm{~Hz}$ ) adaptadas nas orelhas incluídas no GE, foi reduzida à um nível compatível às induzidas pela amplificação menor das próteses auditivas adaptadas nas orelhas incluídas no GC, como também os TTS, induzidos nas altas freqüências nas orelhas protetizadas incluídas no GE, foram menores que os induzidos nas orelhas protetizadas incluídas no GC no final deste estudo.

Deste modo, parece que as orelhas com perdas auditivas maiores aumentaram a susceptibilidade quando expostas inicialmente aos níveis elevados de pressão sonora gerado pela alta potência das próteses auditivas adaptadas, desenvolvendo, no decorrer do estudo, um sistema de proteção mais eficiente se comparado ao das orelhas com perdas auditivas menores, submetidas a uma condição menos traumática durante o uso de suas próteses auditivas.

Com isto, o que se pôde observar é que as alterações ou as mudanças temporárias dos limiares auditivos, provocadas inicialmente nas orelhas incluídas no GE pela alta potência gerada por suas próteses auditivas, parecem ter se reduzido durante e após o treinamento destas. 
As reduções nas alterações induzidas nos limiares auditivos das orelhas incluídas no GE, iniciadas na etapa de treinamento destas orelhas, continuaram a ocorrer até mesmo depois de cessado o treinamento, quando essas orelhas voltaram a ser novamente estimuladas com os níveis elevados de pressão sonora, gerados durante o uso regular das próteses auditivas adaptadas na amplificação inicial (prescrita ou preferencial).

$\mathrm{Na}$ última etapa do treinamento (TTS 6), 26 \% das reduções nas alterações dos limiares auditivos já haviam ocorrido em uma faixa restrita das freqüências alteradas inicialmente pela exposição traumática (abaixo de $1000 \mathrm{~Hz}$ ).

No entanto, um percentual maior (62 \%) de redução nas alterações iniciais induzidas nos limiares auditivos antes do treinamento, foi verificado após o término do treinamento para as orelhas incluídas no GE. Esta redução final foi verificada na faixa de freqüência inicialmente afetada pela alta amplificação das próteses auditivas (250 a $2000 \mathrm{~Hz})$.

Isto significa que a susceptibilidade inicial das orelhas com perdas auditivas maiores expostas à uma condição traumática, representada pela alta potência gerada durante o uso contínuo de próteses auditivas, foi significativamente reduzida.

Esta redução ocorreu na faixa de risco, gerado pela superamplificação das próteses auditivas mesmo depois de cessado o treinamento, quando as orelhas voltaram a ser novamente estimuladas com níveis elevados de pressão sonora.

Portanto, ao contrário do efeito de curta duração (4 dias após o término do treino), verificada no treinamento de orelhas normais nas condições experimentais empregadas por MIYAKITA et al. (1992), as condições experimentais utilizadas para o treinamento das orelhas com perdas pré-existentes, demonstrou um efeito mais persistente, já que a 
avaliação final deste estudo foi realizada, em média, 30 dias após o término do treinamento.

Em um trabalho realizado por CANLON et al. (1991), as orelhas de um grupo de coelhos adquiriram resistência depois de treinadas com um estímulo de baixa intensidade durante 256 horas. Quando este grupo foi posteriormente mantido em um ambiente ruidoso durante 2 semanas a 1 mês e novamente expostos ao mesmo ruído traumático, a resistência adquirida durante o treinamento ainda estava presente.

Estes dados são compatíveis com os observados na última etapa do presente estudo. As orelhas do GE, treinadas durante 60/90 dias com um estímulo de menor amplificação, desenvolveram resistência gradual quando expostas repetidamente a uma mesma condição traumática. Trinta a trinta e cinco dias após cessar o treinamento, estas orelhas foram novamente expostas a mesma condição traumática e a resistência, não só aumentou na faixa de freqüência mais afetada, como até se estendeu para uma faixa superior, inicialmente pouco afetada pelo estímulo traumático. Vale lembrar que, nesta etapa final, os pacientes incluídos no GE já estavam liberados para usar suas próteses auditivas na amplificação prescrita ou preferencial (amplificação maior).

Na pesquisa de MIYAKITA, et al. (1992), os TTS do pós-treino, verificados após a exposição ao mesmo estímulo traumático (105 dBNPS por 10 minutos), aumentaram novamente, aproximando-se dos TTSs iniciais ou de referência (pré-treino).

No entanto, um dado interessante deste trabalho foi observado na última avaliação do pós-treino, quando se verificou uma nova redução no TTS, especialmente nas altas frequiências (3 a $5 \mathrm{kHz}$ ), região de maior sensibilidade das orelhas quando inicialmente expostas ao ruído traumático usado neste experimento (freqüência central em $2000 \mathrm{~Hz}$ ). 
Segundo os autores, talvez exista um certo mecanismo comum que possibilitou o "regatilho" do efeito, e, se isto ocorreu, há que se considerar a possibilidade de que também os ruídos aos quais as orelhas permaneceram expostas durante o período de treinamento, possam ter contribuído, parcialmente, para a redução dos TTS ou para o aumento da resistência das orelhas observados nesta etapa.

No nosso trabalho, embora não tenha havido uma alteração estatisticamente significante nos limiares auditivos para as orelhas incluídas no GC durante o período do estudo, verificou-se uma tendência ao aumento inicial no TTS para as freqüências mais baixas $(250 \mathrm{~Hz})$ e que pode ser atribuído a ação potencializada do ruído do ambulatório (RAE), amplificado pela potência gerada pelas próteses auditivas nesta faixa de freqüência.

Analogamente ao ocorrido nas orelhas integradas ao GE, este aumento inicial nas baixas freqüências, verificada no GC, também foi seguido por uma redução gradual nos momentos subsequientes .

Parece que aqui podemos falar de um efeito protetor mais atuante nas baixas frequiências e que foi possivelmente ativado pelo alto nível de pressão sonora gerado nas orelhas protetizadas nesta região, já que a energia do ruído presente no ambulatório concentrava-se, principalmente, nas freqüências inferiores a $1000 \mathrm{~Hz}$.

Acreditamos que este mecanismo, que possibilitou a redução do TTS relativo aos seus valores iniciais nas baixas frequiências para as orelhas incluídas no GC (e também para as incluídas no GE), mas que não teve o mesmo efeito para as frequiências mais altas, esteja relacionado ao mecanismo de proteção da orelha interna exercido pela orelha média (em especial pelo estapédio), efeito este que já foi comprovado em 
inúmeros trabalhos (REGER, 1960; MOLLER, 1965; WARD, 1965; ZAKRISSON et al, 1980; RYAN et al, 1994).

Parece que este efeito pode ser exercitado pelas orelhas expostas a níveis elevados de pressão sonora, hipótese esta aventada nos trabalhos de CANLON (1988) como uma das justificativas para o aumento da resistência às perdas permanentes desenvolvida nas orelhas de cobaias .

A redução gradual das alterações transitórias dos limiares auditivos, verificada nas orelhas incluídas no GE, ocorreu em toda a faixa de freqüência, inclusive nas freqüências agudas.

Alguns trabalhos têm demonstrado que a orelha média é pouco eficiente na proteção da orelha interna nas altas frequiências. Esta função tem sido creditada ao sistema eferente, em especial o ramo eferente medial, agindo no controle da motilidade das CCE.

Acreditamos ser pouco provável que a redução gradativa nas alterações nos TTS verificada no decorrer do treinamento das orelhas protetizadas possam ter sido mediadas pelo sistema eferente medial. As orelhas integradas ao GE apresentavam, na média, perdas auditivas profundas e, nas orelhas com perdas auditivas superiores a $60 \mathrm{~dB}$, essas estruturas não costumam estar mais presentes.

Gatehouse (1989), usou o termo "aclimatização", ao testar a habilidade de reconhecimento de palavras em um grupo de usuários monoaurais de próteses auditivas.

Ele observou que nas duas orelhas testadas, a protetizada e a não protetizada, esta habilidade melhorava quando o sinal de fala era mais alto, embora, nas orelhas protetizadas, a habilidade para o reconhecimento da fala em níveis mais altos tenha sido 
superior à das orelhas não protetizadas. No entanto, a habilidade para o reconhecimento da fala em níveis mais fracos foi mais favorecida nas orelhas não protetizadas.

A interpretação dele para estes resultados foi que as orelhas não protetizadas estavam acostumadas a processar a fala em níveis mais fracos e, assim, estariam mais adaptadas a esta condição do que as orelhas protetizadas, que recebem a maioria dos sons amplificados e, portanto, mais altos.

Experiências com animais têm demonstrado que as áreas da córtex auditivo que foram originalmente designadas para processar determinadas informações sensoriais, mas cujos sinais de entrada não estariam mais presentes, passariam a processar novas informações sensoriais advindas de sinais de entrada ativos. Exemplificando, se uma pessoa tem uma perda auditiva em alta frequiência, as áreas corticais que estariam processando os sinais de entrada de alta freqüência, poderiam passar a processar sinais de entrada de baixa frequiência. Caso, após algum tempo de privação, o sinal de entrada de alta freqüência for restabelecido por algum tipo de dispositivo ou prótese, não haverá espaço disponível para que esses novos sinais periféricos possam ser devidamente processados no córtex auditivo (PALMER, 1995; IRVINE et al, 2001).

Isto poderia explicar o fenômeno da aclimatização das orelhas, identificado por Gatehouse (1989) nos usuários de próteses auditivas: a orelha que recebe freqüentemente estímulos de entrada fracos (orelha não protetizada) e raramente recebe estímulos altos, provavelmente terá pouco espaço para processá-lo. De maneira análoga, a orelha protetizada, que em geral só recebe estímulos altos, terá pouco espaço para processar estímulos fracos, já que raramente os recebe (PALMER, 1995).

Este mesmo raciocínio poderia ser aplicado para explicar o aumento da resistência das orelhas protetizadas quando expostas, repetidamente, a sons de alta intensidade: a 
orelha, antes da adaptação da prótese auditiva, estava acostumada a processar somente estímulos fracos, e, portanto, teria uma área cortical reduzida para o processamento eficiente de estímulos altos. À medida que passou a receber os estímulos amplificados através do uso sistemático da prótese auditiva, áreas corticais apropriadas foram sendo gradativamente desenvolvidas, com conseqüente melhora no processamento auditivo para os estímulos sonoros elevados. Isto resultou em um sistema auditivo mais eficiente na proteção da orelha interna durante as exposições traumáticas.

É evidente que a disponibilidade de áreas para restabelecer a representatividade dos novos sinais periféricos em alguma região do córtex auditivo não é um efeito imediato e, provavelmente, ocorra de forma gradual.

Os estudos têm sugerido que a aclimatização das orelhas tem como bases fisiológicas a plasticidade do cérebro (ROBINSON e GATEHOUSE, 1995).

Nos últimos 15 - 20 anos, inúmeras pesquisas evidenciam que as propriedades dos campos receptivos dos neurônios das áreas primárias do córtex sensorial têm uma capacidade imensa de plasticidade, mesmo na idade adulta. No caso específico do sistema auditivo, lesões cocleares em áreas restritas, produzidas por uma variedade de técnicas em animais adultos de várias espécies (incluindo os simius primatas), resultaram em mudanças na representatividade da cóclea na córtex auditiva primária (IRVINE et al, 2001).

O desenvolvimento da resistência, verificada nas orelhas com perdas auditivas profundas incluídas no GE, pode estar ligada à plasticidade do sistema auditivo.

Os 25 pacientes escolhidos para integrar este estudo eram todos usuários recentes de próteses auditivas. Um percentual significativo (72\%) das 42 orelhas analisadas estava sendo estimulado regularmente com suas próteses auditivas há menos de três 
meses, estando, portanto, na denominada fase de "aclimatização", que se processa gradualmente após a introdução do "novo estímulo".

O aumento da resistência, verificado nas orelhas protetizadas incluídas neste estudo, ficou evidenciado durante esta fase, cujas bases fisiológicas são atribuídas ao fenômeno da plasticidade.

\section{4 - Considerações Finais}

$\mathrm{Na}$ amostra estudada, as próteses auditivas adaptadas nas orelhas incluídas no GC, reguladas na amplificação prescrita ou preferencial, e as próteses auditivas adaptadas nas orelhas incluídas no GE, quando ajustadas na amplificação reduzida usada durante o período de treinamento, geraram um nível de pressão sonora de saída no interior do CAE que não foi capaz de causar alterações expressivas nos limiares auditivos das orelhas com perdas auditivas severas a profundas.

Se considerarmos que a maioria dos ambientes, onde os pacientes costumam permanecer diariamente com suas próteses auditivas em uso por períodos de tempo contínuos, tenham níveis de ruído iguais ou inferiores aos medidos no ambulatório (70 a $80 \mathrm{dBA}$ ), podemos admitir que esses níveis de amplificação posam oferecer uma boa margem de segurança na adaptação de próteses auditivas de alta potência.

A faixa $250-2000 \mathrm{~Hz}$ parece representar uma faixa de risco de superamplificação para as orelhas adaptadas com próteses auditivas de alta potência.

Esta hipótese é justificável porque quando as próteses auditivas geraram níveis de amplificação elevado nesta faixa de freqüência, verificou - se o efeito de 
potencialização que atribuímos como a provável causa dos TTS observados nas orelhas protetizadas após um período contínuo de estimulação.

Portanto, se necessitamos adaptar próteses auditivas capazes de potencializar o efeito dos ruídos aos quais as orelhas costumam permanecer expostas por períodos contínuos, é importante que isto seja feito com critério.

Os resultados do presente trabalho sugerem que a estimulação de orelhas com perdas auditivas maiores com um estímulo de menor amplificação pareceu favorecer o desenvolvimento dos sistemas de proteção quando estas foram posteriormente submetidas à condições traumáticas de estimulação durante o uso contínuo de suas próteses auditivas.

A resistência desenvolvida nas orelhas protetizadas persistiu e até aumentou depois da eliminação do estímulo menor usado para o treinamento, quando as orelhas incluídas no GE voltaram a ser estimuladas regularmente com a alta amplificação gerada por suas próteses auditivas.

Algumas ressalvas têm que ser consideradas se pretendermos utilizar esta proposta na prática clínica.

Nem todos os pacientes passíveis de serem incluídos nos grupos de risco estariam dispostos a concordar com esta redução na amplificação de suas próteses auditivas por períodos tão longos (60 a 90 dias).

Além do mais, não conhecemos as condições efetivas em que ocorreu o treinamento das orelhas. Os pacientes usaram suas próteses auditivas também fora do ambulatório durante o período deste estudo e em situações acústicas variadas. Isto fugiu do controle deste experimento. 
Também não sabemos quanto e por quanto tempo este treinamento poderá ser eficiente.

Parece que as orelhas humanas necessitam de menos tempo para serem treinadas do que as orelhas de animais (MIYAKITA, et al, 1992). Períodos curtos de treinamento (89 dBNPS /15 minutos) se mostraram tão eficientes no condicionamento de orelhas de rato expostas a condições traumáticas $(8-16 \mathrm{kHz} / 100$ dBNPS /2 horas), quanto em períodos mais longos (81 dBNPS /1 semana). O efeito protetor, verificado nestas orelhas, foi no máximo de 24 horas após o condicionamento, desaparecendo depois de 48 horas. Parece que a síntese de proteínas é necessária para a expressão do efeito protetor (YOSHIDA e LIBERMAN, 2000).

A sugestão para os pacientes que necessitam usar próteses auditivas de alta potência é que a introdução da amplificação gerada seja feita de forma gradual.

As próteses auditivas que geram níveis de pressão sonora considerados de risco deveriam ser providas de sistemas automáticos que possibilitassem a graduação desta amplificação ao longo do dia.

Isto seria importante porque o treinamento das orelhas submetidas a níveis elevados de pressão sonora poderia ser diário e por períodos curtos.

É evidente que muito mais pesquisas serão necessárias para que se possam estabelecer condições que realmente contribuam para a preservação da audição nos pacientes portadores de perdas auditivas severas e profundas e que fazem uso diário de próteses auditivas de alta potência. 


\section{6- CONCLUSÕES}

A análise integral deste estudo nos permitiu extrair as seguintes conclusões:

1- A amplificação prescrita / preferencial, gerada pelas próteses auditivas adaptadas no grupo com perdas auditivas maiores, provocou alterações ou mudanças temporárias significantes nos limiares auditivos quando as orelhas protetizadas foram expostas, por períodos curtos e contínuos, a um ruído intermitente de banda larga de freqüência e de moderada intensidade, comum nos ambientes convencionais.

1.a - A magnitude das mudanças temporárias induzidas nas orelhas protetizadas diminuiu quando a amplificação da prótese auditiva foi reduzida.

1.b - As mudanças temporárias induzidas nos limiares auditivos das orelhas protetizadas ocorreram principalmente na faixa de freqüência onde se verificou uma maior amplificação das próteses auditivas adaptadas.

2 - As mudanças temporárias nos limiares auditivos, induzidas pelo alto nível de pressão sonora gerado nas orelhas com perdas auditivas maiores com suas próteses auditivas adaptadas na amplificação prescrita/preferencial, mostrou uma redução gradual durante o período de estudo.

2.a - Um percentual de redução de $26 \%$ foi verificado na faixa de freqüência inferior a $1000 \mathrm{~Hz}$ durante o período de 60 a 90 dias, em que essas orelhas foram estimuladas ou "treinadas" com as suas próteses ajustadas em uma amplificação mais baixa.

2.b - Um percentual de redução de $62 \%$ foi verificado na faixa de risco (250 a $2000 \mathrm{~Hz}$ ) trinta a trinta e cinco dias após os pacientes terem retornado ao uso cotidiano de suas próteses auditivas reajustadas para a amplificação prescrita /preferencial. 


\section{7- ANEXOS}

\section{1- Tabelas}

Tabela 19 - Relação Da Amostra Estudada Quanto Ao Sexo, Orelha Protetizada, Orelha Testada , Modelo, Marca, Tecnologia Das Próteses Auditivas Adaptadas

$$
(n=25)
$$

\begin{tabular}{|c|c|c|c|c|c|c|c|c|c|}
\hline Número & Identificação & Sexo & Idade & Grupo & $\begin{array}{c}\text { Orelha } \\
\text { Protetizada }\end{array}$ & $\begin{array}{l}\text { Orelha } \\
\text { Testada }\end{array}$ & Modelo & Marca & Tecnologia \\
\hline 1 & BLS & $\mathrm{F}$ & 8 & GE & Bilateral & Binaural & $\begin{array}{c}\text { Phoenix } \\
303\end{array}$ & Siemens & Digital \\
\hline 2 & DGL & $\mathrm{F}$ & 6 & GC & Bilateral & Direita & S46I & Philips & Analógico \\
\hline 3 & DW & M & 16 & GC & Bilateral & Direita & L32 & Widex & Analógico P \\
\hline 4 & DMS & $\mathrm{F}$ & 14 & GC & Bilateral & Esquerda & Quartet & $\begin{array}{c}\text { Sonic } \\
\text { Inovation }\end{array}$ & Digital \\
\hline 5 & ECS & $\mathrm{M}$ & 11 & GC & Bilateral & Binaural & $\begin{array}{c}\text { Phoenix } \\
203 \\
\end{array}$ & Siemens & Digital \\
\hline 6 & EM & $\mathrm{M}$ & 14 & GE & Bilateral & Binaural & 145DFS & Danavox & Analógico \\
\hline 7 & FCS & $\mathrm{M}$ & 12 & $\mathrm{GC}$ & Bilateral & Esquerda & Opus 2 & Bernafon & Analógico \\
\hline 8 & $\mathrm{FG}$ & $\mathrm{M}$ & 10 & $\mathrm{GC}$ & Bilateral & Binaural & $\begin{array}{c}\text { US80PP } \\
\text { L }\end{array}$ & Unitron & Analógico \\
\hline 9 & HRA & $\mathrm{M}$ & 29 & GE & Unilateral & Direita & $\mathrm{C} 2$ & Bernafon & Analógico \\
\hline 10 & IFF & $\mathrm{F}$ & 27 & GE & Unilateral & Direita & $584 \mathrm{PAl}$ & Siemens & Analógico \\
\hline 11 & IJS & $\mathrm{M}$ & 11 & GC & Bilateral & Binaural & L9 & Widex & Analógico $\mathrm{P}$ \\
\hline 12 & JPK & M & 27 & GC & Unilateral & Esquerda & Swift 90 & Oticon & Analógico $\mathrm{P}$ \\
\hline 13 & KPS & $\mathrm{F}$ & 14 & $\mathrm{GC}$ & Bilateral & Binaural & AF 120 & Bernafon & Analógico $\mathrm{P}$ \\
\hline 14 & LBS & $\mathrm{M}$ & 15 & GE & Bilateral & Binaural & S41U & Philips & Analógico \\
\hline 15 & MPS & $\mathrm{M}$ & 16 & GC & Bilateral & Binaural & $\begin{array}{c}\text { Phoenix } \\
303\end{array}$ & Siemens & Digital \\
\hline 16 & MSP & $\mathrm{F}$ & 19 & GE & Bilateral & Binaural & S41U & Philips & Analogico \\
\hline 17 & MGS & $\mathrm{M}$ & 14 & GE & Bilateral & Binaural & PPCL 4 & Phonak & Analogico \\
\hline 18 & MPS & $\mathrm{M}$ & 15 & GE & Bilateral & Binaural & $\begin{array}{c}\text { Phoenix } \\
303\end{array}$ & Siemens & Digital \\
\hline 19 & MFS & $\mathrm{M}$ & 10 & GC & Bilateral & Binaural & B2X & Widex & Digital \\
\hline 20 & PR & $F$ & 15 & GE & Bilateral & Binaural & $\begin{array}{c}\text { Phoenix } \\
303 \\
\end{array}$ & Siemens & Digital \\
\hline 21 & so & $\mathrm{F}$ & 16 & GE & Unilateral & Esquerda & S41U & Philips & Analógico \\
\hline 22 & VBP & M & 16 & GE & Bilateral & Binaural & $\begin{array}{l}\text { Opus } \\
2 \text { SP }\end{array}$ & Bernafon & Analógico \\
\hline 23 & VB & $\mathrm{F}$ & 18 & GE & Bilateral & Binaural & $\begin{array}{c}\text { Phoenix } \\
303\end{array}$ & Siemens & Digital \\
\hline 24 & VRO & $F$ & 26 & GE & Unilateral & Esquerda & $584 \mathrm{PAI}$ & Siemens & Analógico \\
\hline 25 & WB & M & 18 & GC & Bilateral & Binaural & B 12 & Widex & Digital \\
\hline
\end{tabular}

Nota : Analógico P = Programável 
Tabela 20a - Relação Das Perdas Auditivas Por Freqüência Nas 22 Orelhas Incluídas Na Amostra Estudada Grupo Experimental (GE)

$(\mathrm{N}=13)$

\begin{tabular}{|c|c|c|c|}
\hline $\begin{array}{c}\text { Identificação } \\
\text { e número } \\
\text { na amostra }\end{array}$ & $\begin{array}{l}\text { Frequência } \\
\text { (Hz) }\end{array}$ & $\begin{array}{c}\text { Perda Auditiva } \\
\text { (dBNA) } \\
\text { Orelha } \\
\text { Direita }\end{array}$ & $\begin{array}{l}\text { Perda Auditiva } \\
\text { (dBNA) } \\
\text { Orelha } \\
\text { Esquerda }\end{array}$ \\
\hline \multirow[t]{8}{*}{ B.L.S (1) } & 250 & 110 & 111 \\
\hline & 500 & 118,5 & 120 \\
\hline & 1000 & $120^{\mathrm{A}^{*}}$ & $120^{A^{*}}$ \\
\hline & 2000 & $120^{\mathrm{A}^{*}}$ & $120^{\mathrm{A}^{*}}$ \\
\hline & 3000 & $120^{\mathrm{A}^{*}}$ & $120^{\mathrm{A}^{*}}$ \\
\hline & 4000 & $120^{\mathrm{A}^{*}}$ & $120^{\mathrm{A}^{*}}$ \\
\hline & 6000 & $120^{\mathrm{A}^{*}}$ & $120^{\mathrm{A}^{*}}$ \\
\hline & 8000 & $100^{A^{*}}$ & $100^{A^{*}}$ \\
\hline \multirow[t]{8}{*}{ E.M (6) } & $250-$ & 77 & 78 \\
\hline & 500 & 88 & 92 \\
\hline & 1000 & 100 & 99,5 \\
\hline & 2000 & 111,5 & 106,5 \\
\hline & 3000 & $120^{\mathrm{A}^{*}}$ & 116,5 \\
\hline & 4000 & $120^{\mathrm{A}^{*}}$ & $120^{\mathrm{A}^{*}}$ \\
\hline & 6000 & $120^{\mathrm{A}^{*}}$ & $120^{\mathrm{A}^{*}}$ \\
\hline & 8000 & $100^{\mathrm{A}^{*}}$ & $100^{\mathrm{A}^{*}}$ \\
\hline \multirow[t]{8}{*}{ H.R.A (9) } & $250-$ & 54 & \\
\hline & 500 & 54 & \\
\hline & 1000 & 75 & \\
\hline & 2000 & 82,5 & \\
\hline & 3000 & 79 & \\
\hline & 4000 & 82,5 & \\
\hline & 6000 & 90,5 & \\
\hline & 8000 & 75,5 & \\
\hline \multirow[t]{8}{*}{ I.F.F (10) } & $250-$ & 42 & \\
\hline & 500 & 44 & \\
\hline & 1000 & 44,5 & \\
\hline & 2000 & 47 & \\
\hline & 3000 & 51 & \\
\hline & 4000 & 53,5 & \\
\hline & 6000 & 64 & \\
\hline & 8000 & 68 & \\
\hline \multirow[t]{9}{*}{ L.B.S (14) } & 250 & 69 & 72 \\
\hline & 500 & 81,5 & 82,5 \\
\hline & 1000 & 91,5 & 94 \\
\hline & 2000 & 100 & 98 \\
\hline & 3000 & 113,5 & 99,5 \\
\hline & 4000 & $120^{\mathrm{A}^{*}}$ & 109 \\
\hline & 6000 & $120^{\mathrm{A}^{*}}$ & $120^{\mathrm{A}^{*}}$ \\
\hline & 8000 & $100^{A^{*}}$ & $100^{A^{*}}$ \\
\hline & & & $\mathrm{A}$ \\
\hline \multirow[t]{8}{*}{ M.G.S (17) } & 250 & 87 & 94 \\
\hline & 500 & 109,5 & 105 \\
\hline & 1000 & $120^{A^{*}}$ & 109 \\
\hline & 2000 & 118 & 115 \\
\hline & 3000 & 115 & 116 \\
\hline & 4000 & $120^{A^{*}}$ & $120^{A *}$ \\
\hline & 6000 & $120^{\mathrm{A}^{*}}$ & $120^{A *}$ \\
\hline & 8000 & $100^{A^{*}}$ & $100^{\mathrm{A}^{*}}$ \\
\hline \multirow[t]{5}{*}{ M.P.S (18) } & 250 & 76,5 & 90 \\
\hline & 500 & 80 & 93,5 \\
\hline & 1000 & 83 & 85,5 \\
\hline & 2000 & 84 & 85,5 \\
\hline & 3000 & 86,5 & 79 \\
\hline
\end{tabular}




\begin{tabular}{|c|c|c|c|}
\hline & 4000 & 77,5 & 91,5 \\
\hline & 6000 & 78,5 & 74 \\
\hline & 8000 & 78 & 75 \\
\hline \multirow[t]{8}{*}{ P.R (20) } & 250 & 104,5 & 104,5 \\
\hline & 500 & 98,5 & 104,5 \\
\hline & 1000 & 112,5 & 98,5 \\
\hline & 2000 & 119 & 107 \\
\hline & 3000 & $120^{\mathrm{A}^{*}}$ & 112,5 \\
\hline & 4000 & $120^{A^{*}}$ & $120^{A^{*}}$ \\
\hline & 6000 & $120^{\mathrm{A}^{*}}$ & 113,5 \\
\hline & 8000 & $100^{\mathrm{A}^{*}}$ & $100^{A^{*}}$ \\
\hline \multirow[t]{8}{*}{ S.O (21) } & 250 & & 82,5 \\
\hline & 500 & & 75 \\
\hline & 1000 & & 71,5 \\
\hline & 2000 & & 72,5 \\
\hline & 3000 & & 66,5 \\
\hline & 4000 & & 66,5 \\
\hline & 6000 & & 61,5 \\
\hline & 8000 & & 56,5 \\
\hline \multirow[t]{8}{*}{ V.B.P (22) } & 250 & 75,5 & 77 \\
\hline & 500 & 80 & 79 \\
\hline & 1000 & 95,5 & 99 \\
\hline & 2000 & 102 & 100 \\
\hline & 3000 & 98,5 & 103,5 \\
\hline & 4000 & 103 & 110,5 \\
\hline & 6000 & 112 & 119,5 \\
\hline & 8000 & $100^{\mathrm{A}^{*}}$ & $100^{A \star}$ \\
\hline \multirow[t]{8}{*}{ V.B (23) } & 250 & 92,5 & 92,5 \\
\hline & 500 & 97 & 97 \\
\hline & 1000 & 101,5 & 101,5 \\
\hline & 2000 & 120 & 120 \\
\hline & 3000 & 114,5 & 114,5 \\
\hline & 4000 & 115,5 & 115,5 \\
\hline & 6000 & $120^{A *}$ & $120^{A^{*}}$ \\
\hline & 8000 & $100^{A *}$ & $100^{A^{*}}$ \\
\hline \multirow[t]{8}{*}{ V.O (24) } & 250 & & 69 \\
\hline & 500 & & 70,5 \\
\hline & 1000 & & 72,5 \\
\hline & 2000 & & 65 \\
\hline & 3000 & & 63 \\
\hline & 4000 & & 46,5 \\
\hline & 6000 & & 15 \\
\hline & 8000 & & 18,5 \\
\hline
\end{tabular}

$\left(^{*}\right) A=$ Ausência de Resposta. 
Tabela 20b - Relação das Perdas Auditivas por frequência nas 20 orelhas $(n=12)$ incluídas na amostra estudada Grupo Convencional (GC)

\begin{tabular}{|c|c|c|c|}
\hline $\begin{array}{l}\text { Identificação } \\
\text { e número } \\
\text { na amostra }\end{array}$ & $\begin{array}{l}\text { Frequência } \\
\text { (Hz) }\end{array}$ & $\begin{array}{c}\text { Perda Auditiva } \\
\text { (dBNA) } \\
\text { Orelha } \\
\text { Direita }\end{array}$ & $\begin{array}{l}\text { Perda Auditiva } \\
\text { (dBNA) } \\
\text { Orelha } \\
\text { Esquerda }\end{array}$ \\
\hline \multirow[t]{8}{*}{ DGL $(2)$} & 250 & 111 & 82,5 \\
\hline & 500 & 106 & 86,5 \\
\hline & 1000 & 111 & 88 \\
\hline & 2000 & $120^{\mathrm{A}^{*}}$ & 101,5 \\
\hline & 3000 & 120 & 116 \\
\hline & 4000 & 119 & 114,5 \\
\hline & 6000 & $120^{\mathrm{A}^{*}}$ & $120^{A^{*}}$ \\
\hline & 8000 & $100^{\mathrm{A}^{*}}$ & $102^{A^{*}}$ \\
\hline \multirow[t]{8}{*}{$\mathrm{DW}(3)$} & 250 & 88 & \\
\hline & 500 & 93,5 & \\
\hline & 1000 & 98,5 & \\
\hline & 2000 & 106 & \\
\hline & 3000 & 107 & \\
\hline & 4000 & 110,5 & \\
\hline & 6000 & $120^{\mathrm{A}^{*}}$ & \\
\hline & 8000 & $100^{\mathrm{A}^{*}}$ & \\
\hline \multirow[t]{8}{*}{ DMS (4) } & 250 & & 37 \\
\hline & 500 & & 44 \\
\hline & 1000 & & 56,5 \\
\hline & 2000 & & 62 \\
\hline & 3000 & & 62,5 \\
\hline & 4000 & & 71 \\
\hline & 6000 & & 72 \\
\hline & 8000 & & 79,5 \\
\hline \multirow{9}{*}{$\mathrm{ECS}(5)$} & & & \\
\hline & 250 & 89,5 & 104 \\
\hline & 500 & 87 & 104,5 \\
\hline & 1000 & 78,5 & 112 \\
\hline & 2000 & 71,5 & 115 \\
\hline & 3000 & 85 & $120^{A^{*}}$ \\
\hline & 4000 & 109 & $120^{A^{*}}$ \\
\hline & 6000 & $120^{\mathrm{A}^{*}}$ & $120^{A^{*}}$ \\
\hline & 8000 & 112 & $100^{A^{*}}$ \\
\hline \multirow[t]{8}{*}{ FCS (7) } & 250 & & 26,5 \\
\hline & 500 & & 72,5 \\
\hline & 1000 & & 94 \\
\hline & 2000 & & 110 \\
\hline & 3000 & & 109,5 \\
\hline & 4000 & & 116,5 \\
\hline & 6000 & & $120^{\mathrm{A}^{*}}$ \\
\hline & 8000 & & $100^{A^{*}}$ \\
\hline \multirow[t]{8}{*}{ FG (8) } & 250 & 77,5 & 80 \\
\hline & 500 & 81,5 & 80 \\
\hline & 1000 & 99,5 & 97 \\
\hline & 2000 & 113 & 115,5 \\
\hline & 3000 & 108 & 108 \\
\hline & 4000 & 101 & 115 \\
\hline & 6000 & 110,5 & $120^{A^{*}}$ \\
\hline & 8000 & $100^{A^{*}}$ & $100^{A^{*}}$ \\
\hline \multirow[t]{4}{*}{ IJS (11) } & 250 & 39 & 45,5 \\
\hline & 500 & 43 & 61 \\
\hline & 1000 & 69 & 62 \\
\hline & 2000 & 70 & 68,5 \\
\hline
\end{tabular}




\begin{tabular}{|c|c|c|c|}
\hline & 3000 & 53,5 & 64 \\
\hline & 4000 & 55,5 & 61,5 \\
\hline & 6000 & 51,5 & 57 \\
\hline & 8000 & 62 & 60,5 \\
\hline \multirow[t]{8}{*}{ JPK (12) } & 250 & & 35,5 \\
\hline & 500 & & 35 \\
\hline & 1000 & & 83 \\
\hline & 2000 & & 101 \\
\hline & 3000 & & 105 \\
\hline & 4000 & & 103 \\
\hline & 6000 & & 114,5 \\
\hline & 8000 & & 100 \\
\hline \multirow{8}{*}{ KPS (13) } & 250 & 37 & 33,5 \\
\hline & 500 & 69 & 67,5 \\
\hline & 1000 & 101 & 98,5 \\
\hline & 2000 & 100 & 101,5 \\
\hline & 3000 & 111 & 115 \\
\hline & 4000 & 105 & 114,5 \\
\hline & 6000 & 120 & 120 \\
\hline & 8000 & 100 & 100 \\
\hline \multirow[t]{8}{*}{ MPS (15) } & 250 & 79,5 & 77,5 \\
\hline & 500 & 80 & 80 \\
\hline & 1000 & 93 & 89 \\
\hline & 2000 & 106 & 103,5 \\
\hline & 3000 & 114 & 112,5 \\
\hline & 4000 & 119,5 & $120^{\mathrm{A}^{*}}$ \\
\hline & 6000 & $120^{\mathrm{A}^{*}}$ & $120^{A^{*}}$ \\
\hline & 8000 & $100^{\mathrm{A}^{*}}$ & $100^{\mathrm{A}^{*}}$ \\
\hline \multirow[t]{8}{*}{ MFS (19) } & 250 & 59,5 & 55 \\
\hline & 500 & 67 & 72 \\
\hline & 1000 & 89 & 87 \\
\hline & 2000 & 84 & 85 \\
\hline & 3000 & 81,5 & 81 \\
\hline & 4000 & 83,5 & 91 \\
\hline & 6000 & 98,5 & 111 \\
\hline & 8000 & $100^{A^{*}}$ & $100^{\mathrm{A}^{*}}$ \\
\hline \multirow[t]{8}{*}{ WB (25) } & 250 & 99 & 65 \\
\hline & 500 & 96 & 59 \\
\hline & 1000 & 82,5 & 58 \\
\hline & 2000 & 80 & 48 \\
\hline & 3000 & 68,5 & 41,5 \\
\hline & 4000 & 70 & 47,5 \\
\hline & 6000 & 71,5 & 65 \\
\hline & 8000 & 60 & 54,5 \\
\hline
\end{tabular}

$\left({ }^{\star}\right) A=$ Ausência de Resposta. 
Tabela 21- Dosimetria do Nível de Ruído efetuada no

Ambulatório de Especialidades do Hospital Regional da Zona Sul

Outubro 2001 - Dezembro 2003

\begin{tabular}{|c|c|c|c|c|c|c|c|c|c|c|}
\hline & Data & Tempo & Leq & $<70$ & $>=70$ & $>=85$ & $>=90$ & $>=100$ & $>=115$ & Pico \\
\hline & & $\mathrm{h} ; \mathrm{m} ; \mathrm{s}$ & $\mathrm{dBA}$ & $\%$ & $\%$ & $\%$ & $\%$ & $\%$ & $\%$ & dBNPS \\
\hline 1 & $16 / 10 / 01$ & $2: 33: 00$ & 75,2 & 25,31 & 74,69 & 0,83 & 0,09 & 0,00 & 0,00 & 112,1 \\
\hline 2 & $30 / 10 / 01$ & 3:00:00 & 75,6 & 0,00 & 91,23 & 0,71 & 0,05 & 0,00 & 0,00 & 116,5 \\
\hline 3 & $07 / 11 / 01$ & 2:06:00 & 76,9 & 0,00 & 95,31 & 1,29 & 0,08 & 0,00 & 0,00 & 114,4 \\
\hline 4 & $05 / 12 / 01$ & $2: 58: 00$ & 84,2 & 0,00 & 94,79 & 8,52 & 0,86 & 0,12 & 0,00 & 125,5 \\
\hline 5 & $12 / 12 / 01$ & $2: 30: 00$ & 78,8 & 0,00 & 89,87 & 4,29 & 0,67 & 0,01 & 0,00 & 123,6 \\
\hline 6 & $23 / 01 / 02$ & $2: 02: 00$ & 70,9 & 0,00 & 50,76 & 0,00 & 0,00 & 0,00 & 0,00 & 113,6 \\
\hline 7 & $06 / 02 / 02$ & 3:04:00 & 78,9 & 0,00 & 75,94 & 3,58 & 1,29 & 0,06 & 0,00 & 123,9 \\
\hline 8 & $21 / 08 / 02$ & $2: 51: 00$ & 76,7 & 0,00 & 91,87 & 1,29 & 0,16 & 0,00 & 0,00 & 117,6 \\
\hline 9 & 28/08/02 & 3:07:00 & 76,2 & 33,08 & 66,92 & 2,13 & 0,13 & 0,00 & 0,00 & 118,1 \\
\hline 10 & $11 / 09 / 02$ & 3:04:00 & S/R & 43,18 & 56,82 & 0,36 & 0,04 & 0,00 & 0,00 & 118,0 \\
\hline 11 & 02/10/02 & $2: 57: 00$ & 80,7 & 30,53 & 69,47 & 1,05 & 0,18 & 0,07 & 0,00 & 124,5 \\
\hline 12 & $16 / 10 / 02$ & $2: 16: 00$ & $\overline{S / R}$ & 39,49 & 60,51 & 1,53 & 0,26 & 0,00 & 0,00 & 116,4 \\
\hline 13 & $30 / 10 / 02$ & $2: 26: 00$ & 74,6 & 0,11 & 80,63 & 0,45 & 0,06 & 0,00 & 0,00 & 113,0 \\
\hline 14 & $06 / 11 / 02$ & $2: 26: 00$ & 75,9 & 0,00 & 68,84 & 1,94 & 0,31 & 0,02 & 0,00 & 123,0 \\
\hline 15 & $27 / 11 / 02$ & 1:41:00 & 82,0 & 0,00 & 97,81 & 13,85 & 1,85 & 0,00 & 0,00 & 114,2 \\
\hline 16 & 04/12/02 & $2: 40: 00$ & 82,2 & 0,02 & 81,54 & 13,16 & 3,79 & 0,01 & 0,00 & 118,7 \\
\hline 17 & 19/12/02 & $2: 52: 00$ & 75,0 & 0,03 & 63,80 & 1,00 & 0,04 & 0,00 & 0,00 & 117,0 \\
\hline 18 & $08 / 01 / 03$ & 2:38:00 & 75,1 & 0,00 & 48,84 & 1,39 & 0,19 & 0,00 & 0,00 & 118,8 \\
\hline 19 & $13 / 01 / 03$ & $2: 47: 00$ & 81,2 & 0,00 & 89,41 & 0,93 & 0,53 & 0,20 & 0,00 & 124,0 \\
\hline 20 & $27 / 01 / 03$ & 1:58:00 & 70,7 & 0,00 & 45,56 & 0,02 & 0,00 & 0,00 & 0,00 & 110,9 \\
\hline 21 & $12 / 02 / 03$ & $2: 44: 00$ & 77,3 & 0,00 & 65,84 & 2,82 & ,38 & 0,00 & 0,00 & 118,0 \\
\hline 22 & $17 / 02 / 03$ & $2: 34: 00$ & 82,9 & 0,00 & 89,83 & 20,94 & 3,86 & 0,00 & 0,00 & 116,6 \\
\hline 23 & $24 / 02 / 03$ & 2:09:00 & 83,1 & 0,00 & 80,59 & 18,29 & 5,26 & 0,01 & 0,00 & 115,7 \\
\hline 24 & $26 / 02 / 03$ & 3:05:00 & 76,8 & 0,00 & 77,08 & 2,04 & 0,82 & 0,00 & 0,00 & 123,9 \\
\hline 25 & $02 / 04 / 03$ & 1:39:00 & 84,6 & 0,00 & 62,71 & 10,74 & 4,00 & 0,45 & 0,00 & 124,0 \\
\hline 26 & $07 / 04 / 03$ & $2: 41: 00$ & 80,6 & 0,14 & 67,44 & 12,03 & 1,95 & 0,00 & 0,00 & 117,1 \\
\hline 27 & $09 / 04 / 03$ & 3:50:00 & 70,7 & 0,03 & 33,94 & 0,10 & 0,03 & 0,00 & 0,00 & 120,6 \\
\hline 28 & $11 / 04 / 03$ & 1:53:00 & 77,7 & 0,00 & 80,34 & 2,08 & 0,40 & 0,03 & 0,00 & 123,6 \\
\hline 29 & $15 / 04 / 03$ & 2:36:00 & 73,2 & 0,00 & 71,39 & 0,05 & 0,01 & 0,00 & 0,00 & 117,7 \\
\hline 30 & $25 / 04 / 03$ & $2: 46: 00$ & 84,5 & 0,58 & 99,42 & 15,08 & 4,43 & 0,22 & 0,00 & 122,2 \\
\hline 31 & $28 / 04 / 03$ & 2:52:00 & 78,2 & 16,27 & 83,73 & 3,80 & 0,82 & 0,00 & 0,00 & 114,1 \\
\hline 32 & $29 / 04 / 03$ & 2:46:00 & 80,2 & 3,07 & 96,93 & 4,57 & 1,31 & 0,05 & 0,00 & 127,0 \\
\hline 33 & $30 / 04 / 03$ & $1: 50: 30$ & 82,4 & 6,94 & 93,06 & 2,57 & 0,72 & 0,14 & 0,00 & 124,2 \\
\hline 34 & $27 / 05 / 03$ & $2: 00: 00$ & 95,5 & 0,12 & 99,88 & 29,91 & 5,01 & 1,28 & 0,13 & 128,5 \\
\hline 35 & $28 / 05 / 03$ & 1:46:00 & 86,1 & 1,18 & 98,82 & 30,41 & 13,75 & 0,03 & 0,00 & 128,8 \\
\hline 36 & $30 / 05 / 03$ & $2: 00: 00$ & 80,6 & 7,67 & 92,33 & 9,49 & 1,08 & 0,00 & 0,00 & 114,1 \\
\hline 37 & 02/06/03 & $1: 50: 00$ & 80,2 & 7,71 & 92,29 & 6,67 & 1,38 & 0,01 & 0,00 & 132,5 \\
\hline 38 & $30 / 07 / 03$ & $2: 20: 00$ & 79,0 & 27,71 & 72,29 & 4,68 & 1,10 & 0,03 & 0,00 & 121,4 \\
\hline 39 & 01/08/03 & 2:05:00 & S/R & 47,35 & 52,65 & 0,57 & 0,13 & 0,00 & 0,00 & 120,6 \\
\hline 40 & $05 / 08 / 03$ & 1:52:00 & 82,6 & 41,98 & 58,02 & 3,03 & 1,00 & 0,13 & 0,01 & 125,8 \\
\hline 41 & 08/08/03 & 2:58:00 & S/R & 64,31 & 35,69 & 1,13 & 0,22 & 0,00 & 0,00 & 118,4 \\
\hline 42 & $11 / 08 / 03$ & 1:38:00 & 78,6 & 36,43 & 63,57 & 3,37 & 1,25 & 0,06 & 0,00 & 127,5 \\
\hline 43 & $20 / 08 / 03$ & 1:52:00 & S/R & 83,49 & 16,51 & 0,38 & 0,14 & 0,02 & 0,00 & 126,5 \\
\hline 44 & $27 / 08 / 03$ & $1: 37: 00$ & 99,3 & 0,02 & 96,35 & 53,91 & 35,17 & 8,21 & 0,66 & 129,5 \\
\hline 45 & $29 / 08 / 03$ & 2:01:00 & 80,2 & 0,00 & 96,57 & 5,84 & 1,09 & 0,01 & 0,00 & 118,9 \\
\hline
\end{tabular}




\begin{tabular}{|rllllllllll}
$\mathbf{4 6}$ & $01 / 09 / 03$ & $2: 18: 00$ & 77,9 & 0,01 & 79,54 & 2,61 & 0,57 & 0,03 & 0,00 & 125,7 \\
\hline $\mathbf{4 7}$ & $02 / 09 / 03$ & $2: 01: 00$ & 82,3 & 0,03 & 52,15 & 6,31 & 2,85 & 0,26 & 0,00 & 126,5 \\
\hline $\mathbf{4 8}$ & $03 / 09 / 03$ & $2: 04: 00$ & 71,3 & 0,00 & 27,51 & 0,36 & 0,10 & 0,00 & 0,00 & 123,3 \\
\hline $\mathbf{4 9}$ & $05 / 09 / 03$ & $1: 54: 00$ & 81,8 & 0,00 & 91,45 & 4,93 & 1,58 & 0,18 & 0,00 & 126,1 \\
\hline $\mathbf{5 0}$ & $16 / 09 / 03$ & $1: 59: 00$ & 74,9 & 0,00 & 68,61 & 0,70 & 0,06 & 0,00 & 0,00 & 106,2 \\
\hline $\mathbf{5 1}$ & $17 / 09 / 03$ & $1: 51: 00$ & 72,2 & 0,00 & 43,16 & 0,37 & 0,04 & 0,00 & 0,00 & 112,6 \\
\hline $\mathbf{5 2}$ & $19 / 09 / 03$ & $2: 53: 00$ & 76,5 & 0,00 & 76,61 & 1,32 & 0,41 & 0,00 & 0,00 & 125,8 \\
\hline $\mathbf{5 3}$ & $23 / 09 / 03$ & $1: 41: 00$ & 73,6 & 0,00 & 78,5 & 0,34 & 0,02 & 0,00 & 0,00 & 123,6 \\
\hline $\mathbf{5 4}$ & $24 / 09 / 03$ & $1: 38: 00$ & 71,6 & 0,04 & 44,55 & 0,05 & 0,00 & 0,00 & 0,00 & 107,1 \\
\hline $\mathbf{5 5}$ & $26 / 09 / 03$ & $2: 31: 00$ & 70,5 & 0,10 & 28,11 & 0,19 & 0,04 & 0,00 & 0,00 & 119,1 \\
\hline $\mathbf{5 6}$ & $03 / 10 / 03$ & $2: 28: 00$ & 72,9 & 0,00 & 43,69 & 0,44 & 0,44 & 0,12 & 0,00 & 124,1 \\
\hline $\mathbf{5 7}$ & $07 / 10 / 03$ & $2: 04: 00$ & 70,8 & 0,18 & 33,62 & 0,03 & 0,00 & 0,00 & 0,00 & 112,9 \\
\hline $\mathbf{5 8}$ & $08 / 10 / 03$ & $1: 49: 00$ & 75,6 & 0,03 & 74,51 & 1,48 & 0,12 & 0,00 & 0,00 & 108,5 \\
\hline $\mathbf{5 9}$ & $14 / 10 / 03$ & $1: 42: 00$ & 75,4 & 0,07 & 69,07 & 1,53 & 0,32 & 0,00 & 0,00 & 124,2 \\
\hline $\mathbf{6 0}$ & $15 / 10 / 03$ & $1: 54: 00$ & 69,7 & 0,03 & 31,59 & 0,02 & 0,00 & 0,00 & 0,00 & 119,4 \\
\hline $\mathbf{6 1}$ & $21 / 10 / 03$ & $1: 59: 00$ & 77,0 & 0,00 & 66,68 & 2,16 & 0,58 & 0,02 & 0,00 & 123,4 \\
\hline $\mathbf{6 2}$ & $22 / 10 / 03$ & $2: 44: 00$ & 70,8 & 0,00 & 32,34 & 0,16 & 0,03 & 0,00 & 0,00 & 112,4 \\
\hline $\mathbf{6 3}$ & $28 / 10 / 03$ & $1: 28: 00$ & 67,8 & 0,03 & 8,50 & 0,06 & 0,02 & 0,00 & 0,00 & 116,2 \\
\hline $\mathbf{6 4}$ & $29 / 10 / 03$ & $1: 51: 00$ & 72,5 & 0,01 & 60,62 & 0,12 & 0,00 & 0,00 & 0,00 & 115,0 \\
\hline $\mathbf{6 5}$ & $11 / 11 / 03$ & $2: 39: 00$ & 73,7 & 0,06 & 58,26 & 0,25 & 0,06 & 0,01 & 0,00 & 124,3 \\
\hline $\mathbf{6 6}$ & $9 / 12 / 03$ & $1: 25: 00$ & 70,6 & $S / R$ & $S / R$ & $S / R$ & $S / R$ & $S / R$ & $S / R$ & $S / R$ \\
\hline $\mathbf{6 7}$ & $12 / 12 / 03$ & $1: 28: 00$ & 72,3 & $S / R$ & $S / R$ & $S / R$ & $S / R$ & $S / R$ & $S / R$ & $S / R$ \\
\hline & & & & & & & & & \\
\hline
\end{tabular}

PS : $S / R=$ Sem resgate do registro 
Tabela 22a.- Número Total e Média Diária em horas extraídas da Ficha Controle dos Pacientes durante o Uso Regular de duas Próteses Auditivas Grupo Experimental $(\mathrm{N}=13)$

\begin{tabular}{|cccc}
\hline Identificação & Número (dias) & Número total (horas) & Média diária(horas) \\
\hline BLS (8) & 131 & 1244,5 & 9,5 \\
\hline EFM (6) & 124 & 1332 & 11 \\
\hline HRA (9) & 237 & 2469 & 10,5 \\
\hline IFF (10) & 98 & 726,5 & 7,5 \\
\hline LBS (14) & 68 & 547 & 8 \\
\hline MSF (16) & 118 & 1243 & 10,5 \\
\hline MGS (17) & 82 & 963,5 & 12 \\
\hline MPS (18) & 112 & 1154,5 & 10 \\
\hline PR (20) & 128 & 796,5 & 6 \\
\hline SO (21) & 63 & 593 & 9,5 \\
\hline VP (22) & 105 & 1025 & 10 \\
\hline VB (23) & 111 & 1189 & 11 \\
\hline VO (24) & 125 & 750 & 6 \\
\hline MEDIA & 111 & 1079,5 & 10 \\
\hline
\end{tabular}


Tabela 22b - Número total e média diária em horas extraídas da ficha controle dos pacientes durante o uso regular de suas Próteses Auditivas Grupo Convencional $(n=12)$

\begin{tabular}{|cccc}
\hline Identificação & Número (dias) & Número total (horas) & Média diária(horas) \\
\hline DGL (2) & 114 & 1348,5 & 12 \\
\hline DW (3) & 111 & 845,5 & 7,5 \\
\hline DMS (4) & 105 & 1032 & 10 \\
\hline ECS (5) & 124 & 1365 & 11 \\
\hline FCS (7) & 137 & 1714 & 12,5 \\
\hline FG (8) & 59 & 517,5 & 12 \\
\hline IJS (11) & 102 & 1226,5 & 9,5 \\
\hline JPK (12) & 133 & 1256 & 12,5 \\
\hline KPS (13) & 139 & 1154,5 & 11,5 \\
\hline MPS (15) & 49 & 573 & 14 \\
\hline MFS (19) & 146 & 2011 & 7,5 \\
\hline WB (25) & 106 & 801,5 & 10,5 \\
\hline MÉ DIA & 110 & 1154 & \\
\hline
\end{tabular}


7.2- Instruções e o Modelo da Ficha de Controle do uso regular das Próteses Auditivas

\section{Muito importante}

Usar o seu aparelho diariamente é muito importante para que você possa ouvir cada vez melhor .

Hoje você esta recebendo uma ficha para você mesmo anotar toda a vez que usar o seu aparelho.

Queremos que você mesmo anote nesta ficha a hora em que põe e a hora em que tira o seu aparelho toda a vez que for usá-lo.

Por favor, só anote se você realmente o usar. Se você não souber preencher peça a ajuda de um parente ou amigo, mas não deixe de fazer.

\section{Para todos vocês lerem antes de preencher a ficha}

1- Você deve usar o seu aparelho auditivo todos os dias

2- Toda a vez que você usar o aparelho é preciso anotar nesta ficha, que dia foi , que hora você pôs e que hora você tirou o aparelho.

3- Nunca use o aparelho no dia marcado para o seu teste, mas traga-o sempre com você.

4- Se não tiver mais espaço para preencher esta ficha peça outra para a fono 5- Não se esqueça de trazer sempre esta ficha com você no dia marcado para o seu teste

6- Se você não usou o seu aparelho por causa de algum problema não se esqueça de falar para a fono .

Só é para ler quem tem uma fita adesiva fixa no controle de volume do seu aparelho

1- Por favor, não remover o adesivo que a fono colocou no seu aparelho .Se o adesivo caiu ou se você o tirou não tem problema, mas não se esqueça de avisar a fono no dia do seu teste

\section{Controle diário para o uso do seu aparelho auditivo}

Nome:

Data inicial :

Data final:

\begin{tabular}{|c|c|c|c|}
\hline DIA & $\begin{array}{c}\text { HORA QUE } \\
\text { POS }\end{array}$ & $\begin{array}{c}\text { HORA QUE } \\
\text { TIROU }\end{array}$ & $\begin{array}{c}\text { TEMPO } \\
\text { DE USO }\end{array}$ \\
\hline paciente/ & paciente & paciente & pesquisadora \\
\hline & & & \\
\hline
\end{tabular}




\section{8 - REFERÊNCIAS BIBLIOGRÁFICAS}

AHROON, W. A.; HAMERNIK, R. P. Noise-induced hearing loss in the noisetoughened auditory system. Hear Res., v. 129, p. 101-110, 1999.

AHROON, W. A.; HAMERNIK, R. P. The effects of interrupted noise exposures on the noise-damaged cochlea. Hear Res., v.143, p. 103-109, 2000.

BOETTCHER, F. A. Auditory brain-stem responses correlates of resistence to noise induced hearing loss in the mongolian gerbil. J. Acoustic. Soc. Am., v. 94, p.3207-214, 1993.

BOETTCHER, F. A.; SCHIMIEDT, R. A. Distortion product otoacoustic emissions in mongolian gerbils with resistence to noise induced hearing loss. J. Acoustic. Soc. Am. v. 98, p.3215-22, 1995.

BORG, E. Acoustic middle ear reflexes: as sensory control system. Acta Otolaryngol. Suppl., p.304. 1972.

BORG, E.; NILSSON, R.; ENGSTROM, B. Effect of the acoustic reflex on inner ear damage induced by industrial noise. Acta Otolaryngol., v. 96, p. 361, 1983.

CAMPO, P.; SUBRAMIAN, M.; HENDERSON, D. The effect of conditioning exposures on hearing loss from traumatic exposure. Hear.Res., v. 55, p. 195-200, 1991.

CANLON, B.; BORG, E.; FLOCK, A. Protection against noise trauma by pre exposure to a low level acoustic stimulus. Hear Res., v.34, p. 197-200, 1988.

CANLON, B.; BORG, E.; LOFSTRAND,P. Physiological and morphological aspects to low-level acoustic stimulation. In: A . L. Dancer, D. Henderson, R. Salvi and R.P. Hamernik (Eds.), Noise-Induced Hearing Loss. Mosby Year Book. St.Louis ,MO , 1991 , p.489-99.

CANLON, B.; FRANSON, A. Morphological and functional preservation of the outer hair cells from noise trauma by sound conditioning. Hear Res., v. 84, p. 112-24, 1995.

CANLON, B.; FRANSON, A. Reducing noise damage by using a mid- frequency sound conditionning stimulus. Neuroreport, v. 9, p. 269-74, 1998.

CANLON, B.; RYAN, A. F.; BOETTCHER, F. A. On the factors required for obtaining protection against noise trauma by prior acoustic experience. Hear Res., v. 127, p. 158-160, 1999. 
CARHART, R.; JERGER, J. F. Prefered method for clinical determination of pure tone thresholds. J. Speech. Hear. Dis., v. 24, p. 330-45, 1959.

CLARK, W. W.; BOHNE, B. A.; BOETTCHER, F. A. Effect of periodic rest on hearing loss and cochlear damage following exposure to noise. J. Acoustic. Soc. Am., v. 82, p. 1253-1264, 1987.

CLARK, W. W. Recent studies of temporary threshold shift (TTS) and permanent threshold shift (PTS) in animals. J. Acoustic. Soc. Am., v. 90, p. 155-162, 1991.

DAGLI, S.; CANLON, B. Protection against noise trauma by sound conditioning in the guinea pig appears not be mediated by the middle ear muscles. Neuroscience., v. 194, p. 57-60, 1995.

DAVIS, H.; SILVERMANN, S. R. Fisica y psicologia de la audicion. In: Audicion y Sordera, $2^{\mathrm{a}}$ ed. México, La prensa medica mexicana, 1971. p. 27-57.

DE VITTO, U. M. L. Mudanças temporárias dos limiares auditivos causadas pelo uso de próteses auditivas. São Paulo, 2000. 112 p. Dissertação de Mestrado Faculdade de Medicina, Universidade de São Paulo.

DOLAN, D. F.; RAPHAEL, Y.; LAURIKAINEN, E.; FOWLER, T. Effects of vestibular nerve root transection on development of resistence to acoustic trauma. Assoc. Res. Otolaryngol. Abstr. 17, p. 65, 1994.

DURANT, J.D.; LOVRINIC, J.H. Introduction to psychoacoustics. In: Durrant , J.D ., Lovrinic , J.H ., ed . Bases of hearing sciences. 2 ed. Baltimore, Willians \& Wilkins, 1984. p. 214-61.

EARSHEN, J. J. Undertanding noise exposure measurements. Hear. Rev. v. 6, p.37-40, 1999.

FLETCHER, J. L. Reflex response of middle ear muscles protection of the ear from noise. Sound 1, p. 17-21, 1972.

FOWLER, T.; CANLON, B.; DOLAN, D.; MILLER, J. The effects of noise trauma following training exposures in the mouse. Hear. Res., v. 88, p.1-13, 1995.

FRANKLIN, D. J.; LONSBURY-MARTIN, B. L.; STAGNER, B. B.; MARTIN, G.K. Altered susceptibility of 2f1-f2 acoustic distortion products to the effects of repeated noise exposure in rabbits . Hear. Res., v. 53, p. 185-208, 1991.

GATEHOUSE, S. Apparent auditory depravation effects of late onset: The role of presentation level. J. Acoustic. Soc. Am. , v. 86 , p. 2103-2106, 1989

GUINAN, J. J. JR. Effect of efferent neural activity on cochlear mechanics. Scand. Audiol. suppl. v. 25, p.53-62 , 1986 apud OLIVEIRA, 2001. 
HANDROCK, M.; ZEISBERG, J. The influence of the efferent system on adaptation, temporary and permanent threshold shift .Arch. Otorhinolaryngol. v. 234, p. 191-95, 1982.

HENDERSON, D.; SUBRAMANIAM, M.; PAPAZIAN, M.; SPONGR, V. P. The role of middle ear muscles in the development of resistance to noise induced hearing loss. Hear Res., v. 74, p. 22-8, 1994

HENDERSON, D.; HARMERNICK, R. P. Biologic bases of noise-induced hearing loss. Occup.med., v. 10, p. 513-34, 1995.

HENDERSON, D.; SALVI, R. J. Effects on noise exposure on the auditory function .Scand audiol suppl., v. 27, p. 63--73, 1998.

HUMES, L. E.; BESS, F. H. Tutorial on the potential deterioration in hearing due to the hearing aid usage., J. Speech. Hear. Res., v. 24, p. 3-15, 1981.

HUMES, L. E. Noise induced hearing loss as influenced by other agents and by some characteristics of the individual. J. Acoustic. Soc. Am., v. 76, p. 1318-29, 1984.

IRVINI, D. R. F.; RAJAN, R.; BROWN, M. Injury and use related plasticity in adult auditory cortex. Audiol. Neurootol, v. 6, p. 192-5, 2001

JERGER, J. F.; CARHART, R. Temporary threshold shift as an index of noise susceptibility. J. Acoustic. Soc. Am., v. 28, p. 611-13, 1956.

LIBERMAN, M. C.; GAO, W. Y. Chronic cochear de-efferentiation and susceptibility to permanent acoustic injury. Hear.Res., v. 90, p. 158-168, 1995.

MACFADDEN, S. L.; ZHENG, X. Y.; DING, D. L. Conditioning induced protection from impulse noise in female and male chinchillas. J. Acoustic. Soc. Am., v. 107, p. 2162-68, 2000.

MACRAE ,J.H. Permanent threshold shift associated with overamplification by hearing aids . J. Speech. Hear. Res., v.34, p.403-14, 1991

MACRAE, J. H. Prevention of noise induced permanent threshold shift due to hearing aid use. Australian J. Audiol., v. 14, p. 1-11, 1992.

MACRAE, J. H. Temporary threshold shift caused by hearing aid use. J. Speech Hear. Res., v.36, p. 365-72, 1993.

MACRAE, J. H. Prediction of asymptotic threshold shift caused by hearing aids use. J. Speech Hear. Res., v. 37, p. 1450-58, 1994. 
MACRAE, J. H. Temporary and permanent threshold shift caused by hearing aid use. J. Speech Hear. Res., v.38, p. 949-59, 1995.

MELNICK, W. Human temporary threshold shift (TTS) and damage risk. J. Acoustic. Soc. Am., v. 90, p.147-153, 1991 .

MELNICK, W. Saúde auditiva do trabalhador. In:Tratado de audiologia clínica, $1^{\mathrm{a}}$ ed. bras. São Paulo: Manole, 1999. p. 529-47.

MILLER, J. D.; WATSON,C.S.; COVELL, W. P. Deafening effect of noise on the cat. Acta otolaryngol (stockh), supl. v. 176, p. 44-52, 1963.

MILLS, J. H. Threshold shifts produced by exposure to noise in chinchillas with noiseinduced hearing losses. J. Speech. Hear. Res., v. 16, p. 700-8, 1973.

MILLS, J. H.; ADKINS ,W.Y.; GILBERT, R.M. Temporary threshold shifts produced by wideband noise. J. Acoustic. Soc. Am., v. 70, p. 390-6, 1981.

MIYAKITA, T.; HELLSTROM, P-A.; FRIMANSON, E.; AXELSON, A. Effect of low level acoustic stimulation on temporary threshold shift in young humans. Hear. Res., v. 60, p. 149-155, 1992.

MOLLER, J. D. An experimental study of the acoustic impedance of the middle ear and its transmission properties. Acta Otolaryngol, v. 59, p. 1- 19, 1965.

NIU, X.; CANLON, B. Protective mechanisms of sound conditioning. Adv. Otorhinolaryngol, v. 59, p. 96-105, 2002.

NORDMANN, A. S.; BOHNE B. A.; HARDING G. Histophatological differences between temporary and permanent threshold shift. Hear.Res., v. 139, p. 13-30, 2000.

OLIVEIRA, J. A. A. Prevenção e proteção contra perda auditiva induzida por ruído. In: Nudelmann, A .A , Costa ,E .A , Seligman , J., Ibañez ., ed. R .N .PAIR - Perda auditiva induzida por ruído (volume II). São Paulo: Revinter, 2001. p. 17-44.

PALMER, C.V. Deprivation, acclimatization, adaptation: what do they mean for your hearing aid. Hear. J., v. 48, p.10-45, 1995

QUARANTA, N.; ATTANASIO G.; SALLUSTIO, V. Development of resistance to noise. Scand.Audiol., v.27 ,p.45-52, 1998.

RAJAN, R. Unilateral hearing losses alter loud sound induced temporary threshold shifts and efferent effects in normal hearing ear. J. Neurophysiol., v. 85, p. 125769, 2001. 
ROBINSON, K.; GATEHOUSE, S. Changes in intensity discrimination following monoaural long term use of a hearing aid. J. Acoust. Soc. Am. v. 97, p. 1183-90, 1995.

ROSS, M.; LERMAN, J. Hearing aid usage and its effect upon residual hearing. Arch. otol., v.86, p.57-62, 1967.

REGER, S.N. Effect of middle ear muscle action on certain psychophysical measurements. Ann. Otol. Rhinol. Laryngol., v. 69, p.1179-98, 1960.

RYAN, A. F.; BENNETT, T.M.; WOOLF, N.K.; AXELSSON, A. Protection from noise induced hearing loss by prior exposure to a non-traumatic stimulus: role of the middle ear muscles. Hear. Res., v. 72, p. 23-8, 1994.

SANTOS, U.; MORATA, T. C. Efeitos do ruído na audição. In: Santos, U. P. L, Matos, M.P., Morata T. C., Okamoto, V.A . ed. Ruído riscos e prevenção, $2^{a}$ edição. São Paulo: Hucitec, 1996. p. 43-53.

SATALOFF, J.; MENDUKE, H.; HUGHES, A. Temporary threshold shift in normal and abnormal ears. Arch. of Otor., v. 76, p. 52-4, 1962.

SATALOLOFF, J.; MICHAEL, P. L. Noise measurements .In: Sataloff , M.D. , Michael, P.L. , ed. Hearing conservation. Springfield, III., Charles C. Thomas, 1973, p. 193-209.

SAUNDERS, G. H.; CIENKOWSKI, K. M.; Acclimatization to hearing aids. Ear. Hear., v. 18, p. 129-38, 1997.

SINEX, D.G.; CLARK, W. W.; BOHNE, B. A. Effect of periodic rest on physiological measures of auditory sensitivity following exposure to noise. J. Acoustic. Soc. Am., v. 82, p. 1265- 1273, 1987.

SKELlET, R. A; CUllEN, J. K.; FALlON, M.; BOBBIN, R. P. Conditioning the auditory system with continuous vs. Interrupted noise of equal acoustic energy: it is either exposure more protective? Hear. Res., v. 116, p. 21-32, 1998.

SPOENDLIN, H. Histopathology of noise deafness. J. Otolaryngol., v. 14, p. 282-6, 1985.

SUBRAMANIAN, M.; CAMPO, P.; HENDERSON, D. The effect of exposure level on the development of progressive resistence to noise. Hear. Res., v. 52, p. 181-88, 1991.

TAKEYAMA, M.; KUSAKARI, J.; NISHIKAWA, N.; WADA, T. The effect of crossed olivo-cochear bundle stimulation on acoustic trauma. Acta Otolaryngol., v. 112, p. 205-9, 1992. 
VEUILLET, E.; MARTIN, V.; SUC, B.; VESSON, J. F.; MORGON, A.; COLLET, L. Otoacoustic emissions and medial olivococlear suppression during auditory recovery from acoustic trauma in humans., Acta Otolaryngol., v. 121, p. 278-83, 2001.

VOLDRICH, L. Noise-noise effect upon the spreading of the posttraumatic progressive necrosis in the organ of the corti, Arch. Otorhinolayngol., v. 222, p. 169-173, 1979.

WARD, W. D. Temporary threshold shift following monoaural and binaural exposure . J. Acoustic. Soc. Am., v. 38, p. 121-5, 1965.

WARD, W. D.; CUSTING, E. M.; BURNS, E. M. Effective quiet and moderate TTS: implications for noise exposure standards. J. Acoustic Soc. Am., v. 59, p. 160-5, 1976.

WARD, W. D. The role of intermittence in PTS. J. Acoustic. Soc. Am., v. 90, p. 16469, 1991.

WHITE, D. R.; BOETCHER, F. A; MILES, L. R.; GRATTON, N. A. Effectiveness of intermittent and continuous acoustic stimulation in preventing noise-induced hearing and hair cell loss. J. Acoustic. Soc. Am., v. 103, p. 1566-72, 1998.

WORKING GROUP ON COMMUNICATION AIDS FOR THE HEARING IMPAIRED. Review and Tutorial of the Speech - perception aids for hearingimpaired people: current status and needed research. J. Acoustic. Soc. Am., v. 90, p. $637-85,1991$.

YAMASOBA, T.; DOLAN, D. F. The medial efferent system does not appear to contribute to development of acquired resistence to noise trauma. Hear. Res., v. 120, p. 143-151, 1998.

YAMASOBA, T.; DOLAN, D. F.; MILLER, J. M. Acquired resistance to acoustic trauma by sound conditioning is primary mediated by changes restricted to the cochlea ,not by systemic responses., Hear. Res., v. 127, p. 31-40, 1999.

YOSHIDA, N.; LIBERMAN, M. C. Sound conditioning reduces noise-induced permanent threshold shift in mice., Hear.Res., v. 148, p. 213-19, 2000.

ZAKRISSON , J. E . The role of the stapedius reflex in post stimulatory auditory fatigue .Acta Otolaryngol., v. 79, p. 1-10, 1974.

ZAKRISSON , J. E.; BORG, E.; LIDEN,G.; NILSON,R. Stapedius reflex in industrial noise: fatigability and role for temporary threshold shift . Scand. Audiol., v. 12 (Suppl), p. 326-334, 1980. 
ZHENG, X.Y.; HENDERSON, D.; MCFADDEN, S. L.; HUA HU, B. The role of cochlear efferent system in acquired resistance to noise-induced hearing loss. Hear. Res., v. 104, p. 191-203, 1997a.

ZHENG, X. Y.; HENDERSON, D.; HUA HU, B.; DING, D. L.; MCFADDEN, S. L. The influence od the coclear efferent system on chronic acoustic trauma. Hear. Res., v. 107, p. 147-159, 1997b.

\section{Livros Consultados:}

MAXWELL, D. L.; SATAKE, E. Research and statistical methods in communication Disorders. EUA: William \& Wilkins, 1997. 